\title{
Value and Technology Assessment to Enhance the Business Case for the CERTS Microgrid
}

Prepared For:

US Department of Energy

Robert Lasseter

Joe Eto

Prepared By:

University of Wisconsin-Madison
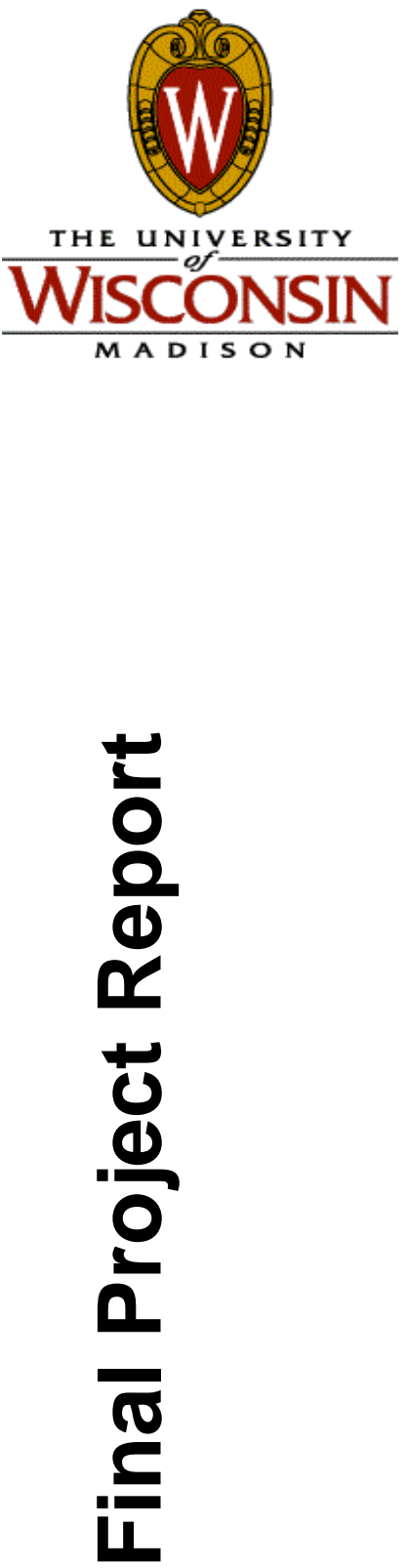

May 15, 2010

DE-FC02-06CH11350 


\section{Prepared By:}

University of Wisconsin -Madison

Robert Lasseter, Principal Investigator

Madison, Wi 53706

Joseph H. Eto, Lawrence Berkeley National Laboratory 


\section{Acknowledgments}

The authors are grateful for the support of Steve Waslo, U S Department of Energy, Chicago Program Office,

and Merrill Smith, U S Department of Energy, Office of Electricity Delivery and Energy Reliability. This research was funded by the U S Department of Energy under contract DE-FC02-06CH11350

-Work was also supported by the U.S. Department of Energy under Contract No. DE-AC02-05CH11231. 


\section{Executive Summary}

The CERTS Microgrid concept is an advanced approach for enabling integration of, in principle, an unlimited quantity of distributed energy resources into the electricity grid. A key feature of a microgrid, is its ability, during a utility grid disturbance, to separate and isolate itself from the utility seamlessly with no disruption to the loads within the microgrid (including no reduction in power quality). Then, when the utility grid returns to normal, the microgrid automatically resynchronizes and reconnects itself to the grid, in an equally seamless fashion.

What is unique about the CERTS Microgrid is that it can provide this technically challenging functionality without extensive (i.e., expensive) custom engineering. In addition, the design of the CERTS Microgrid also provides high system reliability and great flexibility in the placement of distributed generation within the microgrid. The CERTS Microgrid offers these functionalities at much lower costs than traditional approaches by incorporating peer-to-peer and plug-and-play concepts for each component within the Microgrid.

The predecessor to the current project involved the construction of and completion of initial testing using the world's first, full-scale, inverter-based, distributed generation test bed. The project demonstrated three advanced techniques, collectively referred to as the CERTS Microgrid concept, which collectively significantly reduce the level of custom field engineering needed to operate microgrids consisting of small generating sources. The techniques are: 1) a method for effecting automatic and seamless transitions between grid-connected and islanded modes of operation; 2) an approach to electrical protection within the microgrid that does not depend on high fault currents; and 3) a method for microgrid control that achieves voltage and frequency stability under both grid and islanded conditions without requiring high-speed communications.

The work conducted in this phase of RD\&D on the CERTS Microgrid Concept builds upon this base of technical accomplishments to prioritize, develop, and then demonstrate 
technology enhancements to further enhance the business case for microgrids. That is, having demonstrated the technical feasibility of microgrid functions, RD\&D optimization efforts are now needed to accelerate commercial deployment. The current phase is a contribution to these efforts.

This project involved seven distinct analysis, bench-, and full-scale testing tasks. The first five tasks were described in the original proposal submitted and awarded through DOE's solicitation. Two additional tasks were added to address issues that had been identified in the earlier, first phase of testing.

\section{Task 1. Construction of Baselines for Microgrid Business Case Assessments}

The organizing principles for this project are prioritization, development, and demonstration of technology enhancements to improve the business case for microgrids. DOE and the California Energy Commission have previously funded the development of a software tool that addresses the first of these principles. The tool, called the Distributed Energy Resources Customer Adoption Model (or DER-CAM) is an engineeringeconomic optimization tool that among other things can identify cost-targets and the economic value of alternative microgrid configurations and operating strategies.

We implemented two major enhancements to DER-CAM to expand the capabilities of the tool in assessing the business case for microgrids. First, we revised DER-CAM to explicitly consider both thermal and electrical energy storage technologies. This is a difficult optimization problem because involves simultaneous optimization of daily and seasonal operating strategies, as well as equipment selection and sizing. Second, we developed an analysis procedure to enable use of the tool to place an economic value on improvements to customer power quality and reliability (PQR). The procedure involved establishing priorities for each component of a customers' energy demand and, along with information on the reliability of individual microgrid components establishing an optimal dispatch to ensure uninterrupted service to meet the components of customer's demands in order of decreasing priority. 
We demonstrated the enhancements by examining the economic value of microgrids in key target markets for distributed generation on the East and West Coast of the US. The demonstrations confirmed that at current equipment costs and energy prices, microgrids are only economic in a handful of settings. In particular, energy storage is currently too expensive to be economic in most settings. By re-expressing our economic results as hurdle rates, however, we were able to establish cost targets for distributed generation technologies, given forecasts of future energy prices. We also conducted a key demonstration that illustrates the competition for economic operation, which may arise between distributed generation in the form of PV and electricity storage; this finding is contrary to the popular expectation that operation these technologies always complement one another.

\section{Task 2. Examination of Protection Issues}

There are three aspects to protection for the CERTS Microgrid: 1) Conventional protection for the feeders, which do not have microsources, consistent with industrial and commercial standards; 2) Protection of the utility and the microgrid during critical events at the point of common coupling using an interface switch; and 3) Specially designed protection schemes associated with each microsource within the CERTS Microgrid to address internal faults during parallel and islanded operation. Current implementation at the CERTS microgrid test bed of the third aspect of this scheme relies on expensive, external digital relays with independent current and voltage sensors. In order to lower the overall cost of the CERTS Microgrid, we sought to determine whether this protection logic could become an integral part of the control logic within each microsource. This would allow for elimination of the external relays and enhance the plug-and-play functionality of the microsources.

Our approach was to imbed the protection control logic and then connect the supporting sensors directly into the inverters on each microsource, repeat the detailed protection tests performed previously at the Test Bed, and compare the results. While we obtained good agreement with the results from the earlier tests for some of the repeated tests, we obtained different results for several of the other repeated tests. On the one hand, 
subsequent investigation has not fully determined the reasons for these differences, which is a cause for concern. On the other hand, the significance of these unexpected differences is greatly reduced due to findings from Task 7, which is leading us to reconsider the importance of the specialized protection schemes examined in this task. As we shall discuss later in this executive summary, the findings from Task 7 suggest that these schemes may no longer required because the assumption upon which they were designed (namely, that inverters would not be designed to generate significant fault current) is incorrect.

\section{Task 3. Examination of DC Storage Issues}

DC storage on the CERTS Microgrid is defined by the need to ensure fast response of the inverter, decouple the prime mover dynamics from the microgrid's dynamics, and support the DC bus voltage. In this task we sought to identify ways to lower the cost of a microgrid by optimizing the amount of storage required, including possibly, eliminating the need for DC storage altogether.

We reviewed data originally collected while conducting other the original tests of the CERTS Microgrid to better understand the role of DC storage and prime mover response on the CERTS Microgrid's dynamic performance. We found that the surge module as initially designed for the CERTS microgrid test bed is a reasonable design that functions well. The specific battery selected for this application has been a good choice, although money and space can be saved in the future by using a smaller battery. The only clear shortcoming of our original design choice was found to be the need for better temperature monitoring techniques, as the present design has led to thermal damage to most of the batteries. Consequently, we recommend modifying the temperature monitoring technique to ensure adequate thermal protection for the batteries in the future. We also recommend implementing techniques for predicting battery end-of-life. As with many maintenance operations, it is best to replace the batteries before they fail, rather than waiting for failure and the associated additional costs that failure during operation can bring. End-of-life prediction can be performed by counting amp-hours out of the battery 
and then replacing the battery when it reaches a value close to that reported on "Life Expectancy" on battery specification sheets.

\section{Task 4. Role of AC Storage in Enhanced Microgrid.}

The addition of AC storage to the CERTS Microgrid's architecture has the potential to enhance the functionality and business case for microgrids by enabling peak shaving, providing dispatchability for intermittent sources, and allowing energy transfer in order to take advantage of time-varying energy prices. Our approach to incorporation of AC storage involved determining whether we could add these values while retaining the high inherent reliability of the CERTS Microgrid concept. For storage, this meant determining whether we could retain the basic peer-to-peer microgrid functionality in the event of loss of the AC storage (i.e. that the microgrid should be able to continue operating following the loss of one or more microgrid elements) by imbedding CERTS control concepts into the inverter controls directing energy flows into and out of the AC storage unit. We investigated application of AC storage for its backup power capabilities, which involved ensuring that when an islanding event occurs that there will be a sink or source for power depending on the disparity between fixed-power sources such as wind, solar, and geothermal plants and the microgrid's power demand. This investigation utilized batteries as the energy storage medium for both its power capabilities as well as the energy reserve capacity. Beyond the functionalities previously demonstrated in earlier phases of research, we had to also develop energy management methods that recognized and took into account the state of charge of the AC storage unit. The work was carried out by designing, implementing, and testing an AC storage unit using the bench-scale, University-of-Wisconsin (UW) microgrid test bed.

We confirmed that ac energy storage would add an extra degree of flexibility to a microgrid by allowing the temporal separation between generation and consumption of power. Extensive testing of hardware revealed that the system is inherently stable under a variety of operating conditions, including upper and lower controlled states. The algorithm was demonstrated to operate autonomously, providing an added feature to the plug-and-play topology of the CERTS microgrid. Various additions to the control laws 
included a saturation that limited the role of the limit controllers beyond $0.6 \mathrm{~Hz}$ in either direction, slew rate limitations on the power modifier command, and limit-triggered controller engagement. The $0.6 \mathrm{~Hz}$ limitation provides a nominal operating point just beyond the specified operating frequency range of the microgrid, which is $0.5 \mathrm{~Hz}$. This allows for operation at a region beyond the $0.5 \mathrm{~Hz}$ limit, but within the $1 \mathrm{~Hz}$ limit, to signal a non-preferential situation such as a critically low battery state of charge

The limit controller for state of charge management was also found to have well behaved characteristics. It provided autonomous management of the state of charge of the battery, retained some of the transient suppression abilities even in a controlled state, and operated seamlessly regardless of system frequency. Regardless of the power set-point specified by the supervisory controller, this control methodology appears to be capable of ensuring plug-and-play functionality of the energy storage unit.

\section{Task 5. Non-Inverter-based DG in Enhancing Microgrid.}

As presently designed, the CERTS Microgrid requires each generator sets to add an inverter interface in order to function properly in the system. In order to gain wider market acceptance, the CERTS Microgrid concept must be expanded to include generator sources that do not include inverter interfaces because the additional cost associated with the inverter increases the cost of the generator equipment. This task involved bench tests also conducted at the UW microgrid test bed. A $12.5 \mathrm{kVA}$ Kohler diesel-generator set with a wound-field synchronous machine was installed and new governor and exciter control hardware together with improved control algorithms where implemented. A series of tests were conducted to document the system's steady-state and dynamic performance capabilities.

We improved the performance of the genset for operation in a microgrid environment by developing and implementing a state variable controller based on a system observer. The state variable controller incorporates more suitable droop curves for both the real and reactive power components, which enable the genset to rapidly respond to load changes and interact positively with other sources in the absence of any form of external 
communication system. The observer for the system includes two components that measure the mechanical parameters of the system such as rotor position and speed and the electrical parameters of the system such as flux voltages. The observer, which was designed in the continuous time domain, accurately estimated the various quantities (within a certain bandwidth) even in the presence of parameter errors.

The controller was implemented on a test genset and various experiments were carried out to verify its operation. The operation of the observer and controller was demonstrated using EMTP based simulations and further validated using the test setup. The results show that the IC engine-based genset is well-behaved during load changes and islanding maintaining system frequency and voltage within prescribed limits.

\section{Task 6. Continuous Run of the CERTS Microgrid}

Up to this point, testing at the CERTS Microgrid Test Bed had been limited to a large number of one-off tests to confirm the operation of specific functionalities of CERTS Microgrid concepts. For this project, the Test Bed was operated unattended for several long periods of time to examine issues and demonstrate functionalities that cannot be observed in short-duration tests. First, we examined the performance of the CERTS Microgrid in responding to power quality events originating on the utility distribution system. Second, we examined the performance of automatic power factor corrections implemented through CERTS Microgrid controls to respond to voltage fluctuations detected at the point of common coupling with the utility distribution system. Third, throughout these periods of uninterrupted operation, we examined the performance of CERTS Microgrid in automatically adjusting generation outputs in response to commands issued by an energy management system to replicate unattended operation at a customer site responding diurnal and hourly changes in customer energy demands.

In responding to power quality events originating on the utility distribution system, we found one distribution disturbance event. The event appeared to be an A phase to B phase to Ground fault. The depth of the voltage sag was mild and the duration short term. The cause was either an intermittent fault like a tree contact or a distant fault that 
was cleared by a downstream recloser. To our knowledge no upstream distribution protection equipment operated to clear this fault. This fault resulted in an $83 \%$ Voltage sag to phases A and B of the distribution supply. The unprotected load in Load Bank 6 of $18 \mathrm{~kW}$ experiences the full $83 \%$ voltage sag event lasting over a 1.5 second window. The time from fault, thru detection, to clearing appears to be $\sim 25 \mathrm{msec}$. At this point, the voltage within the islanded microgrid recovered having only experienced 1.5 cycles of sag. This was an excellent demonstration of the power quality enhancing functionality provided by the CERTS Microgrid

In examining the performance of automatic power factor corrections implemented through CERTS Microgrid controls to respond to voltage fluctuations detected at the point of common coupling with the utility distribution system, we used the existing Energy Management System to control the reactive power being drawing from the utility. This motivation was two fold, one to avoid problems with the utility and two to potentially sell an ancillary service to the utility. We used the Energy Management System for this purpose because kVar usage is measured on 15 minute intervals and faster corrections of reactive power consumption are not required. Hence, we found that the Energy Management System was well-suited to make the decisions of how many $\mathrm{kVars}$ are required and from where they should be generated. We found that the Energy Manage System was able to improve average power factor from 0.795 to 0.928 , or approximately $16.7 \%$.

The final area of interest deals with the automation of the load and genset equipment. During this continuous run period, the loads and gensets were automatically operated by individual agents. These agents were given a base load profile for electrical $\mathrm{kW}, \mathrm{kVar}$ and thermal demand. They were also given the freedom to deviate from this base profile by a certain amount. This allowed for the bounded, random generation of a large number of load flows within the microgrid. In total, the system operated through approximately 27,300 load changes and approximately 5,800 generation dispatches over 1,024 hours of operation. 
We observed a general deviation from the base profile can be seen in the early morning hours of operation by all three gensets. This was caused inadvertently in order to maintain compliance with the IEEE 1547 standard at the point of common coupling. The base thermal demand profile was constructed around a customer with higher thermal demand in the late evening and early morning hours, similar to a customer space heating requirement in the winter season. The thermal generation and therefore electrical generation was high enough to frequently offset the entire electrical demand at the point of common coupling. Because the chosen technique for anti-islanding detection within the CERTS microgrid is a minimum real power import the static switch would open each time power was exported to the utility for more than two seconds. Finally the static switch was automated to re-dispatch the generators to a lower set point and resynchronize to the utility system. This effectively lowered the generation dispatch to match that of the electrical load in the late evening and early morning hours of interest. As a consequence, a customer with this particular thermal and electrical demand would need to make adjustments to their system operation to ensure there energy demands were met continuously.

\section{Task 7 Inverter Short Circuit Tests}

In the first phase of testing of the CERTS Microgrid, we encountered an unexpected result. We observed that our inverters could, under some fault conditions, produce significantly more current. While this finding did not invalidate or affect the basic results of tests that had been conducted, it was contrary to expectations. We speculated that, if the fault current can be predicted and controlled, then the electrical utility grid and microgrid customer could have a better understanding of the fault contribution of the microgrid based on location and greatly reduce the protection problems when in islanded operation. In order to explore this possibility, we implemented changes to the inverter controls and then sought to determine whether the amount of current could be limited to a much lower target value. We demonstrated this capability by repeating the original tests using the modified inverters and comparing the results to the earlier findings. 
We found that the fault current contribution can be controlled by the genset equipment. We identified an approximately linear relationship between the Percent Surge and the fault current contributed. However if the value for Percent Surge is projected to 0, the fault current contribution is projected to be approximately 325 amps, not 0 amps as intuition would suggest. A similar relationship may exist past a Percent Surge value of 100. In this case the term Percent Surge is misleading and should be better connected to a deliverable value of fault current contribution.

\section{Next Steps}

The next steps in the advancement and commercialization of CERTS Microgrid Concepts are two-fold. First, field demonstrations are needed to take the advances already demonstrated at the AEP Test Bed and work-through the site-specific, real-world challenges involved in deploying production-grade installations that embody CERTS Microgrid Concepts. Industrial partners must be sought would will license and implement CERTS Microgrid Concepts in commercial products.

Second, the integrated program of theory, simulation, bench-scale demonstration, and then full-scale demonstration at the AEP Test Bed needs to continue. Several advances demonstrated at bench-scale in this phase of research, including integration of AC storage and synchronous generation in a microgrid are now ready for demonstration at full-scale at the AEP Test Bed. In addition and in view of these enhancements, the benefits of the CERTS Microgrid for supporting integration of variable renewable generation in the form of PVs should be examined, ultimately, at full-scale at the AEP Test Bed. Finally, on-going work to examine alternatives to the static switch should be pursued to target market segments with less demanding requirements for power quality. 


\section{Table of Contents}

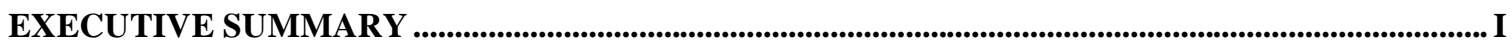

TABLE OF CONTENTS ................................................................................................................................................ XI

CHAPTER 1. INTRODUCTION ....................................................................................................................1

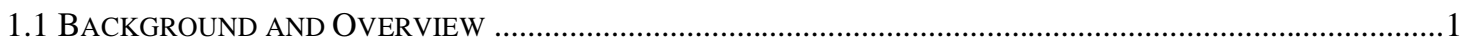

1.2 DESCRIPTIONS OF TECHNICAL TASKS AND SCHEDULE...........................................................................

CHAPTER 2. CERTS MICROGRID CONCEPT .................................................................................................

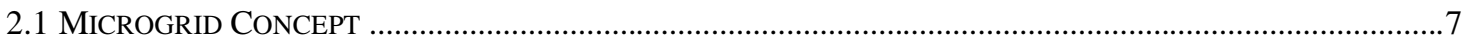

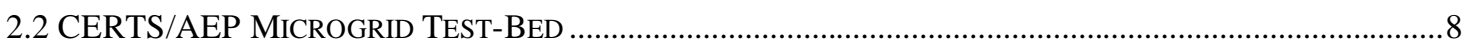

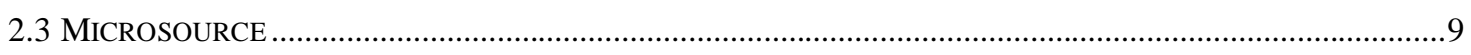

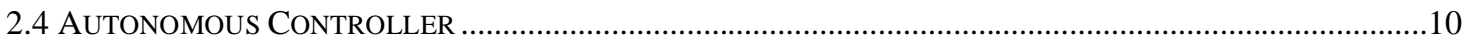

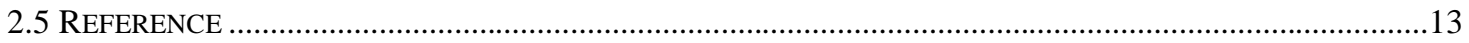

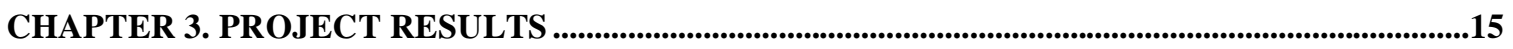

3.1 TASk-1 Construction of BASELINES For Microgrid Business CASE ASSESSMENTS .....................15

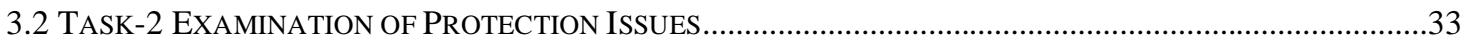

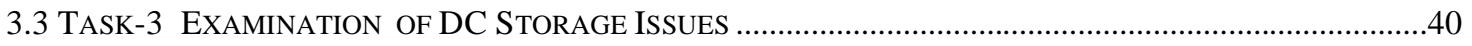

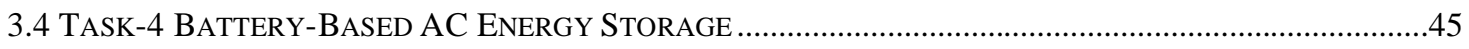

3.5 TASK-5 Microgrid OPERATION WITH NON-INVERTER-BASED DG. .......................................................56

3.6 TASK-6. CONTINUOUS RUN OF THE CERTS MICROGRID ..............................................................64

3.7 TASK-7 INVERTER FAULT CURRENT CONTRIBUTION .........................................................................76

CHAPTER 4. CONCLUSIONS AND RECOMMENDATIONS ...............................................................81

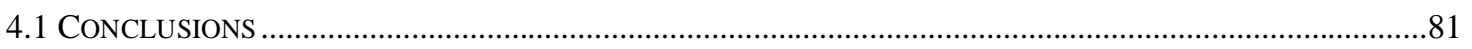

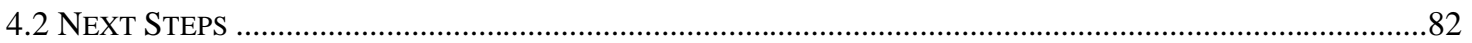




\section{CHAPTER 1. Introduction}

The objective of this project is to build from the technical proof-of-concept that had been previously demonstrated using the Consortium for Electric Reliability Technology Solutions (CERTS) Microgrid - the world's first, full-scale, inverter-based, distributed generation microgrid - to prioritize, develop, and, as appropriate, demonstrate technology enhancements to the original implementation to enhance the business case for microgrids. The project involved seven distinct analysis, bench-, and full-scale testing tasks. The first five tasks were described in the original proposal submitted and awarded through DOE's solicitation. Two additional tasks were added to address issues that had been identified in the earlier, first phase of testing.

The background, motivation, and approach taken to complete each of the seven tasks are outlined in this chapter. The design principles, technical concepts, and work completed in the prior project are then briefly reviewed in chapter 2. Project results and findings for each of the tasks are then described in chapter 3. Each discussion provides references to one or more stand-alone, technical publications that contain extensive details on the execution of each task. Chapter 4 summarizes the project findings and conclusions, and recommends next steps in advancing the CERTS Microgrid concept.

\subsection{Background and Overview}

The CERTS Microgrid concept is an advanced approach for enabling integration of, in principle, an unlimited quantity of distributed energy resources into the electricity grid. The CERTS Microgrid concept is driven by two fundamental principles: 1) A systems perspective is necessary for customers, utilities, and society to capture the full benefits of integrating distributed energy resources into an energy system; and 2) The business case for accelerating adoption of these advanced concepts will be driven, primarily, by lowering the first cost and enhancing the value of microgrids. 
A key feature of a microgrid, is its ability, during a utility grid disturbance, to separate and isolate itself from the utility seamlessly with no disruption to the loads within the microgrid (including no reduction in power quality). Then, when the utility grid returns to normal, the microgrid automatically resynchronizes and reconnects itself to the grid, in an equally seamless fashion.

What is unique about the CERTS Microgrid is that it can provide this technically challenging functionality without extensive (i.e., expensive) custom engineering. In addition, the design of the CERTS Microgrid also provides high system reliability and great flexibility in the placement of distributed generation within the microgrid. The CERTS Microgrid offers these functionalities at much lower costs than traditional approaches by incorporating peer-to-peer and plug-and-play concepts for each component within the Microgrid.

The predecessor to the current project was the CERTS Microgrid Laboratory Test Bed project, which involved the construction of and completion of initial testing using the world's first, fullscale, inverter-based, distributed generation test bed. The project demonstrated three advanced techniques, collectively referred to as the CERTS Microgrid concept, which collectively significantly reduce the level of custom field engineering needed to operate microgrids consisting of small generating sources. The techniques are: 1) a method for effecting automatic and seamless transitions between grid-connected and islanded modes of operation; 2) an approach to electrical protection within the microgrid that does not depend on high fault currents; and 3) a method for microgrid control that achieves voltage and frequency stability under both grid and islanded conditions without requiring high-speed communications.

The work conducted in this phase of RD\&D on the CERTS Microgrid Concept built upon this base of technical accomplishments to prioritize, develop, and then demonstrate technology enhancements to further enhance the business case for microgrids. That is, having demonstrated the technical feasibility of microgrid functions, RD\&D optimization efforts are now needed to accelerate commercial deployment. The current phase is a contribution to these efforts. The work paid special attention to the economic drivers outlined in the DOE solicitation: "economic 
dispatch responsive to pricing signals and demand management programs, customer willingness to pay premiums for increased power reliability and quality, etc."

\subsection{Descriptions of Technical Tasks and Schedule}

This project involved seven distinct analysis, bench-, and full-scale testing tasks. The first five tasks were described in the original proposal submitted and awarded through DOE's solicitation. Two additional tasks were added to address issues that had been identified in the earlier, first phase of testing.

Task 1. Construction of Baselines for Microgrid Business Case Assessments

Task 2. Examination of Technical Requirements to Reduce Protection Costs

Task 3. Examination of Technical Requirements to Reduce DC Storage Costs

Task 4. Enhancing Microgrid Functionality by Optimizing the Role of AC Storage

Task 5. Enhancing Microgrid Functionality by Incorporating Non-Inverter-based DG

Task 6. Continuous Run of the CERTS Microgrid

Task 7. Inverter Short Circuit test

In the remaining subsections, we describe the background, motivation, and approach taken to complete each of the seven tasks. The results and findings are presented in chapter 3

\section{Task 1. Construction of Baselines for Microgrid Business Case Assessments}

The organizing principles for this project were prioritization, development, and demonstration of technology enhancements to improve the business case for microgrids. DOE and the California Energy Commission have previously funded the development of a software tool that addresses the first of these principles. The tool, called the Distributed Energy Resources Customer Adoption Model (or DER-CAM) is an engineering-economic optimization tool that among other things can identify cost-targets and the economic value of alternative microgrid configurations and operating strategies. For this project, two major enhancements were implemented to expand the capabilities of the tool to explicitly consider both thermal and electrical energy storage technologies and to place an economic value on improvements to customer power quality and reliability $(\mathrm{PQR})$. The enhancements were then demonstrated by examining the economic value 
of microgrids in key target markets for distributed generation on the East and West Coast of the US. The demonstrations focused, in part, on showing the interactions that occur between renewable distributed generation in the form of PV and electricity storage.

\section{Task 2. Examination of Protection Issues}

There are three aspects to protection for the CERTS Microgrid: 1) Conventional protection for the feeders, which do not have microsources, consistent with industrial and commercial standards; 2) Protection of the utility and the microgrid during critical events at the point of common coupling using an interface switch; 3) Specially designed protection schemes associated with each microsource within the CERTS Microgrid to address internal faults during parallel and islanded operation. Current implementation at the CERTS microgrid test bed of the third aspect of this scheme relies on expensive, external digital relays with independent current and voltage sensors. In order to lower the overall cost of the CERTS Microgrid, we sought to determine whether this protection logic could become an integral part of the control logic within each microsource. This would allow for elimination of the external relays and enhance the plug-andplay functionality of the microsources. The approach was to imbed the protection control logic and then connect the supporting sensors directly into the inverters on each microsource, repeat the detailed protection tests performed previously at the Test Bed, and compare the results.

\section{Task 3. Examination of DC Storage Issues}

DC storage on the CERTS Microgrid is defined by the need to ensure fast response of the inverter, decouple the prime mover dynamics from the microgrid's dynamics, and support the DC bus voltage. This task sought to lower the cost of a microgrid by optimizing the amount of storage required, including possibly, eliminating the need for DC storage altogether. The work required a detailed assessment and optimization of DC storage including consideration of enhancements to the prime mover's controls. The work was based on new analysis of data that had collected been collected previously through testing of other functionalities at the CERTS/AEP Microgrid test site. These data provided information that enabled us to better understand the role of DC storage and prime mover response on the CERTS Microgrid's dynamic performance.

\section{Task 4. Role of AC Storage in Enhanced Microgrid.}


The addition of AC storage to the CERTS Microgrid's architecture has the potential to enhance the functionality and business case for microgrids by enabling peak shaving, providing dispatchability for intermittent sources, and allowing energy transfer in order to take advantage of time-varying energy prices. Our approach to incorporation of AC storage involved determining whether we could add these values while retaining the high inherent reliability of the CERTS Microgrid concept. For storage, this meant determining whether we could retain the basic peer-to-peer microgrid functionality in the event of loss of the AC storage (i.e. that the microgrid should be able to continue operating following the loss of one or more microgrid elements) by imbedding CERTS control concepts into the inverter controls directing energy flows into and out of the AC storage unit. Beyond the functionalities previously demonstrated, we had to develop energy management methods that recognized and took into account the state of charge of the AC storage unit. The work was carried out by designing, implementing, and testing an AC storage unit using the bench-scale, University-of-Wisconsin (UW) microgrid test bed.

\section{Task 5. Non-Inverter-based DG in Enhancing Microgrid.}

As presently designed, the CERTS Microgrid requires each generator sets to add an inverter interface in order to function properly in the system. In order to gain wider market acceptance, the CERTS Microgrid concept must be expanded to include generator sources that do not include inverter interfaces because the additional cost associated with the inverter increases the cost of the generator equipment. This task involved bench tests also conducted at the UW microgrid test bed. A $12.5 \mathrm{kVA}$ Kohler diesel-generator set with a wound-field synchronous machine was installed and new governor and exciter control hardware together with improved control algorithms where implemented. A series of tests were conducted to document the system's steady-state and dynamic performance capabilities.

\section{Task 6. Continuous Run of the CERTS Microgrid}

Up to this point, testing at the CERTS Microgrid Test Bed had been limited to a large number of one-off tests to confirm the operation of specific functionalities of CERTS Microgrid concepts. For this project, the Test Bed was operated unattended for several long periods of time to examine issues and demonstrate functionalities that cannot be observed in short-duration tests. 
First, we examined the performance of the CERTS Microgrid in responding to power quality events originating on the utility distribution system. Second, we examined the performance of automatic power factor corrections implemented through CERTS Microgrid controls to respond to voltage fluctuations detected at the point of common coupling with the utility distribution system. Third, throughout these periods of uninterrupted operation, we examined the performance of CERTS Microgrid in automatically adjusting generation outputs in response to commands issued by an energy management system to replicate unattended operation at a customer site responding diurnal and hourly changes in customer energy demands. In total, we operated the Microgrid through approximately 27,300 load changes and approximately 5,800 generation dispatches.

\section{Task 7 Inverter Short Circuit Tests}

In the first phase of testing of the CERTS Microgrid, we encountered an unexpected result. We observed that our inverters could, under some fault conditions, produce significantly more current. While this finding did not invalidate or affect the basic results of tests that had been conducted, it was contrary to expectations. We speculated that, if the fault current can be predicted and controlled, then the electrical utility grid and microgrid customer could have a better understanding of the fault contribution of the microgrid based on location and greatly reduce the protection problems when in islanded operation. In order to explore this possibility, we implemented changes to the inverter controls and then sought to determine whether the amount of current could be limited to a much lower target value. We demonstrated this capability by repeating the original tests using the modified inverters and comparing the results to the earlier findings. 


\section{CHAPTER 2. CERTS Microgrid Concept}

CERTS Microgrid concepts were first formulated in 1998 as a cluster of micro-generators and storage with the ability to separate and isolate itself from the utility seamlessly with little or no disruption to the loads. Key concepts include controllers based on local terminal quantities only, fast load tracking and the use of frequency droop methods to insure load sharing between microsources. This work was later formalized in a white paper and a US patent, [1-3].

\subsection{Microgrid Concept}

CERTS Microgrid control is designed to facilitate an intelligent network of autonomous units. The concept has three critical components, the static switch, the microsources and loads. The static switch has the ability to autonomously island the microgrid from disturbances such as faults, IEEE 1547 events or power quality events. After islanding, the reconnection of the microgrid is achieved autonomously after the tripping event is no longer present. Each microsource can seamlessly balance the power on the islanded microgrid using a power vs. frequency droop controller. If there is inadequate generation the frequency will droop below the normal operating range signaling the non-critical loads to shed. The coordination between sources and loads is through frequency,

The voltage controller at each source provides local stability. Without local voltage control, systems with high penetrations of DG could experience voltage and/or reactive power oscillations. Voltage control must also insure that there are no large circulating reactive currents between sources. This requires a voltage vs. reactive power droop controller so that, as the reactive power generated by the source becomes more capacitive, the local voltage set point is reduced. Conversely, as reactive power becomes more inductive, the voltage set point is increased [4].

The CERTS Microgrid has no "master" controller or source. Each source is connected in a peerto-peer fashion with a localized control scheme implemented for each component. This arrangement increases the reliability of the system in comparison to having a master-slave or 
centralized control scheme. In the case of master-slave controller architecture the failure of the master controller could compromise the operation of the whole system. The CERTS Testbed uses a central communication system to dispatch DG set points as needed to improve overall system operation. However this communication network is not used for the dynamic operation of the microgrid. This plug and play approach allows us to expand the microgrid to meet the requirements of the site without extensive re-engineering. This implies that the microgrid can continue operating with loss of any component or generator. With one additional source, $(\mathrm{N}+1)$, we can insure complete functionality with the loss of any source. Plug-and-play implies that a unit can be placed at any point on the electrical system without re-engineering the controls thereby reducing the chance for engineering errors. The plug-and-play model facilitates placing generators near the heat loads thereby allowing more effective use of waste heat without complex heat distribution systems such as steam and chilled water pipes.

\subsection{CERTS/AEP Microgrid Test-Bed}

The objective of the CERTS Microgrid Laboratory Test Bed project was to demonstrate the ease of integrating small energy sources into a microgrid. The project accomplished this objective by developing and demonstrating three advanced techniques, collectively referred to as the CERTS Microgrid concept, that significantly reduce the level of custom field engineering needed to operate microgrids consisting of small generating sources. The techniques comprising the CERTS Microgrid concept are: 1) a method for effecting automatic and seamless transitions between grid-connected and islanded modes of operation; 2) an approach to electrical protection within the microgrid that does not depend on high fault currents; and 3) a method for microgrid control that achieves voltage and frequency stability under both grid and islanded conditions without requiring high-speed communications.

The test bed is shown in Figure 1. There are three feeders (A, B and C) with loads and three microsources. Two microsources are on Feeder-A, (A-1 and A-2) with the third, B-1, on FeederB. Feeder-A uses a four-wire cable with a common ground point. The cable between A-1 and A2 is $100 y d s$, providing impedance to verify the plug and play feature and local stability. The second feeder (B) with a single load and source is a three-wire system with an isolation 


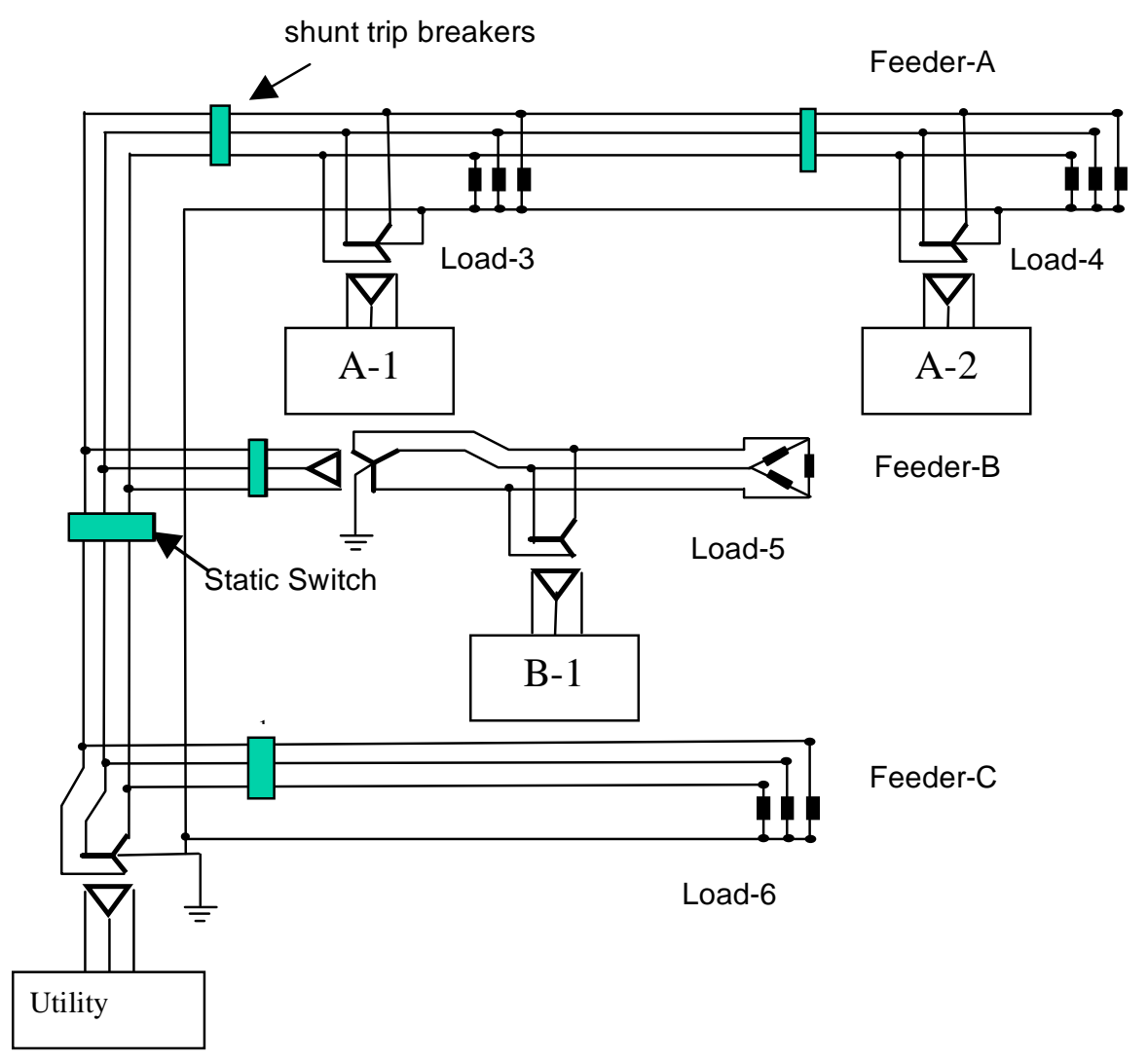

\section{Figure 1. CERTS/AEP Microgrid Test Site}

transformer. Feeders-A and B can be islanded from the utility using a static switch. The static switch hardware consists of back-to-back thyristors with local implement of the CERTS Microgrid islanding and re-synchronization procedures.

The four load banks, Load-3 through Load-6 can be remotely controlled from 0-90 kW and 0-45 kVar. Each load bank also has remote fault loads which range from bolted faults to high impedance faults $(60 \mathrm{~kW}$ and $83 \mathrm{~kW})$. Other loads include an induction motor $0-20 \mathrm{HP}$. The other equipment includes; protection relays, shunt trip breakers and a complete digital acquisition system. The digital acquisition system includes twelve 7650 ION meters providing detailed voltage and current waveforms for each phase conductor including the neutral.

\subsection{Microsource}

At the AEP site the prime mover is a 7.4 liter, naturally aspirated V-8, specially modified for natural gas, [5]. The block and exhaust manifolds are liquid cooled. Typical coolant temperatures supplied to the host facility are in the range of $185 / 235 \mathrm{~F}$ when exhaust heat recovery is used for CHP applications. Heat is recovered from an external oil cooler as well. The fuel supply, natural 
gas at low pressure (18 inches of water column) is combined with air in a venturi mixer upstream of the throttle and intake manifold. To maintain the precise air/fuel ratio control required for the catalyst emissions system, a closed loop feedback control system is utilized incorporating twin oxygen sensors in the exhaust system. The generator is liquid-cooled permanent magnet type designed specifically to match the speed and power curve of the engine. Voltage and power are proportional to RPM. The cooling fluid can be combined with the main heat recovery system in some cases where temperatures are relatively low.

The power conditioning system has three fundamental stages: an AC/DC diode rectifier bridge with voltage boost, DC storage and a DC/AC inverter. Diode rectifier and boost has two tasks: the first is to convert the $\mathrm{AC}$ waveform into a DC voltage and the second is to increase the DC voltage to a higher level so that the inverter has extra room to be able to synthesize a voltage larger than nominal. When the inverter injects reactive power to regulate voltage at the feeder, the magnitude of the voltage at the inverter can exceed 1 PU. To make sure that the inverter does not operate in the over modulation region, a larger DC bus voltage is used. [6]

The DC storage can provide short bursts of power, drawing from an internal supply of stored energy. This insures that the inverter can provide the power required by the microgrid independent of the rate of the prime mover. Subsequent to a burst and settling to steady state, a charger ensures that the energy is slowly replenished into the batteries. The inverter is a power electronic block composed of a matrix of solid state devices with high switching frequency that can convert a DC voltage into an stiff AC voltage. For these tests storage was not used since the prime mover could prove needed energy to the inverters.

\subsection{Autonomous Controller}

Integration of large numbers of microsources into a Microgrid is not possible with basic unity power factor controls. Voltage regulation is necessary for local reliability and stability. Without local voltage control, systems with high penetrations of microsources could experience voltage and/or reactive power oscillations. Voltage control must also insure that there are no large circulating reactive currents between sources. With small errors in voltage set points, the circulating current can exceed the ratings of the microsources. This situation requires a voltage 
vs. reactive power droop controller so that, as the reactive power, Q, generated by the microsource becomes more capacitive, the local voltage set point is reduced. Conversely, as Q becomes more inductive, the voltage set point is increased.

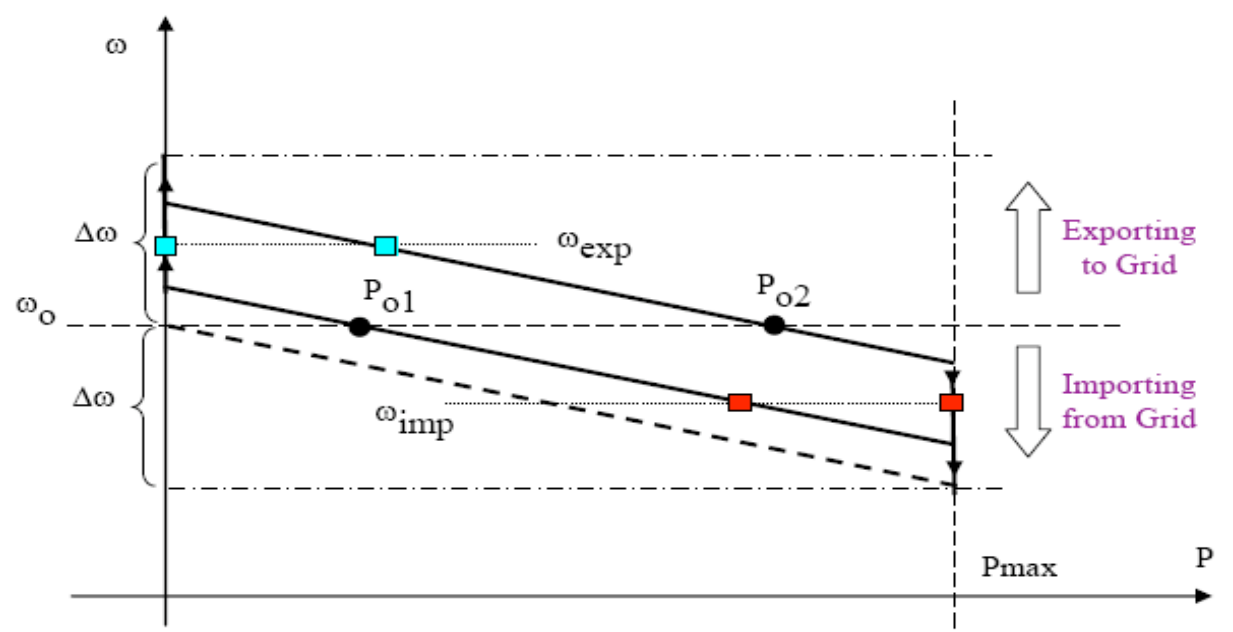

Figure 2. Steady state power vs. frequency droop

Each microsource uses a power vs. frequency droop controller to insure power balance in an islanded state. There are two possible power droop controllers. One is unit power control, which controls the power being injected by the microsource. The other is zone flow power controller which regulates the power in a feeder, for example the flow into Feeder-A in Figure 1. When regulating unit power, each source has a constant negative slope droop on the $\mathrm{P}, \omega$ plane as shown in Figure 3. In zone control each source has a positive slope on $\mathrm{P}, \omega$ plane. The fixed slope is the same magnitude used in unit power control, but with a reversed sign. When regulating unit power the relative location of loads and source is irrelevant but when regulating zone flow these factors becomes important. Power flow into the feeder is positive while power from the feeder is negative. Figure 2 shows power vs. frequency droop for unit power control. The slope is chosen by allowing the frequency to drop by a given amount, $\Delta \omega$, as the power spans from zero to Pmax. Figure 2 also shows the power set-points Po1 and Po2 for two units. This is the amount of power injected by each source when connected to the grid, at system frequency, $\omega_{0}$. 
When the microgrid is connected to the grid, loads receive power both from the grid and from local microsources, depending on the customer's situation. If the grid power is lost because of IEEE 1547 events, voltage droops, faults, blackouts, etc., the Microgrid can autonomously transfer to island operation. If the system transfers to island when importing from the grid, the generation needs to increase power to balance power in the island. The new operating point will be at a frequency that is lower than the nominal value. In this case both sources have increased their power output with unit 2 reaching its maximum power point. If the system transfers to island when exporting power to the grid, then the new frequency will be higher, corresponding to a lower power output from the sources with unit 1 at its zero power point.

The characteristics shown on Figure 2 are steady state characteristics. They have a fixed slope in the region where the unit is operating within its power range. The slope becomes vertical as soon as any limit is reached. The droop is the locus where the steady state points are constrained to come to rest, but during dynamics the trajectory will deviate from the characteristic.

The dynamics of this droop characteristic is shown in Figure 3. The figure shows the response of two sources during an islanding event. The data is from Test 8.3 taken on 21 February 2008 at 11:45 AM at the microgrid laboratory test bed, [7-10]. Figure 3a traces are measured at unit A-1, see figure 1 . Before islanding at time $=0.0$ seconds both sources are connected to AEP. The real power output of A-1 is $5 \mathrm{~kW}$ and reactive power (capacitive) is close to $9 \mathrm{kVAr}$. The three phase current is from the Y side of the source is shown in the middle plot and the lower plot is voltage at the point of connection to feeder-A.

Figure $3 \mathrm{~b}$ traces are measured at unit A-2. Before islanding The real power output of A-2 is $55 \mathrm{~kW}$ and reactive power (capacitive) is close to $5 \mathrm{kVAr}$. This test is close to the operating point shown in Figure 2. With A-1 set very low while A-2 set is close to the steady state maximum of $60 \mathrm{~kW}$. When connected to the grid the microgrid is importing $32 \mathrm{~kW}$ of power from the utility. After islanding the units need to compensate for lost power. A-2 overshoots its steady state maximum for less than 200 milliseconds peaking at $70 \mathrm{~kW}$ but then the controls backs off the generation while unit A-1 increases its output to meet its share of the loads. The new steady state operating point for A-1 is $29 \mathrm{~kW}$ and A-2 is $60 \mathrm{~kW}$. Note that the reactive output is greatly 
reduced. Voltage magnitudes are unchanged for both sources demonstrating the stiffness of the inverter voltages. The current traces are from the inverters.
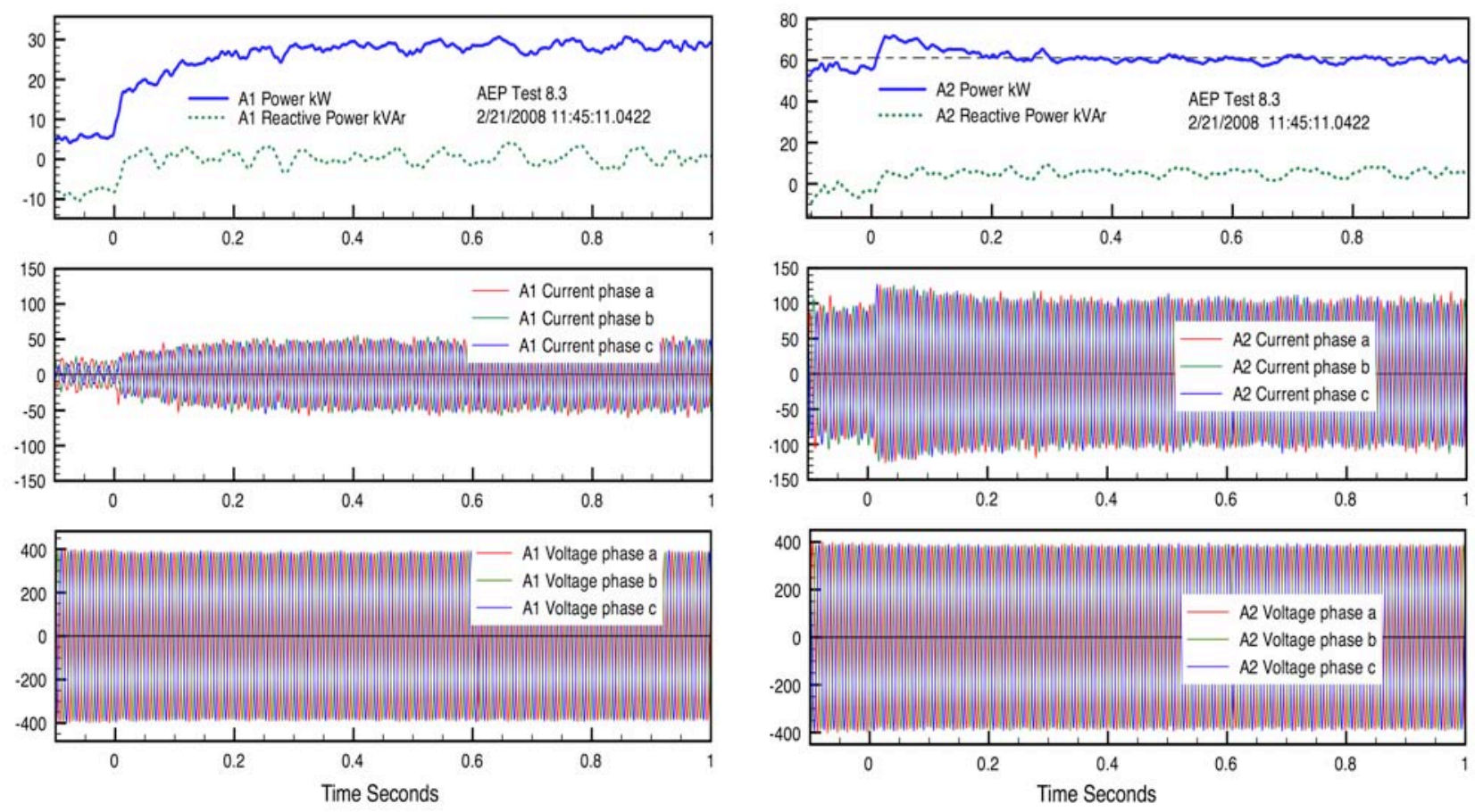

Figure 3a. Dynamic response of unit A-1

Figure 3b. Dynamic response of unit A-2

\subsection{Reference}

1. Lasseter, R. H and P Piagi, "Control of small distributed energy resources" \# 7,687,937 B2 March 30, 2010

2. Lasseter, R. H., A. Akhil, C. Marnay, J Stephens, J Dagle, R Guttromson, A. Meliopoulous, R Yinger, and J. Eto, "The CERTS Microgrid Concept," White paper for Transmission Reliability Program, Office of Power Technologies, U.S. Department of Energy, April 2002. Available: http://certs.lbl.gov/certs-der-pubs.html

3. Lasseter, R.H., P. Piagi, "Control of small distributed energy resources," US Patent 7116 010, Oct. 3, 2006.

4. Lasseter, R.H., P. Piagi, "Microgrid: A Conceptual Solution," PESC'04 Aachen, Germany 20-25 June 2004

5. Panora, R., J. Gerhrt, P. Piagi, "Design and Testing of an Inverter-Based CHP Module for Special Application in a Microgrid," IEEE PES General Meeting, 24-28 June 2007, Tampa, FL

6. Piagi, P., R.H. Lasseter, "Autonomous Control of Microgrids," IEEE PES Meeting, Montreal, June 2006. 
7. Eto, Joseph, Robert Lasseter, Ben Schenkman, John Stevens, Harry Volkommer, Dave Klapp, Ed Linton, Hector Hurtado, Jean Roy, Nancy Jo Lewis, "CERTS Microgrid Laboratory Test Bed Report:Appendix K," http://certs.lbl.gov/CERTS P DER.html

8. Klapp, D., H. Vollkommer, "Application of an Intelligent Static Switch to the Point of Common Coupling to Satisfy IEEE 1547 Compliance," IEEE PES General Meeting, 2428 June 2007, Tampa, FL.

9. Eto, J., R. Lasseter, B.Schenkman, J. Stevens, D. Klapp, H. Volkommer, E. Linton , H. Hurtado and J. Roy, "CERTS Microgrid Laboratory Test Bed," CIGRI Calgary 2009

10. Lasseter, R.H., J. H. Eto, B. Schenkman, J. Stevens, H. Volkmmer, D. Klapp, E. Linton, H. Hurtado, J. Roy, CERTS Microgrid Laboratory Test Bed, IEEE Transactions on Power Delivery, 2010 


\section{CHAPTER 3. Project Results}

\subsection{Task-1 Construction of Baselines for Microgrid Business Case Assessments}

The organizing principles for this project were prioritization, development, and demonstration of technology enhancements to improve the business case for microgrids. DOE and the California Energy Commission have previously funded the development of a software tool that addresses the first of these principles. The tool, called the Distributed Energy Resources Customer Adoption Model (or DER-CAM) is an engineering-economic optimization tool that among other things can identify cost-targets and the economic value of alternative microgrid configurations and operating strategies. This task began with 3 major goals:

1. To extend the analysis capability of DER-CAM to include both heat and electricity storage,

2. To make an initial effort towards adding consideration of power quality and reliability (PQR) to the capabilities of DER-CAM, and

3. To conduct detailed analysis to find the optimal equipment combination for microgrids at a few promising commercial building hosts in the two favorable markets of California and New York,

These objectives were pursued via analysis of the attractiveness of a Consortium for Electric Reliability Technology Solutions (CERTS) Microgrid consisting of multiple nameplate $100 \mathrm{~kW}$ Tecogen Premium Power Modules (CM-100). This unit consists of an asynchronous inverterbased variable speed internal combustion engine genset with combined heat and power (CHP) and power surge capability. The essence of CERTS Microgrid technology is that smarts added to the on-board power electronics of any microgrid device enables stable and safe islanded operation without the need for complex fast supervisory controls. This approach allows plug and play development of a microgrid that can potentially provide high PQR with a minimum of specialized site-specific engineering. A notable feature of the CM-100 is its time-limited surge rating of $125 \mathrm{~kW}$, and DER-CAM capability to model this feature was also a necessary model enhancement. 


\section{DER-CAM}

demonstrates the fundamental philosophy of the DER-CAM approach. For the purposes of this study, the graphic can be thought of as showing the energy system of a commercial building or group of buildings. On the right are the energy services that need to be provided to building occupants, and on the left are the purchases of commercial fuels entering the facility. In between are various devices for energy use, conversion, and storage. A building may often have other fuel opportunities available, and solar is shown in the figure. The goal of DER-CAM development is to build a model that can solve the entire system shown such that the entire cost, carbon footprint, other metric, or combination of metrics is minimized. The approach is fully technology-neutral and can include energy purchases, on-site conversion, both electrical and thermal local renewable harvesting, and end-use efficiency investments. In this study, DER-CAM minimizes only the annual costs for providing energy services to the modeled site, including utility electricity and natural gas purchases plus amortized capital and annual maintenance costs for distributed generation (DG) investments. In addition to the CM-100 engines, the DER available include solar thermal, photovoltaics (PV) and fuel cells.

Furthermore, system choice considers the simultaneity of solutions, especially regarding the building cooling problem; that is, multiple technologies can be used for cooling and results reflect the benefit of electricity demand displacement by heat-activated or direct-fire cooling that lowers building peak load, and therefore, the generation requirement. Similarly, operation of storage is optimized over all time periods of the simulation. Achieving these optimums requires above all else sophisticated representation of tariffs. 


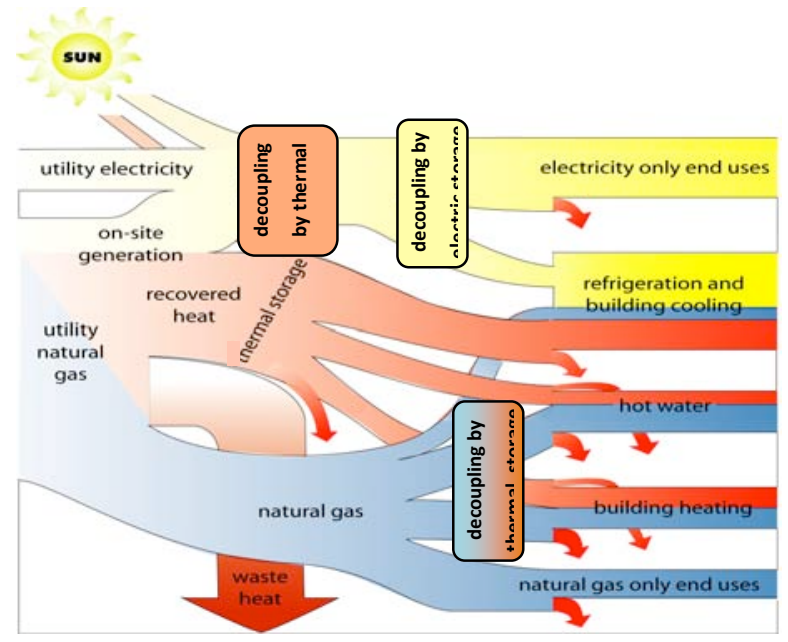

Figure ES 1. Schematic of the energy flow model used in DER-CAM

Technically, DER-CAM is a mixed-integer linear program (MILP) written and executed in the General Algebraic Modeling System (GAMS) using the CPLEX solver.

\section{Test Sites}

The key site-specific inputs to DER-CAM are hourly energy service requirements aggregated into the categories shown in

, plus electricity and natural gas tariff structure and rates. The hourly data requirement is typically the most difficult to meet. Few monitored building results are available, so almost always the end-use detail must be developed using some form of building energy use simulation. An earlier market assessment showed that nursing homes and assisted living facilities, K-12 schools, and data centers are three promising markets, so end-use data sets were collected for 
representative example buildings of each of these three types in both California and New York. The details are shown in Table ES 1.

Table ES 1. Key characteristics of test buildings and sites

\begin{tabular}{|c|c|c|c|c|c|c|c|c|c|c|}
\hline & & $\begin{array}{c}\text { floorspace } \\
\left(\mathbf{m}^{2}\right)\end{array}$ & $\begin{array}{c}\text { electricity } \\
\text { peak load } \\
(\mathbf{k W})\end{array}$ & \begin{tabular}{|c|} 
annual \\
electricity \\
consumption \\
$(\mathrm{kWh})$
\end{tabular} & $\begin{array}{c}\text { annual } \\
\text { NG } \\
\text { consumption } \\
\text { (therms) }\end{array}$ & vicinity & $\begin{array}{c}\text { elec. } \\
\text { utility }\end{array}$ & $\begin{array}{c}\text { gas } \\
\text { utility }\end{array}$ & $\mathbf{F}_{\mathrm{s}, \text { Base }}$ & $\mathbf{F}_{\mathrm{s}, \text { Peak }}$ \\
\hline \multirow{3}{*}{ CA } & $\begin{array}{l}\text { nursing } \\
\text { home }\end{array}$ & 31587 & 958 & 5761690 & 194522 & $\begin{array}{l}\text { northern } \\
\text { CA }\end{array}$ & PG\&E & PG\&E & 0.5 & 0.1 \\
\hline & school & 17652 & 885 & 1508883 & 24868 & $\begin{array}{l}\text { southern } \\
\text { CA }\end{array}$ & SCE & $\begin{array}{l}\text { SoCal } \\
\text { Gas }\end{array}$ & 0.25 & 0 \\
\hline & data center & 617 & 1788 & 11420823 & 0 & $\begin{array}{l}\text { northern } \\
\text { CA }\end{array}$ & PG\&E & PG\&E & 1 & 1 \\
\hline \multirow{3}{*}{ NY } & $\begin{array}{l}\text { nursing } \\
\text { home }\end{array}$ & 31587 & 1067 & 6016309 & 243563 & NYC & ConEd & ConEd & 0.5 & 0.1 \\
\hline & school & 17652 & 746 & 1120653 & 32193 & NYC & ConEd & ConEd & 0.25 & 0 \\
\hline & datacenter & 617 & 1591 & 12070888 & 0 & NYC & ConEd & ConEd & 1 & 1 \\
\hline
\end{tabular}

Data sets for these example buildings were obtained in diverse ways. The nursing homes are based on an Oakland example taken from the California Commercial End-Use Survey (CEUS). It is used as-is for California, but end-use requirements were weather adjusted for New York conditions. The two schools are standard building models taken from a database of commercial prototype EnergyPlus models. The data center is based on billing information for a real Silicon Valley facility, with a climate adjusted version used for New York.

The structure and level of utility rates frequently proves to be a critical determining input, and these examples are typical in this regard.

Table ES 2. Comparison of the average fuel costs for each case

\begin{tabular}{|c|l|r|r|r|}
\hline \multicolumn{2}{|c|}{ Average Fuel Costs } & NG (\$/therm) & NG (\$/kWh) & Electricity $\mathbf{\$} / \mathbf{k W h})$ \\
\hline \multirow{3}{*}{ CA } & Nursing Home & 1.055 & 0.036 & 0.131 \\
\cline { 2 - 5 } & School & 0.996 & 0.034 & 0.172 \\
\cline { 2 - 5 } & Data Center & 1.055 & 0.036 & 0.129 \\
\hline
\end{tabular}




\begin{tabular}{|l|l|r|r|r|}
\hline \multirow{3}{*}{ NY } & Nursing Home & 1.436 & 0.049 & 0.140 \\
\cline { 2 - 5 } & School & 1.436 & 0.049 & 0.188 \\
\cline { 2 - 5 } & Data Center & 1.436 & 0.049 & 0.137 \\
\hline
\end{tabular}

Fuel price levels and spark spread are not too different between California and New York, as can be seen in Table ES 2, but the tariff structures are different. Both Pacific Gas \& Electric (PG\&E) and Southern California Edison (SCE) have time-of-use tariffs with stiff demand charges, while Consolidated Edision (ConEd) has flat energy charges along with a severe demand charge. The ConEd tariffs, with flat electrical energy charges, and somewhat higher natural gas costs create an environment less amenable to microgrid development. The $F_{s, b a s e}$ and $F_{s, p e a k}$ variables in Table ES 1 refer to assumptions about the extent to which site loads are considered critical. These two variables are fractions of base and peak loads respectively that must be met during loss of grid power, i.e. the available on-site generation and storage capacity must exceed these ratings. It is a goal of this work to add consideration of the reliability benefits of microgrids to DER-CAM analysis capabilities. The load fractions considered critical by assumption have been shown, but within the DER-CAM framework an economic value of the added reliability is sought. While it may sound as if the cost of an alternative, such as backup generation, is a reasonable indicator of the site's willingness to pay for the higher reliability, in practice this faces three problems. First, some critical loads either require backup by code or are of such high value that cost is no object. Having on-site generation offers limited advantage to such customers. Second, the advantage of a CERTS microgrid is coverage of relatively short disturbances, e.g. ones for which on-site fuel storage would not be required. Third, short outages are difficult to include in DER-CAM's hourly time resolution. The approach taken in this study is a two-step one. In the first, the true optimum system is found, and in the second, a system is forced into existence that meets the critical load requirement. Then a value of reliability is incrementally added to the objective function until the equivalent cost of the optimum system is achieved. The value necessary for this equivalency represents the value the site must put on the added reliability for this capability to be cost effective.

\section{Equipment Available}


One of the key barriers to detailed optimization of building energy systems is the potentially high computational requirement. This burden arises in part because the number of technology options is large and the number of possible combinations huge. Also, note that these are difficult optimization problems because energy purchase from the grid is always a possibility and the conditions for those purchases are complex because tariffs are complex. Further, with storage involved, decisions made in any timestep can potentially affect all other timesteps. The upshot of these conditions is a quite flat surface of alternative choice combinations that have similar objective function values. In other words, there are a large number of alternative combinations of equipment that produce similar results and choosing between them is not easy.

An effective shortcut is to include only technologies that experience has shown to be competitive. Alternatively, computation may be reduced by representing lumpy technologies with strong diseconomies of small scale as integer alternatives, while representing the others as continuous functions. The upshot of these two simplifications is the short menu of equipment shown in Table ES 3 and

Table ES 5. Note that representing a technology as continuous does not mean it cannot exhibit economies of scale, only that such economies are linear and that it can be sized to exactly match the most desirable capacity and partial units are allowed. For many types of equipment, this approximation is quite reasonable, e.g. lead acid batteries are available in a wide range of sizes. Conversely, the scale economies of equipment such as gensets are considerable and they should be represented as integer technologies.

Table ES 3. Menu of available equipment options, discrete investments

\begin{tabular}{|l|c|c|}
\cline { 2 - 3 } \multicolumn{1}{c|}{} & Tecogen $\mathbf{C M - 1 0 0}$ & fuel cell \\
\hline capacity $(\mathbf{k W})$ & 100 & 200 \\
\hline sprint capacity $(\mathbf{k W})$ & 125 & \\
\hline installed costs $(\mathbf{\$} / \mathbf{k W})$ & 2400 & 5005 \\
\hline installed costs with heat recovery $\mathbf{( \$ / k W )}$ & 3000 & 5200 \\
\hline variable maintenance $\mathbf{\$ / k W h )}$ & 0.02 & 0.03 \\
\hline Efficiency $(\%),(\mathbf{H H V})$ & 26 & 35 \\
\hline lifetime $(\mathbf{a})$ & 20 & 10 \\
\hline
\end{tabular}

Table ES 4. Menu of available equipment options, continuous investments 


\begin{tabular}{|l|c|c|c|c|c|c|}
\cline { 2 - 7 } \multicolumn{1}{c|}{} & $\begin{array}{c}\text { lead-acid } \\
\text { batteries }\end{array}$ & $\begin{array}{c}\text { thermal } \\
\text { storage }^{1}\end{array}$ & flow battery & $\begin{array}{c}\text { absorption } \\
\text { chiller }\end{array}$ & $\begin{array}{c}\text { solar } \\
\text { thermal }\end{array}$ & photovoltaics \\
\hline intercept costs $\mathbf{\$})$ & 295 & 10000 & 0 & 20000 & 1000 & 1000 \\
\hline $\begin{array}{l}\text { variable costs } \\
\mathbf{\$} / \mathbf{k W} \text { or } \mathbf{\$} / \mathbf{k W h})\end{array}$ & 193 & 100 & $\begin{array}{c}220 \$ / \mathrm{kWh} \text { and } \\
2125 \$ / \mathrm{kW}\end{array}$ & 127 & 500 & 6675 \\
\hline lifetime (a) & 5 & 17 & 10 & 15 & 15 & 20 \\
\hline
\end{tabular}

Table ES 5. Energy storage parameters

\begin{tabular}{|l|l|c|c|c|}
\cline { 2 - 5 } \multicolumn{1}{c|}{} & \multicolumn{1}{c|}{ Description } & $\begin{array}{l}\text { lead-acid } \\
\text { batteries }\end{array}$ & flow battery & thermal \\
\hline charging efficiency (1) & $\begin{array}{l}\text { portion of energy input to storage that is } \\
\text { useful }\end{array}$ & 0.9 & 0.84 & 0.9 \\
\hline discharging efficiency (1) & $\begin{array}{l}\text { portion of energy output from storage that } \\
\text { is useful }\end{array}$ & 1 & 0.84 & 1 \\
\hline decay (1) & portion of state of charge lost per hour & 0.001 & 0.01 & 0.01 \\
\hline maximum charge rate (1) & $\begin{array}{l}\text { maximum portion of rated capacity that can } \\
\text { be added to storage in an hour }\end{array}$ & 0.1 & $\mathrm{n} / \mathrm{a}$ & 0.25 \\
\hline $\begin{array}{l}\text { maximum discharge rate } \\
(\mathbf{1})\end{array}$ & $\begin{array}{l}\text { maximum portion of rated capacity that can } \\
\text { be withdrawn from storage in an hour }\end{array}$ & 0.25 & $\mathrm{n} / \mathrm{a}$ & 0.25 \\
\hline $\begin{array}{l}\text { minimum state of charge } \\
\text { (1) }\end{array}$ & $\begin{array}{l}\text { minimum state of charge as apportion of } \\
\text { rated capacity }\end{array}$ & 0.3 & 0.25 & 0 \\
\hline
\end{tabular}

\footnotetext{
${ }^{1}$ Please note that cold thermal storage is not among the set of available technologies, but could be added.
} 


\section{Results}

\section{Detailed Microgrid Results}

Table ES 6. Nursing homes results

\begin{tabular}{|c|c|c|c|}
\hline CA nursing home & $\begin{array}{c}\text { do } \\
\text { nothing }\end{array}$ & $\begin{array}{l}\text { invest in all } \\
\text { technologies }\end{array}$ & $\begin{array}{l}\text { low storage cost \& } \\
60 \% \text { PV incentive }\end{array}$ \\
\hline Units of CM-100 (units) & & 3 & 3 \\
\hline absorption chiller (kW) & & 48 & 40 \\
\hline Solar thermal (kW) & & 134 & 43 \\
\hline PV $(\mathrm{kW})$ & & 0 & 517 \\
\hline lead-acid batteries (kWh) & & 0 & 2082 \\
\hline thermal storage $(\mathrm{kWh})$ & & 0 & 47 \\
\hline electricity bill (k\$) & 758.02 & 429.42 & 261.83 \\
\hline NG bill (k\$) & 205.88 & 359.14 & 362.88 \\
\hline microgrid equipment (k\$) & & 137.81 & 285.45 \\
\hline total bill $(\mathrm{k} \$)$ & 963.90 & 926.37 & 910.16 \\
\hline Bill effect (\%) & & -3.89 & -5.58 \\
\hline electricity use (GWh) & 5.76 & 3.23 & 2.40 \\
\hline electricity effect (\%) & & -43.92 & -58.33 \\
\hline NG use (GWh) & 5.70 & 9.99 & 10.10 \\
\hline NG effect (\%) & & 75.36 & 77.19 \\
\hline carbon emissions (tC) & 1087.74 & 945.05 & 833.96 \\
\hline carbon effect (\%) & & -13.12 & -23.33 \\
\hline NYC nursing home & $\begin{array}{c}\text { do } \\
\text { nothing }\end{array}$ & $\begin{array}{l}\text { invest in all } \\
\text { technologies }\end{array}$ & $\begin{array}{l}\text { low storage cost \& } \\
60 \% \text { PV incentive }\end{array}$ \\
\hline Units of CM-100 (units) & & 0 & 0 \\
\hline absorption chiller $(\mathrm{kW})$ & & 100 & 112 \\
\hline solar thermal $(\mathrm{kW})$ & & 1438 & 2350 \\
\hline $\mathrm{PV}(\mathrm{kW})$ & & 0 & 0 \\
\hline lead-acid batteries (kWh) & & 0 & 294 \\
\hline thermal storage $(\mathrm{kWh})$ & & 0 & 4862 \\
\hline electricity bill (k\$) & 845.66 & 825.89 & 823.68 \\
\hline NG bill (k\$) & 349.84 & 256.97 & 171.46 \\
\hline microgrid equipment (k\$) & & 78 & 153 \\
\hline total bill $(\mathrm{k} \$)$ & 1195.50 & 1161.27 & 1148.60 \\
\hline Bill effect (\%) & & -2.86 & -3.92 \\
\hline electricity use (GWh) & 6.02 & 5.90 & 5.95 \\
\hline
\end{tabular}


electricity effect (\%)
NG use (GWh)
NG effect $(\%)$
carbon emissions (tC)
carbon effect $(\%)$

Table ES 7. Schools results

$$
\begin{aligned}
& \text { Units of CM-100 (units) } \\
& \text { absorption chiller (kW) } \\
& \text { solar thermal (kW) }
\end{aligned}
$$$$
\text { PV }(\mathrm{kW})
$$$$
\text { Lead-acid batteries (kWh) }
$$$$
\text { thermal storage }(\mathrm{kWh})
$$$$
\text { electricity bill }(\mathrm{k} \$)
$$$$
\text { NG bill (k\$) }
$$$$
\text { microgrid equipment }(\mathrm{k} \$)
$$$$
\text { Total bill (k\$) }
$$$$
\text { bill effect (\%) }
$$$$
\text { electricity use (GWh) }
$$$$
\text { electricity effect (\%) }
$$$$
\text { NG use (GWh) }
$$$$
\text { NG effect (\%) }
$$$$
\text { carbon emissions (tC) }
$$$$
\text { carbon effect (\%) }
$$

NYC school

Units of CM-100 (units)

absorption chiller $(\mathrm{kW})$

solar thermal $(\mathrm{kW})$

PV (kW)

Lead-acid batteries (kWh) thermal storage $(\mathrm{kWh})$

electricity bill (k\$)

NG bill (k\$)

$\begin{array}{rrr} & -1.99 & -1.16 \\ 7.14 & 5.24 & 3.50 \\ & -26.61 & -50.98 \\ 1555.23 & 1439.26 & 1361.49 \\ & -7.46 & -12.46\end{array}$

$-1.16$

$-50.98$

$-12.46$

$\begin{array}{crr}\text { do } & \text { invest in all } & \text { low storage cost \& } \\ \text { nothing } & \text { technologies } & 60 \% \text { PV incentive } \\ & 0 & 0 \\ & 139 & 101 \\ & 65 & 72 \\ & 0 & 181 \\ & 0 & 1518 \\ 263.93 & 0 & 41 \\ 24.19 & 245.90 & 153.24 \\ & 26.51 & 23.96 \\ 288.12 & 7 & 72 \\ & 279.85 & 249.18 \\ 1.51 & -2.87 & -13.51 \\ & 1.48 & 1.19 \\ 0.73 & -1.99 & -21.19 \\ & 0.80 & 0.72 \\ 360.35 & 9.59 & -1.37 \\ & 358.26 & 291.34 \\ & -0.58 & -19.15\end{array}$

$\begin{array}{ccc}\text { do } & \text { invest in all } & \text { low storage cost \& } \\ \text { nothing } & \text { technologies } & 60 \% \mathrm{PV} \text { incentive }\end{array}$

$\begin{array}{rrr} & 0 & 0 \\ & 96 & 72 \\ & 103 & 187 \\ & 0 & 166 \\ & 0 & 569 \\ 211.83 & 0 & 440 \\ 46.37 & 404.63 & 147.45 \\ & 40.37 & 33.76\end{array}$


microgrid equipment $(\mathrm{k} \$)$

Total bill (k\$)

bill effect (\%)

electricity use (GWh)

electricity effect (\%)

NG use (GWh)

NG effect (\%)

carbon emissions (tC)

carbon effect (\%)

Table ES 8. Data center results

Units of CM-100 (units)

absorption chiller $(\mathrm{kW})$
CA data center

Units of CM-100 (units)
absorption chiller $(\mathrm{kW})$
solar thermal $(\mathrm{kW})$
$\mathrm{PV}(\mathrm{kW})$
lead-acid batteries $(\mathrm{kWh})$
thermal storage $(\mathrm{kWh})$
electricity bill $(\mathrm{k} \$)$
$\mathrm{NG}$ bill $(\mathrm{k} \$)$
microgrid equipment $(\mathrm{k} \$)$
total bill (k\$)
bill effect (\%)
electricity use $(\mathrm{GWh})$
electricity effect (\%)
NG use (GWh)
NG effect (\%)
carbon emissions (tC)
carbon effect $(\%)$

\[ \text { CA data center } \]
Units of CM-100 (units)
absorption chiller $(\mathrm{kW})$
solar thermal $(\mathrm{kW})$
PV (kW)
lead-acid batteries $(\mathrm{kWh})$
thermal storage $(\mathrm{kWh})$
electricity bill $(\mathrm{k} \$)$
NG bill $(\mathrm{k} \$)$
microgrid equipment $(\mathrm{k} \$)$
total bill $(\mathrm{k} \$)$
bill effect $(\%)$
electricity use $(\mathrm{GWh})$
electricity effect $(\%)$
NG use $(\mathrm{GWh})$
NG effect $(\%)$
carbon emissions $(\mathrm{tC})$
carbon effect $(\%)$

\footnotetext{
NYC data center
}

9

258.20

253.83

$-1.69$

1.12

0

0.94

0.82

$-12.77$

263.70

$-2.57$

62

243.56

$-5.67$

0.87

$-22,32$

0.69

$-26.60$

208.67

$-22.90$

$\begin{array}{ccc}\text { do } & \text { invest in all } & \text { low storage cost \& } \\ \text { nothing } & \text { technologies } & 60 \% \mathrm{PV} \text { incentive }\end{array}$

$\begin{array}{rrr} & 0 & 0 \\ 141 & 116 \\ 0 & 0 \\ 0 & 1577 \\ & 0 & 6434 \\ 1478.36 & 0 & 0 \\ 1.78 & 1459.46 & 949.11 \\ & 9.73 & 6.01 \\ 1480.15 & 4 & 467 \\ & 1473.18 & 1422.24 \\ 11.42 & -0.47 & -3.91 \\ & 11.39 & 8.91 \\ 0.00 & -0.26 & -21.98 \\ & 0.23 & 0.12 \\ & 0.45 & -21.57\end{array}$

do invest in all low storage cost \&

nothing technologies $60 \% \mathrm{PV}$ incentive 


\begin{tabular}{|c|c|c|c|}
\hline solar thermal $(\mathrm{kW})$ & & 0 & 0 \\
\hline $\mathrm{PV}(\mathrm{kW})$ & & 0 & 4 \\
\hline lead-acid batteries $(\mathrm{kWh})$ & & 0 & 94 \\
\hline thermal storage $(\mathrm{kWh})$ & & 0 & 0 \\
\hline electricity bill $(\mathrm{k} \$)$ & 1654.66 & 1654.66 & 1651.50 \\
\hline NG bill $(\mathrm{k} \$)$ & 0.15 & 0.15 & 0.15 \\
\hline microgrid equipment $(\mathrm{k} \$$ ) & & 0 & 2 \\
\hline total bill $(\mathrm{k} \$)$ & 1654.81 & 1654.81 & 1654.01 \\
\hline bill effect (\%) & & 0 & 0.05 \\
\hline electricity use (GWh) & 12.07 & 12.07 & 12.07 \\
\hline electricity effect (\%) & & 0 & 0 \\
\hline NG use (GWh) & 0.00 & 0.00 & 0.00 \\
\hline NG effect (\%) & & 0 & 0 \\
\hline carbon emissions (tC) & 2414.18 & 2414.18 & 2413.52 \\
\hline carbon effect (\%) & & 0.00 & -0.03 \\
\hline
\end{tabular}

Table ES 6 through Table ES 8 show the results for the nursing homes, schools, and data centers, respectively. The tables show three cases. The no-invest case shows results if the sites buy all their energy from their local utilities at published tariffs. The invest in all technologies case is the pure optimum result from DER-CAM. This represents the lowest possible energy cost case and is the benchmark against which all others can be compared. The first two cases represent the key microgrid results. In the case of the nursing homes, the CA and NY results are noticeably different. In CA conditions, three of the Tecogen CM-100 units are selected together with an absorption chiller that is also fed by solar thermal heat. This proves the only case in which the CM-100 is chosen based on simple cost effectiveness. NG use increases by a dramatic $75 \%$ to fuel the engines, but the overall energy bill is down by $4 \%$ and the carbon footprint by $13 \%$. In NY by contrast, the Tecogen units are not chosen but absorption chillers using solar thermal heat are, and the carbon abatement effects are smaller. The CA school also does not pick the Tecogen units, but solar thermal and absorption cooling are attractive, and in this case, the NY school results are similar. The cost and carbon reduction benefits are similarly small in both cases. The data center cases are similarly disappointing with only absorption chilling adopted in the CA case and nothing in the NY case. 


\section{Storage results}

A considerable achievement of this project has been the addition of electricity and heat storage capabilities to DER-CAM. Storage poses a difficult problem because any decision made in any one time period must consider the effects on all other time periods. There are also some longer time period problems, for example how might storage on weekends for use on weekdays be handled, or potentially even storage in winter for us in summer, etc. In general, these issues have not been addressed and only storage over a day is currently considered. Both traditional batteries, such as the familiar lead-acid ones, and flow batteries are considered. The key distinction of the latter technology is that storage capacity and charge-discharge capacity are quasi-independent because the electrolyte flows through the battery and can be stored in either its charged or discharged states. All batteries are amenable to optimization using DER-CAM because finding a good chargedischarge schedule by simple search would be ineffective. Flow batteries are additionally challenging because of the dual optimization needed to pick both the storage and chargedischarge capabilities separately.

Unfortunately, as has already been reported above, when available at approximately their estimated current full cost, no storage technologies are chosen for any of the test sites, and the same is true for PV. To demonstrate the capabilities for storage and PV adoption and scheduling, and because these two technologies are connected and are strong candidates for government support, several cases with various levels of subsidy were conducted. The third case shown in Table ES 6 through Table ES 8 above, low storage and PV costs, is one in which storage and PV have been heavily subsidized. In this case, electricity storage costs are reduced from $193 \$ / \mathrm{kWh}$ to 60 , heat storage is halved from $100 \$ / \mathrm{kWh}$ to 50 , and $60 \%$ of PV costs are written down. With these costs, both electricity storage and heat storage become attractive to the CA nursing home, as does $\mathrm{PV}$. The PV array is substantial $(517 \mathrm{~kW})$ and the battery bank huge $(2082 \mathrm{kWh})$, while the heat storage is modest. Note that despite these significant subsidies, the net bill savings are modest, although the carbon footprint is reduced by almost a quarter. Interestingly, the NY results are almost reversed, with a huge amount of heat storage (4862 kWh) installed, but only $294 \mathrm{kWh}$ of batteries and no PV. Again, given the value of the subsidy, the net effect on costs is minimal. At the CA school, all technologies 
except the CM-100 and flow batteries are selected. The PV array is sizeable (181 kW), as is the battery bank (1518 $\mathrm{kWh})$. In this case the effect on costs is more promising $(13.5 \%)$ and the emissions reduction is $19 \%$. The NY school adopts the same fleet of technologies with almost as much PV $(166 \mathrm{~kW})$, but less electricity and more heat storage. The lower attraction of batteries in NY (569 kWh) is probably driven by the absence of a time of use tariff for electrical energy. The CA data center installs both a huge $1577 \mathrm{~kW}$ PV array and a huge battery bank $(6434 \mathrm{kWh})$. Note that this PV array could supply $88 \%$ of the building peak load. Also, the battery bank could meet the peak load of the building for fully $3.6 \mathrm{~h}$. The NY data center results are starkly different with only $4 \mathrm{~kW}$ of PV and $94 \mathrm{kWh}$ of electricity storage adopted. Again, the absence of a significant diurnal electricity price differential clearly makes a dramatic difference to the outcome. Finally, consider the CA nursing home schedule for the low storage and PV costs run shown in Figure ES 2.

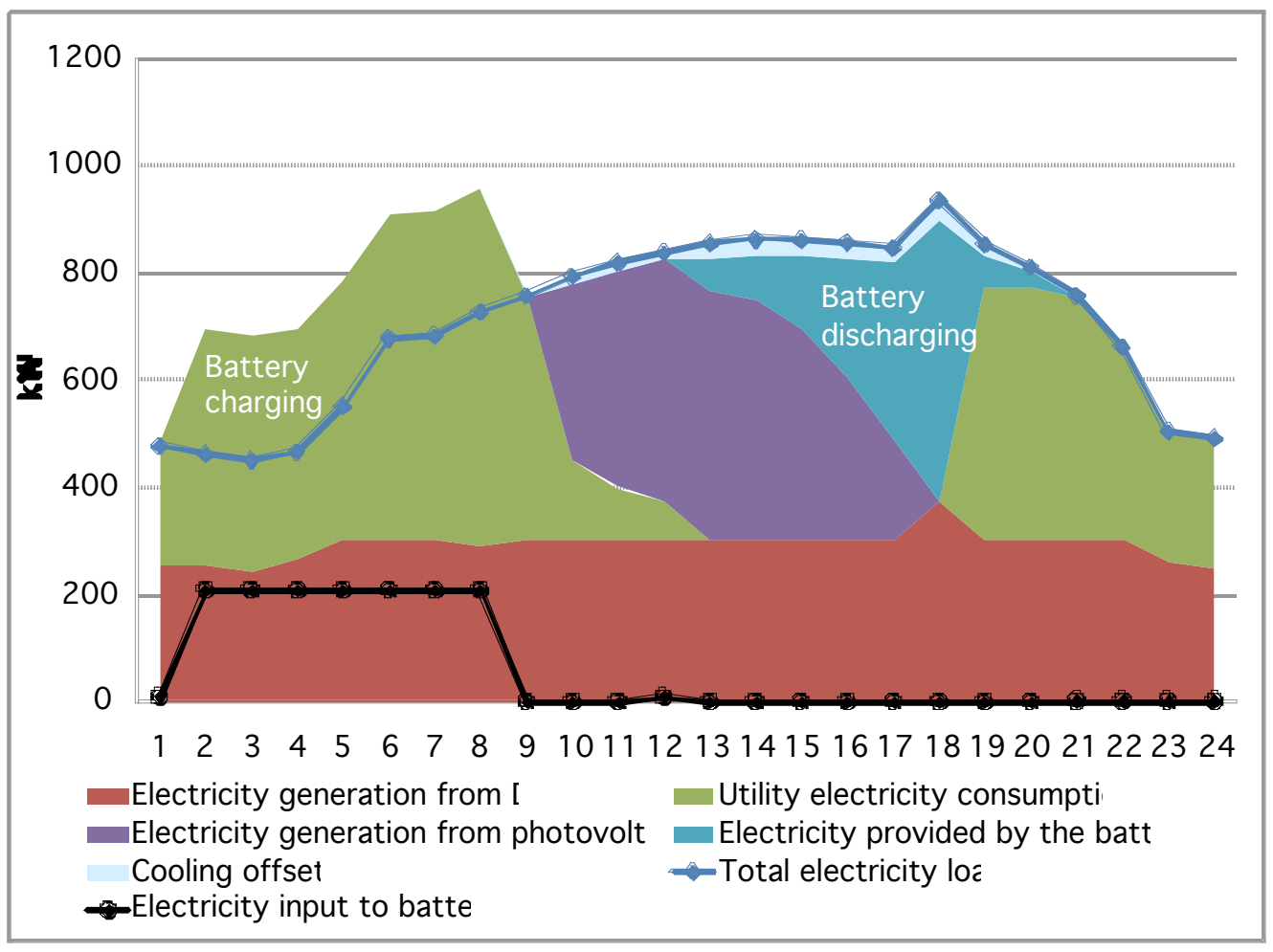

Figure ES 2. CA nursing home electricity pattern: July weekday low storage \& $60 \%$ PV incentive 
The graphic shows a July weekday from the DER-CAM results. The three engines run at close to full power all day and the surge capability is actually used briefly at 18:00. The heavy blue line shows the actual electricity consumed in each hour without DER. This can be thought of as the electricity service requirement. When the electricity supply exceeds this line, the battery bank is charging. This occurs from 1:00 to 9:00, as shown by the black line. The PV system produces from 9:00 to 18:00, and the battery is discharged between 12:00 and 21:00, with a strong peak discharge at 18:00. The tiny slice of light blue represents the electricity requirement that is displaced by the absorption chiller. One key result to note is that the nursing home makes considerable grid electricity purchases over the course of the day, but buys virtually nothing during the peak period, 12:00-18:00, and this shows the power of the time-of-use tariff. The engines, the PV, and the batteries are all used to avoid afternoon grid purchase. In other words, the batteries are used to save cheap off-peak electricity for consumption during the expensive on-peak hours; therefore, the PV and the batteries are in competition to provide this service.

\section{$P Q R$ results}

To model the PQR benefit of the microgrid, a certain amount of site load was assumed to be critical. During a macrogrid failure:

- the nursing home must meet $50 \%$ of its base load and $10 \%$ of its peak load (defined as any hourly load above the base);

- the school must meet $25 \%$ of its base load, and

- the data center must cover its entire load.

For the PQR runs, availability of the different technologies such as ICEs, batteries or PVs is important. For example, PV cannot be used as backup during the night and batteries might not be fully charged when a grid failure occurs. Additionally, lead-acid batteries can only be discharged to $30 \%$ of total battery capacity to avoid battery damaging. These boundaries limit the potential of the different technologies to contribute to sensitive loads during a grid failure.

However, DER-CAM calculates the availability of storage technologies as well as PV depending on the charge / discharge cycle and solar radiation. The reliability / availability of ICEs and fuel cells were assumed to be $90 \%$, and there is an $18 \%$ to $22 \%$ chance that photovoltaics can contribute to sensitive loads during a grid failure (see also Table ES 9). 
To satisfy the sensitive load, the product of the installed technology's availability factor and its installed capacity must be greater than the sensitive load. Or, in cases with multiple technologies, the sum of the products must be greater than the sensitive load. The detailed mathematical formulations for calculating the average availability can be found in the appendix equations A58 to A62.

Table ES 9. Electric sensitive load supply

\begin{tabular}{|l|l|l|}
\hline technology & $\begin{array}{l}\text { can it contribution to } \\
\text { electric sensitive } \\
\text { loads? }\end{array}$ & $\begin{array}{l}\text { average possible contribution of max. } \\
\text { installed capacity, availability factor (= } \\
\text { chance that it can contribute to sensitive } \\
\text { loads) }\end{array}$ \\
\hline CM-100 & yes & 0.90 \\
\hline fuel cell & yes & 0.90 \\
\hline electric storage & yes & 0.15 to 0.21 (southern CA school) \\
\hline heat storage & no & n/a \\
\hline flow battery & yes & 1 \\
\hline abs. chiller & no & n/a \\
\hline photovoltaic & yes & $\begin{array}{l}0.18 \text { (NY examples) to } 0.22 \text { (southern CA } \\
\text { School) }\end{array}$ \\
\hline solar thermal & no & n/a \\
\hline
\end{tabular}

It is further assumed that the necessary PQR features add $\$ 25 / \mathrm{kW}$ to the capital cost of CM-100 engines plus $\$ 100 / \mathrm{kW}$ for a fast DER switch, which seamlessly separates the site from the macrogrid during a grid disturbance. However, the possibility of supporting sensitive loads during a grid failure also adds benefits to the microgrid. In DER-CAM, these benefits are currently expressed only as monetary benefits. And since estimates of such benefits are difficult to find empirically, a set of $P Q R$ runs with variable benefits and fixed PQR costs were performed. Finding an optimal solution which delivers the same total bill costs as run invest all technologies from Table ES 6 through Table ES 8 
provides an estimate of the monetary $\mathrm{PQR}$ benefits necessary to make the microgrid attractive. In other words, the value of $\mathrm{PQR}$ derived in this way is a hurdle that the site must clear to find the microgrid cost effective.

For the CA nursing home, the same equipment as in run invest all technologies from Table ES 6 meets the critical load. Further, the breakeven monetary benefit from PQR features is quite little, less than $\$ 25 / \mathrm{kW}$ (or less than $6.5 \mathrm{k} \$ / \mathrm{a}$ added to an annual energy bill of approaching one M\$), with no additional adoption of DER generation necessary. The added reliability benefit certainly seems promising in this case. For the NY nursing home, the results are more interesting and show an adoption of two CM-100 units to satisfy the critical load condition. The monetary benefit from the PQR features is again quite little, less than $\$ 25 / \mathrm{kW}$ resulting in a similar cost consequence as its CA equivalent. In the NY nursing home case then, the consideration of $\mathrm{PQR}$ has a small effect on costs but makes a considerable difference to the attractiveness of a microgrid. Both of these examples support the notion that the nursing home/assisted living sector might be a promising market for microgrids.

In both of the school examples, DER adoption changes only slightly due to the small critical load assumed. No additional CM-100 units are installed; the only changes occur in lead-acid battery adoption; and the benefit from PQR features is low (less than $\$ 25 / \mathrm{kW}$ ). Therefore, for the schools, a low value of the added reliability is necessary for the adoption of basic microgrid capability but it comes in the rather traditional form of battery back-up.

The data center critical load requirement is the most demanding, and the microgrid needs to satisfy $100 \%$ of the data center load during a grid failure. This requirement results in massive CM-100 adoption. The CA data center adopts 16 units and the NY data center 14; however, the found $\mathrm{PQR}$ benefit requirements are higher than for the other examples, $\$ 125 / \mathrm{kW}$ for CA and $\$ 200 / \mathrm{kW}$ for NY. For example, for the CA data center, this cost represents an addition of about $223 \mathrm{k} \$$ to its $1.4 \mathrm{M} \$$ annual energy bill. While these costs are considerable, given the extreme priority placed on reliability by data centers, they are certainly feasible. 
Overall, the results of the reliability analyses are promising, while none of the results are surprising in and of themselves. For sites at which a microgrid is already or close to being viable, the added value of reliability can easily enhance the economics. The two nursing homes substantiate the claim that a large potential market exists at sites where CHP is possible and reliability has some additional modest value when a significant share of load needs to be supported. The schools tend to argue that if a microgrid is not attractive absent a reliability benefit and the sensitive load is small, alternatives to a microgrid are likely to be more appealing, e.g. traditional back-up. Finally, the data center results show that if sites with significant sensitive loads value the reliability benefit high enough and many such sites are likely to - then the effect on the attractiveness of a microgrid could be dramatic.

\section{References}

1. Stadler, Michael, Chris Marnay, Afzal Siddiqui, Judy Lai, Brian Coffey, and Hirohisa Aki. Effect of Heat and Electricity Storage and Reliability on Microgrid Viability: A Study of Commercial Buildings in California and New York States, LBNL-1334E, Oct 2008.

2. Siddiqui, Afzal, Michael Stadler, Chris Marnay, and Hirohisa Aki. "Control of Greenhouse Gas Emissions by Optimal Technology Investment and Operation in Zero-Net-Energy Buildings," European Transactions on Electric Power, forthcoming (LBNL-2693E, Aug 2009).

3. Marnay, Chris, Giri Venkataramanan, Michael Stadler, Afzal Siddiqui, Ryan Firestone, and Bala Chandran. "Optimal Technology Selection and Operation of Microgrids in Commercial Buildings," IEEE Transactions on Power Systems, 10.1109/TPWRS.2008.922654, vol. 23(3), Aug 2008. Previously published in the Proceedings of the IEEE Power Engineering Society General Meeting 2007, Tampa Convention Center, 24-28 Jun 2007, Tampa FL, 10.1109/PES.2007.385847 (LBNL-62315).

4. Marnay, Chris. "Microgrids and Heterogeneous Power Quality and Reliability: Matching the Quality of Delivered Electricity to End-Use Requirements," International Journal of Distributed Energy Resources, vol 4(4),1 Oct-Dec 2008 (LBNL-63524).

5. Marnay, Chris, Michael Stadlera, Gonçalo Cardoso, Olivier Mégel, Judy Lai, and Afzal Siddiqui. "The Added Economic and Environmental Value of Solar Thermal Systems in Microgrids with Combined Heat and Power," Procedings of the 3rd International Conference on Solar Air-Conditioning, 30 Sep - 2 Oct 2009, University of Palermo, Sicily, Italy.

6. Marnay, Chris, Judy Lai, Michael Stadler, and Afzal Siddiqui "Added Value of Reliability to a Microgrid: Simulations of Three California Buildings," paper presented at the Cigré Integration of Wide-Scale Renewable Resources into the 
Power Delivery System conference, Calgary, Canada, 29-31 Jul 2009 (LBNL-1853E, Apr 2009).

7. Stadler, Michael, Chris Marnay, Afzal Siddiqui, Judy Lai, and Hirohisa Aki, "Integrated building energy systems design considering storage technologies," paper presented at the 2009 ECEEE Summer Study, 1-6 Jun 2009, La Colle sur Loup, France (LBNL-1752E, Apr 2009).

8. Stadler, Michael, Hirohisa Aki, Ryan Firestone, Judy Lai, Chris Marnay, and Afzal Siddiqui. "Distributed Energy Resources On-Site Optimization for Commercial Buildings with Electric and Thermal Storage Technologies," paper presented at the 2008 ACEEE Summer Study on Energy Efficiency in Buildings, Scaling Up: Building Tomorrow's Solutions, Asilomar, CA, August 17-22, 2008 (LBNL-291E, May 2008).

9. Marnay, Chris, Michael Stadler, Hirohisa Aki, Brian Coffey, Ryan Firestone, Judy Lai, and Afzal Siddiqui. "Microgrid Selection and Operation for Commercial Buildings in California and New York States," paper presented at the $4^{\text {th }}$ European PV-Hybrid and Mini-Grid Conference, Glyfada, Greece, 29-30 May 2008 (LBNL-313E, May 2008). 


\subsection{Task-2 Examination of Protection Issues}

\section{Protection testing summary}

There are three aspects to protection for the CERTS Microgrid: 1) Conventional protection for the feeders, which do not have microsources, consistent with industrial and commercial standards; 2) Protection of the utility and the microgrid during critical events at the point of common coupling using an interface switch; 3) Specially designed protection schemes associated with each microsource within the CERTS Microgrid to address internal faults during parallel and islanded operation.

The microgrid interconnects with the utility through a point of common coupling using an interface switch that can island the microgrid when necessary and reconnect autonomously. For faults, this switch provides for fast protection against high fault current due to faults on either side of the switch. This switch is also used to satisfy all IEEE 1547 and sensitive load requirements. This allows for seamless transfer from grid connected to islanded and back based on local information.

The underlying problem with inverter-based power sources is the reduced fault current. For a typical thermal trip breaker to open in less than one cycle during a fault situation requires approximately 15 to 20 times the rated current of the breaker. This problem is addressed in the CERTS Microgrid using a novel approach that does not rely on the need for high source fault current. At each microsource in the CERTS Microgrid, a shunt trip molded case breaker is used to isolate faults within the microgrid. Line-to-ground faults are detected using zero sequence current signals that trip the breaker when a threshold is exceeded. Line-to-line faults are detected using current negative sequence measurements to activate the shunt trip. Current implementation at the CERTS microgrid test bed of this designed scheme relies on expensive Schweitzer digital relays with independent current and voltage sensors. These relays are specified for the initial test bed demonstration to implement and modify the CERTS protection coordination schemes at the test site. 
In order to lower the overall cost of the CERTS Microgrid, the protection logic needs to become an integral part of the control logic within each microsource. This will allow for elimination of the expensive external relays and enhance the plug-and-play functionality of the microsources.

\section{Protection testing summary}

In the second phase of microgrid testing the protection equipment was relocated. Originally the protection was designed to measure the voltage and current as it enters each zone of the microgrid from the utility source. In this phase the protection instead measured the voltage and current as it enters each zone of the microgrid from each microgrid generation source. In theory this would allow the genset manufacturer to incorporate the necessary microgrid protection directly into the genset equipment with no additional protection equipment required, a value add cost cutting measure. A comparison between the utility source and generator source protection schemes was made. In both protection schemes the protection set points remained the same.

Testing was performed to verify phase-to-ground and phase-to-phase overload fault protection. $I^{2} t$ protection was not retested as it should remain unaffected by the changes in the protection scheme. These tests were performed in each zone with all gensets being utilized at different times. These tests were to verify zero-sequence, negative-sequence, or residual over-current protection trips. To perform this testing the measurement points for each relay were relocated from the feeder entrance to that of the generator entrance on zones 3,4 , and 5 .

Utilizing the same test procedures from the protection testing of phase one the repeated tests in phase two show some differing results.

In test procedure 7.7 of the previous phase this fault was detected and cleared by the protection scheme. In the recent phase none of the protection relays tripped for the fault in Zone 3, and Genset B1 also remained online. 
In test procedure 7.8 of the previous phase this fault was detected and cleared by the protection scheme, CB51 opened and Genset B1 shutdown properly. In the recent phase none of the protection relays tripped for the fault in Zone 5, and Genset B1 also remained online.

In test procedure 7.13 of the previous phase the Static Switch opened on negative sequence, and all other breakers remained closed. Also Gensets A1 and A2 remained online. In the recent phase all of the protection relays tripped for the fault in Zone 3, Genset A1 and A2 shutdown.

In test procedure 7.14 of the previous phase this fault was detected and cleared by the protection in Zone 4, the Static Switch and CB41 opened with Genset A2 shutting down. In the recent phase all of the protection relays tripped for the fault in Zone 4, and Gensets A1 and A2 shutdown.

In test procedure 7.15 of the previous phase none of the protection relays tripped for the fault in Zone 2, and Genset B1 also remained online. In the recent phase all of the protection relays tripped for the fault in Zone 2, with the exception of relay 4, Genset A1 and $\mathrm{B} 1$ shutdown.

In test procedure 7.16 of the previous phase this fault was detected and cleared by the protection in Zone 5 and the Static Switch and CB51 opened shutting down Genset B1. In the recent phase all of the protection relays tripped for the fault in Zone 5 with the exception of relay 4, and Genset A1 and B1 shutdown. 
Phase two tabular results of protection testing with measurement points located at the generator entrance on zones 3,4 , and 5.

\begin{tabular}{|c|c|c|c|c|c|c|c|c|c|c|c|c|}
\hline & LB3 & LB4 & LB6 & & & & Relay & Relay & Relay & Genset & Genset & Genset \\
\hline \multirow[t]{2}{*}{ Test } & kW & $\mathbf{k W}$ & $\mathbf{k W}$ & Fault & Zone & SS & 3 & 4 & 5 & A1 & A2 & B1 \\
\hline & & & & $28 \mathrm{~kW}$ & & & & & & & & \\
\hline \multirow[t]{2}{*}{7.5} & 40 & & 40 & A-G & 3 & $\mathrm{G} / \mathrm{I}$ & $\mathrm{G} / \mathrm{I}$ & $\mathrm{R}$ & $\mathrm{R}$ & $\mathrm{SE}$ & N/A & N/A \\
\hline & & & & $28 \mathrm{~kW}$ & & & & & & & & \\
\hline \multirow[t]{2}{*}{7.6} & 40 & 40 & 40 & $\mathrm{~A}-\mathrm{G}$ & 3 & G/I & $\mathrm{R}$ & $\mathrm{R}$ & $\mathrm{R}$ & SE & SE & N/A \\
\hline & & & & $28 \mathrm{~kW}$ & & & & & & & & \\
\hline \multirow[t]{2}{*}{7.7} & 40 & & 40 & B-G & 3 & $\mathrm{R}$ & $\mathrm{R}$ & $\mathrm{R}$ & $\mathrm{R}$ & N/A & N/A & $\mathrm{R}$ \\
\hline & & & & $28 \mathrm{~kW}$ & & & & & & & & \\
\hline \multirow[t]{2}{*}{7.8} & 40 & 40 & 40 & B-G & 5 & $\mathrm{R}$ & $\mathrm{R}$ & $\mathrm{R}$ & $\mathrm{R}$ & $\mathrm{R}$ & N/A & $\mathrm{R}$ \\
\hline & & & & $28 \mathrm{~kW}$ & & & & & & & & \\
\hline \multirow[t]{2}{*}{7.9} & 40 & 40 & 40 & B-G & 4 & G/I,NS & $\mathrm{R}$ & RG/IT & $\mathrm{R}$ & $\mathrm{R}$ & SE & N/A \\
\hline & & & & $28 \mathrm{~kW}$ & & & & & & & & \\
\hline \multirow[t]{2}{*}{7.10} & 40 & 40 & 40 & $\mathrm{C}-\mathrm{G}$ & 2 & $\mathrm{G} / \mathrm{I}$ & RG/I & $\mathrm{R}$ & UV & SE & N/A & SE \\
\hline & & & & $84 \mathrm{~kW}$ & & & & & & & & \\
\hline \multirow[t]{2}{*}{7.13} & 40 & 40 & 40 & A-B & 3 & NS & NST & NST & UV & SE & SE & N/A \\
\hline & & & & $84 \mathrm{~kW}$ & & & & & & & & \\
\hline \multirow[t]{2}{*}{7.14} & 40 & 40 & 40 & A-B & 4 & NS & NST & NST & UV & SE & SE & N/A \\
\hline & & & & $84 \mathrm{~kW}$ & & & & & & & & \\
\hline \multirow[t]{2}{*}{7.15} & 40 & 40 & 40 & A-B & 2 & NS & NST & $\mathrm{R}$ & NST & SE & N/A & SE \\
\hline & & & & $84 \mathrm{~kW}$ & & & & & & & & \\
\hline \multirow[t]{2}{*}{7.16} & 40 & 40 & 40 & A-B & 5 & NS & NST & $\mathrm{R}$ & NST & SE & N/A & SE \\
\hline & & & & $84 \mathrm{~kW}$ & & & & & & & & \\
\hline 7.15R & 40 & 40 & 40 & A-B & 2 & NS & NST & $\mathrm{R}$ & NST & SE & N/A & SE \\
\hline
\end{tabular}

Key

$\begin{array}{ll}\text { G/I=Ground Over current } & \text { RG/IT = Residual Ground Over Current Timed } \\ \text { NS = Negative Sequence } & \text { SE = Shutdown External (Relay Tripped) } \\ \text { NST = Negative Sequence Timed } & \text { UV = Under voltage } \\ \text { R = Remained Connected } & \text { N/I = Neutral Over Current } \\ \text { RG/I = Residual Ground Over Current } & \text { N/A = Not Used } \\ \text { OU = Opened Reason Not Recorded } & \end{array}$


Phase one tabular results of testing with points of measurement located at the feeder entrance.

\begin{tabular}{|c|c|c|c|c|c|c|c|c|c|c|c|c|}
\hline & LB3 & LB4 & LB6 & & & & Relay & Relay & Relay & Genset & Genset & Genset \\
\hline \multirow[t]{2}{*}{ Test } & $\mathbf{k W}$ & $\mathbf{k W}$ & $\mathbf{k W}$ & Fault & Zone & SS & 3 & 4 & 5 & A1 & A2 & B1 \\
\hline & & & & $28 \mathrm{~kW}$ & & & & & & & & \\
\hline \multirow[t]{2}{*}{7.5} & 40 & & 40 & A-G & 3 & $\mathrm{G} / \mathrm{I}$ & $\mathrm{G} / \mathrm{I}$ & $\mathrm{R}$ & $\mathrm{R}$ & SE & N/A & N/A \\
\hline & & & & $28 \mathrm{~kW}$ & & & & & & & & \\
\hline \multirow[t]{2}{*}{7.6} & 40 & 40 & 40 & A-G & 3 & $\mathrm{G} / \mathrm{I}$ & $\mathrm{G} / \mathrm{I}$ & $\mathrm{N} / \mathrm{I}$ & OU & SE & SE & N/A \\
\hline & & & & $28 \mathrm{~kW}$ & & & & & & & & \\
\hline \multirow[t]{2}{*}{7.7} & 40 & & 40 & B-G & 3 & NS & $\mathrm{R}$ & $\mathrm{R}$ & $\mathrm{G} / \mathrm{I}$ & N/A & N/A & SE \\
\hline & & & & $28 \mathrm{~kW}$ & & & & & & & & \\
\hline \multirow[t]{2}{*}{7.8} & 40 & 40 & 40 & B-G & 5 & $\mathrm{R}$ & $\mathrm{R}$ & $\mathrm{R}$ & $\mathrm{G} / \mathrm{I}$ & $\mathrm{R}$ & N/A & SE \\
\hline & & & & $28 \mathrm{~kW}$ & & & & & & & & \\
\hline \multirow[t]{2}{*}{7.9} & 40 & 40 & 40 & B-G & 4 & $\mathrm{G} / \mathrm{I}$ & $\mathrm{R}$ & $\mathrm{G} / \mathrm{I}$ & $\mathrm{R}$ & $\mathrm{R}$ & $\mathrm{SE}$ & N/A \\
\hline & & & & $28 \mathrm{~kW}$ & & & & & & & & \\
\hline \multirow[t]{2}{*}{7.10} & 40 & 40 & 40 & C-G & 2 & $\mathrm{G} / \mathrm{I}$ & $\mathrm{G} / \mathrm{I}$ & $\mathrm{R}$ & UV & SE & N/A & $\mathrm{SE}$ \\
\hline & & & & $84 \mathrm{~kW}$ & & & & & & & & \\
\hline \multirow[t]{2}{*}{7.13} & 40 & 40 & 40 & A-B & 3 & NS & $\mathrm{R}$ & $\mathrm{R}$ & $\mathrm{R}$ & $\mathrm{R}$ & $\mathrm{R}$ & N/A \\
\hline & & & & $84 \mathrm{~kW}$ & & & & & & & & \\
\hline \multirow[t]{2}{*}{7.14} & 40 & 40 & 40 & A-B & 4 & NS & $\mathrm{R}$ & NS & $\mathrm{R}$ & $\mathrm{R}$ & SE & N/A \\
\hline & & & & $84 \mathrm{~kW}$ & & & & & & & & \\
\hline \multirow[t]{2}{*}{7.15} & 40 & 40 & 40 & A-B & 2 & $\mathrm{R}$ & $\mathrm{R}$ & $\mathrm{R}$ & $\mathrm{R}$ & $\mathrm{R}$ & N/A & $\mathrm{R}$ \\
\hline & & & & $84 \mathrm{~kW}$ & & & & & & & & \\
\hline 7.16 & 40 & 40 & 40 & A-B & 5 & NS & $\mathrm{R}$ & $\mathrm{R}$ & NST & $\mathrm{R}$ & N/A & SE \\
\hline
\end{tabular}

Key

$\mathrm{G} / \mathrm{I}=$ Ground Over current

RG/IT =Residual Ground Over Current Timed

NS $=$ Negative Sequence

$\mathrm{SE}=$ Shutdown External (Relay Tripped)

NST $=$ Negative Sequence Timed

$\mathrm{UV}=$ Under voltage

$\mathrm{R}=$ Remained Connected

$\mathrm{N} / \mathrm{I}=$ Neutral Over Current

RG/I =Residual Ground Over Current

$\mathrm{N} / \mathrm{A}=$ Not Used

$\mathrm{OU}=$ Opened Reason Not Recorded 


\section{Summary}

In general, a microgrid can operate in both the grid-connected mode and the islanded mode where the microgrid is interfaced to the main power system by a fast semiconductor switch called static switch, (SS). It is essential to protect a microgrid in both the grid-connected and the islanded modes of operation against all types of faults. The major issue arises in island operation with inverter-based sources. Fault currents in islanded inverter based microgrids may not have adequate magnitudes to use traditional over-current protection techniques. This possibility requires an expanded protection strategy.

The philosophy for protection is to have the same protection strategies for both islanded and grid-connected operation. The static switch is designed to open for all faults. With the static switch open, faults within the microgrid need to be cleared with techniques that do not rely on high fault currents, this was based on the assumption that inverter short currents are limited to $2 \mathrm{pu}$. Moving to more advance protection it was also assumed that it was possible to remove the faulted portion of the islanded microgrid while preserving the remaining sections. This was first successfully demonstrated in the first phase of testing [1-3]. In this case the CERTS/AEP test site had four protection zones with circuit breakers between zones and relays looking at zone currents and voltages.

In the second phase of microgrid testing the protection equipment was relocated. Originally the protection was designed to measure the voltage and current as it enters each zone of the microgrid from the utility source. In this phase the protection instead measured the voltage and current as it enters each zone of the microgrid from each microgrid generation source. In theory this would allow the genset manufacturer to incorporate the necessary microgrid protection directly into the genset equipment with no additional protection equipment required, a value added cost cutting measure. A comparison between the utility source and generator source protection schemes was made. In both protection schemes the protection set points remained the same. 
The assumption that inverter fault currents are limited to 2 p.u. current is not correct. Tradition inverters on a utility are current controlled and can easly restrice their current to 2pu. The CERTS microgrid concept requires that the DER unity be voltage sourced. During a load change, fault or other events the voltage is held fixed and the necessary currents are provided. This results in current closer to $8 \mathrm{pu}$ than $2 \mathrm{pu}$. Please refer to Section 3.7 "Inverter Fault Current Contribution" of this chapter for more details. This available short circuit current completely changes the protection methods need for a microgrid.

In summary the direction taken is too complex and unnecessary. The interface switch still plays a central role in protection. For a fault within the microgrid the interface switch needs to open quickly limiting large fault currents from the utility. For faults on the utility the interface switch limits large fault currents from the microgrid and preservers the power quality seen by the loads in the microgrid. Once islanded the microgrid must protect itself from internal fault. The basic objectives are to use the traditional protection systems based on over currents and shut down or isolate any microsource feeding the fault after an appropriate delay to allow fault clearing based on over currents.

\section{References}

1. Nikkhajoei, H, and R. H. Lasseter, "Microgridgrid Protection," Microgrid Research and Field Testing, IEEE PES General Meeting, 24-28 June 2007, Tampa, FL

2. Eto, Joseph, Robert Lasseter, Ben Schenkman, John Stevens, Harry Volkommer, Dave Klapp, Ed Linton, Hector Hurtado, Jean Roy, Nancy Jo Lewis, "CERTS Microgrid Laboratory Test Bed Report: Appendix J", 2009

3. "CERTS Test Bed Protection Device Selection and Settings," Northern Power Systems Energy Technology Laboratory, 2005 


\subsection{Task-3 Examination of DC Storage Issues}

The CERTS microgrid accommodates many inverter based microsources that vary in power output response time to load increases. Response time can be as fast as $250 \mathrm{msec}$ demonstrated by the Tecogen units used in the CERTS microgrid test bed from 0kW to rated power output and as long as several tens of seconds when using a fuel cell for the same load increase. A surge module is used to supply the DC current void during the load increase until the prime mover can increase its output power to the level at which the load demand requires. This allows the microsource to supply power for the load demand almost instantaneously.

Thus, DC storage on the CERTS Microgrid is defined by the need to ensure fast response of the inverter, decouple the prime mover dynamics from the microgrid's dynamics, and support the DC bus voltage. The storage sizing needs to be optimized including, possibly, eliminating the need for DC storage altogether. That is, changes in the prime mover response and control could greatly reduce or eliminate the need for DC storage.

This reduction in first cost must be balanced against the need to meet economic operating objectives. Certain algorithms, which may lead to more efficient engine operation when the microsources are tied to the grid, may not be amenable to stand-alone operation. If this assessment shows that there is a target market, which would require the CERTS Microgrid to operate disconnected from the grid for a significant fraction of the system's operating time, the efficiency of energy production will, most likely, be of extreme importance. However, if the CERTS Microgrid will be grid-connected virtually all the time, this aspect of efficiency may not be as important. In the first instance, a significant amount of DC storage may be needed to achieve the high efficiency. In the second instance, the microsources could be operated in a slightly less efficient manner that could obviate the need for DC storage and reduce first cost, provided that the interaction between the prime mover and the inverter can be controlled. In all likelihood, several different target markets will be identified and it will be necessary to develop the technical feasibility and role of DC storage separately for each one. 


\section{Concept}

Principle operation of the surge module is to supply power when the prime mover cannot and will stop supplying power as soon as the microsource has increased its power output to the demand of the load. As soon as the microsource is greater than the load demand, then the excess power is used to charge the surge module DC technology. Once the surge module DC technology has become fully charged it moves into a standby state until it is needed to provide power. The surge module consists of two main parts: DC technology and controller. The DC technology will supply high current for short amounts of time, therefore the DC technology used for the surge module is considered a power storage device rather than an energy device which is used for supplying current for long periods of time which can be hours to days. Some DC technologies that have the power storage characteristics are batteries, ultra-capacitors, and flywheels. The DC technology used in the surge module must not only possess the capability to produce high currents for short amounts of time frequently, it also has to be robust, maintenance requirements are in line with other hardware at the installation (that is, if all other hardware at the installation can be maintained with twice annual visits, power storage should not require monthly visits), be readily available in many locations for service purposes, and have a cost that is in line with the benefit added to the installation. With these requirements in mind, the technology selected for the CERTS microgrid Tecogen surge module is valve-regulated lead acid (VRLA) batteries. Specifically, absorbed-electrolyte glass mat batteries from MK Batteries were selected. The MK battery is a power battery also known as an SLI (starting, lighting, and ignition) battery. SLI batteries typically discharge hundreds of amps for a few seconds.

Once the technology was selected the size of the battery needed to be determined. The batteries sized for the CERTS microgrid surge module can be applied to any type of inverter based microsource surge module in any microgrid configuration. An important concept in battery selection is that the amp-hour rating of a battery is discharge-rate specific. The greater the discharge rate, the less energy can be withdrawn from a specific battery. Preliminary design studies for the microsources used at the CERTS Microgrid test bed indicated that the maximum discharge current for the dc storage should be 200 amps, and that this current should be available for 250 milliseconds. Using this design 
requirement, batteries to be used in the surge module were designed based off the datasheet value of "Maximum Discharge Current" and voltage. The MK battery selected based off data-sheet values that met the 200 amps for 250 millisecond requirement was the ES10-12S battery. ES10-12S battery has a maximum discharge current of 400 amps for 5 seconds which is a lot more than needed but was selected because this was a research project and a conservative approach was selected for unforeseen problems. Taking the conservative approach out and sizing the battery for a new installation, MK battery ES5-12 would be adequate to be used as the DC source of the surge module. The ES5-12 battery has a maximum discharge current of 200 amps for 5 seconds meeting the design requirements. This battery is substantially smaller than the ES10-12S battery that was originally selected, having one-half the Ah capacity, weighing 4.0 pounds as opposed to 7.3 pounds, and having reduced physical size. These are all benefits to the overall microsource because they will result in a less expensive installation that requires less physical space.

The surge module design used for the microsources in the CERTS microgrid test bed consisted of 16 MK ES10-12S lead acid batteries for the DC power source. These are 12 volt valve regulated connected in a center-tapped arrangement with 8 batteries on the positive side and 8 on the negative side of neutral, resulting in nominally \pm 96 volts DC. This is then converted to \pm 450 volts DC in order to be compatible with the microsource's DC bus. Power electronics are used to boost the battery voltage to the microsource's DC bus voltage level and to buck the DC bus voltage to the DC voltage of the surge module when the battery needs to be charged. The boost converter in the surge module has a maximum current limit of 200 amps and limits the power output to $20 \mathrm{~kW}$. This boost converter is currently programmed to discharge the surge module for 250 milliseconds when output current increase by a set amount for 2 cycles. This discharge time can be altered to be appropriate for the prime-mover being used. The discharge is performed by sending $20 \mathrm{~kW}$ to the internal bus, or the amount of energy necessary to regulate the bus voltage to \pm 450 volts DC. Thus, the discharge power will typically taper during the discharge period as the prime-mover output increases and the amount of power required from the surge module is decreased to maintain \pm 450 volts DC. Charging is performed over a significantly longer period of time than discharging, so less current capacity is 
required. The buck converter has a maximum current capacity of 70 amps, and regulates the battery bus to \pm 110 volts DC ( 8 batteries at 13.8 volts).

\section{Issues}

During the commissioning testing of the microsources, several of the batteries in the surge modules were thermally damaged. This appears to be because of prolonged cycling of the surge modules. That is, the surge modules were discharged, then recharged, then discharged numerous times over a period of several hours while performing the commissioning tests. This resulted in the thermal damage to the batteries because they did not have adequate time to cool off between discharges and shortened the life of the batteries because of being continually discharged without being fully recharged.

Two techniques were recommended for avoiding this type of battery damage. One technique was to program the software to limit the number of discharges possible in an hour, or some other unit of time as is appropriate for the specific design. The technique that was applied to the CERTS surge module was improving battery temperature monitoring along with appropriate response to elevated battery temperature. In the initial design, the battery temperatures were monitored by placing a thermal switch on the top of 4 selected cells in the surge module battery bank. These thermal switches were calibrated for $130^{\circ} \mathrm{F}$, at which point the thermal switches would disable the surge module. They did not monitor battery temperature accurately due to the realization that the top of the batteries was a "secondary" cover, and there was only dead air space below it, followed by the actual battery cover.

Many in the battery industry recommend monitoring the battery temperature from the battery's negative terminal. The negative terminal is directly connected to the plates becoming a metallic pathway to the inside of the battery and a good thermal conductor. Another reason to use the negative terminal rather than the side or top of the battery is that the specific batteries used in the surge module are VRLA batteries. These batteries are not filled with electrolyte to the point that one can be certain that there is electrolyte touching any given inner surface of the battery case. Additionally, as the battery ages any electrolyte that may have originally been in contact with the battery case often pulls 
away from the case. Thus, a side-of-case or top-of-case measurement may give good results early in the battery's life, but then become unreliable as the battery ages [5].

\section{Summary}

In conclusion, the surge module as initially designed for the CERTS microgrid test bed is a reasonable design that functions well. The specific battery selected for this application is a good choice, although money and space can be saved in the future by using a smaller battery. The choice of batter temperature monitoring techniques, which allowed thermal damage to most of the batteries, is the only clear shortcoming of this design. Modifying the temperature monitoring technique will assure thermal protection for the batteries in the future. Also, a technique for predicting battery end-of-life is desirable. As with many maintenance operations, it is best to replace the batteries before they fail, rather than waiting for failure and the associated additional costs that failure during operation can bring. Predicting end-of-life can be done by counting amp-hours out of the battery and replacing the battery when it reaches a value close to the "Life Expectancy" data from their specification sheets.

\section{References}

1. Tecogen Factory Testing, 03/15/2006, “TECOGEN 60kW Inverter-Based CHP Modules", CERTS Microgrid Test Bed Project

2. Nikkhajoei, H., Lasseter, R.H., "Distributed Generation Interface to the CERTS Microgrid”, IEEE Transactions on Power Delivery, Volume 24, Issue 3, July 2009 


\subsection{Task-4 Battery-Based AC Energy Storage}

Battery energy storage units provide an added degree of freedom to a microgrid that allows time-shifting between the generation and use of energy. Microgrid energy storage elements are very similar to any other inverter-based source with the exception of bidirectional power flow capabilities. Having the ability to generate and accept power means that the demand and the supply can be disparate by as far as the power capabilities of the energy storage unit allow. This enables combined heat power systems to support a heat load demand independent of local electric power demand. Having an energy storage element on standby also allows for a certain amount of immediately available power to reduce the need for idling or lightly loaded rotating generators under the n-1 stability criterion. The relative speed of any inverter based source allows a sub-cycle change in power output to ensure that dynamic loads will be supplied regardless of the slow reaction of larger rotating sources that require seconds of response time to transients. Thirdly, they can act as a UPS system during grid faults, providing backup power for some time even for non-essential loads while the microgrid is islanded. Lastly, the energy storage element can provide an economic and/or logistical advantage by regulating the power drawn by and supplied to the grid interface. This not only permits capitalizing on fluctuating power prices, but even regulating a line loading by making better use of off-peak hours to supply the daily energy needs [1].

\section{Fixed and fluctuation Sources}

For transients in the presence of a fixed-power source with a slow time constant like a fuel cell, the storage unit may have to absorb extra energy generated as the fuel cell slowly decreases its output power for the system to remain online. In this case, the energy storage unit may also be required to provide a reference voltage for the power injected by the fuel cell. In the case of an islanding event when no other sources were online, the energy storage element then becomes the solitary source of fast power transients. Energy storage unit can help also decoupled loads and renewable fluctuation within a microgrid from the grid. The net effect is a significant reduction in peak power levels drawn from the grid reducing the peak power cost incurred by the utility. 


\section{Distributed Storage Issues}

Despite the obvious advantages of energy storage elements in a microgrid environment, it is still debated whether energy storage should exist at each source or whether a centralized energy storage element should bear the sole duty of energy storage. From an energy accounting perspective, the amount of energy absorbed and transmitted is a function only of the size of the unit, which is typically directly proportional to the cost. The power systems industry has used the economies of scale as reasoning for larger and larger power generation facilities, but since both battery and inverter costs scale at a linear rate there seems to be little economic advantage to a consolidated energy storage element. Reliability also supports the distributed model for storage by removing the storage as a single unit failure mode that could disable islanding of a microgrid.

Stand-alone energy storage becomes more dominant as the system scales. For the AEP microgrid it is cost effective to use inverters with traditional small generation allowing effective combined storage/generation. For microgrid systems at the distribution level, megawatt level inverter based generation is much less feasible. In the presence of generators with slow dynamic responses, an energy storage unit offers the ability to provide supplemental temporary power to compensate for the initial deficit of slower sources.

\section{Example of storage and synchronous machine dymanics .}

Figure 1 shows power vs. frequency droops for a storage unit and synchronous generator operating in a microgrid. The slope for the synchronous generator is chosen to cause a $0.5 \mathrm{~Hz}$ droop for $1 \mathrm{pu}$ of power error. The slope for the storage unit is chosen to cause a $0.5 \mathrm{~Hz}$ droop for $1.5 \mathrm{pu}$ of power error. Figure 1 also shows the power set-points $P_{\mathrm{S} \text { ref }}$ and $P_{G}$ ref for the storage system and the synchronous generator respectively. This is the amount of power injected by each source when connected to the grid, at system frequency, $\omega_{0}$. Note that the storage unit is charging while the generator is near its maximum output.

If the system transfers to island when importing from the grid, the generation and the storage moves to balance power in the island. The new operating points are at a frequency that is lower than the nominal value. In this case both sources have increased 
their power output with the synchronous generator reaching its maximum power point and the storage moving from a charge mode to a discharge mode. If the system transfers to island when exporting power to the grid, then the new frequency will be higher, corresponding to a lower power output from the sources with storage at a greater charging level.

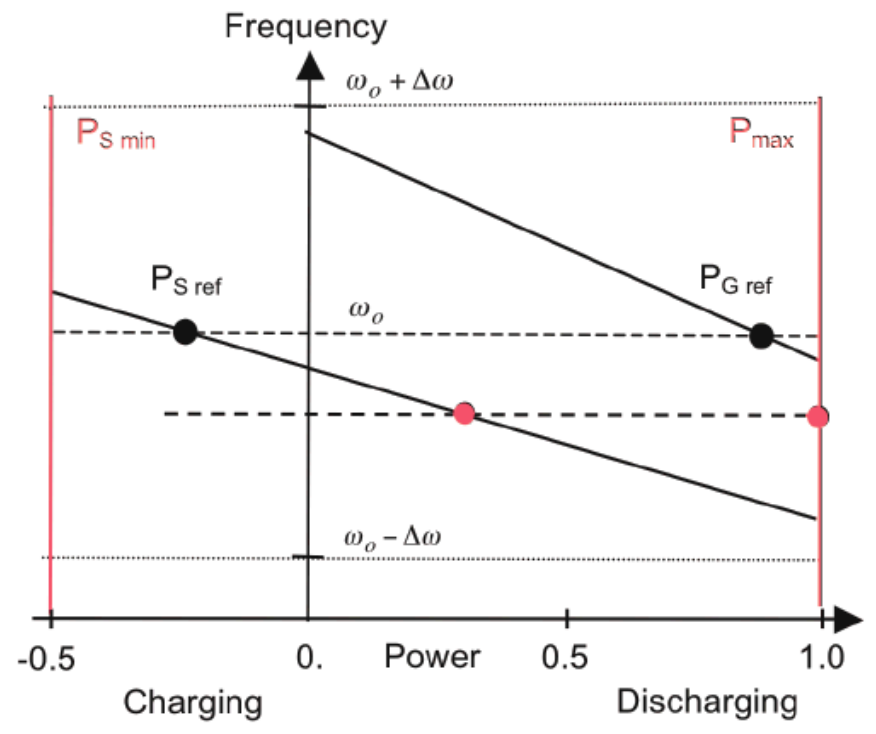

Figure 1 - Steady state power vs. frequency droop

The characteristics shown on Figure 1 are steady state characteristics. They have a fixed slope in the region where the unit is operating within its power range. The slope becomes vertical as soon as any power limit is reached. The droop is the locus where the steady state points are constrained to come to rest, but during transient events the trajectory will deviate from the characteristic.

The dynamics of this droop characteristic are shown in figures 2-4. The figures show the response of two sources during an islanding event where the Microgrid had previously been importing power and has to provide the power to the load by increasing the power of the output from each source. Immediately after the transient event, the change in source loadings depends on the proximity of each source relative to the static switch, but soon follows with the relative responses of each frequency controller. Since the inverterbased energy storage element (ES) doesn't have any physical inertia, it can change its 
frequency at will, which is a luxury the synchronous machine (SM) does not have and explains one reason for the second-order frequency response characteristics seen in figure 4. The second reason for the damped-oscillatory response of the synchronous machine is the time delay that exists between when an increase in the fuel/power command is sent and the time that the fuel is actually combusted in a power-stroke of the engine. This instantaneous increase in power output to results in an increase of load torque from the synchronous machine before the engine torque can be changed to compensate, causing an initial disturbance in operating frequency.

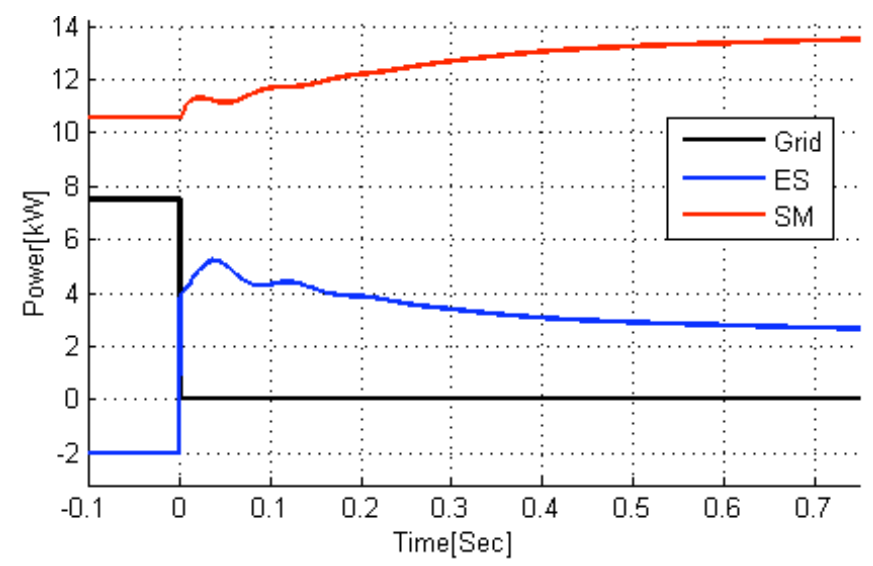

Figure 2 - Instantaneous 3-phase power output of each source through island transient

After $150 \mathrm{~ms}$ following the island event transient, the response is dominated by the synchronous machine's ability to regulate its frequency and thus take up its share of the power as described by the power vs. frequency characteristic presented in figure 1 .

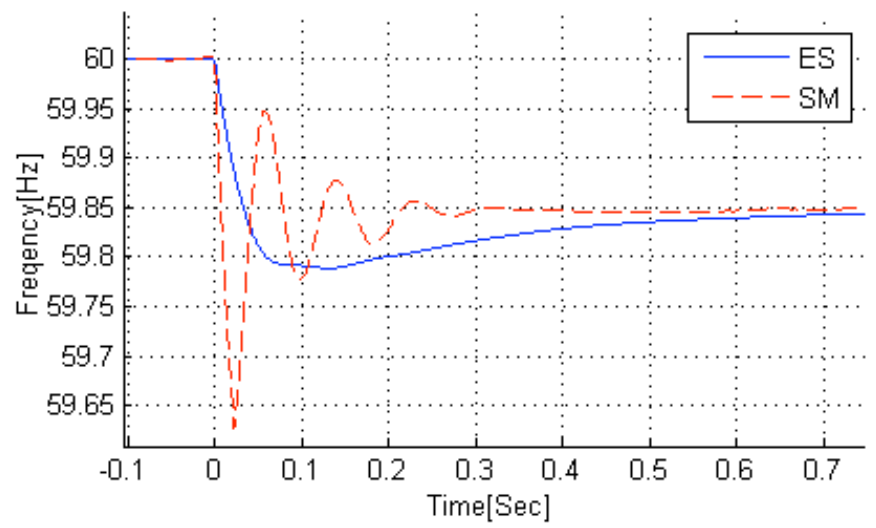

Figure 3 - Instantaneous frequency of each source through island transient 
Despite some momentary differences in operating frequency, the system settles to the same operating frequency as each source develops a relative power/load angle between them to establish the new difference in power outputs as outlined by the power vs. frequency characteristic. In this case, the energy storage element takes the majority of the load as the synchronous machine has a delayed response, but the synchronous machine frequency above that of the energy storage element indicates an increase in relative load angle and causes the two sources to converge to a similar frequency.

Though the transient, there is little effect on the voltage for either the synchronous machine or the inverter. Both systems employ closed-loop voltage control and have relatively small impedances on their output to ensure the load angles needed for rated power can still be considered small, which also makes the voltage drop across them small during transients. As the voltage remains constant, the current magnitude in figure 4 follows the power characteristic in figure 2 , as circulating reactive power is limited by the voltage controllers.
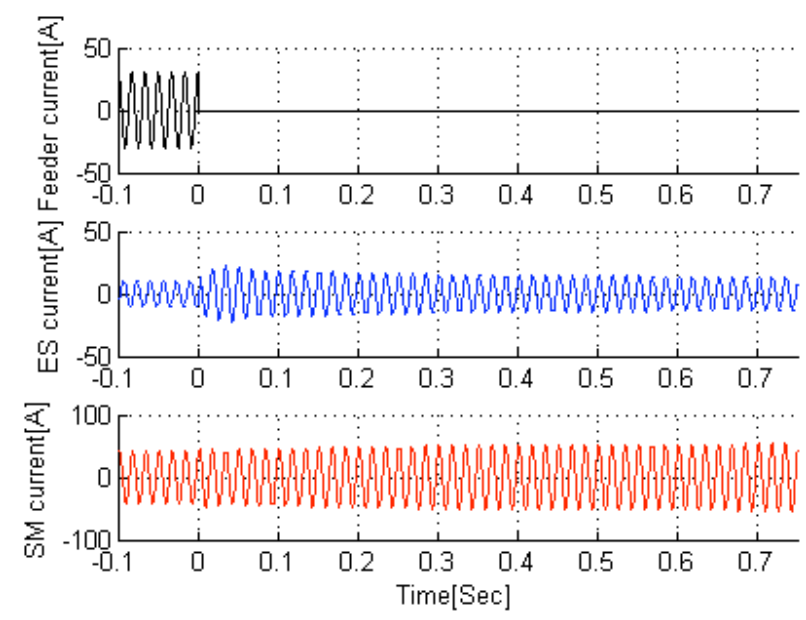

Figure 4 - Phase currents from each source through island

\section{State-of-charge Management}

To effectively control the state of charge of the energy storage element, upper and lower limit-controllers were developed to keep the SOC within specified preferable limits. The controller utilized a power modifier variable (Pmod) to modify the power set-point. The upper SOC controller controlled the SOC directly, developing an error signal from the 
upper limit and the current SOC, engaging only when the error was positive and disengaging when the output goes negative. The lower limit controller controls the SOC indirectly by closing a loop on the input power, commanding the system to charge at a specified rate until a marginal value above the lower limit is reached. Both controllers represent different approaches to SOC management and they are equally as effective. From a system standpoint, there is no specific reason for using two types of control for different limits, but including both types illustrates the operation of each.

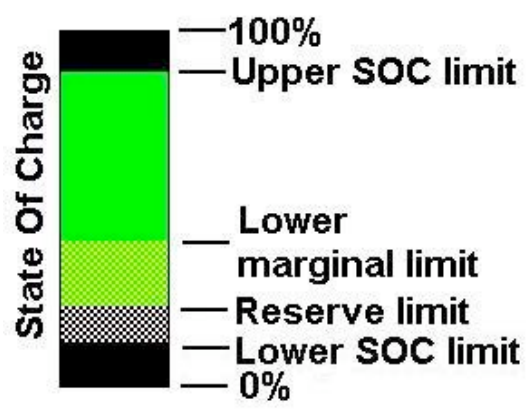

Figure 5. Regions of SOC defined for control the SOC to within defined limits

Identical with other CERTS DER units, CERTS storage regulates the voltage at its connection point and uses a power vs. frequency droop. Storage differs from other DER units since it has bi-directional power flow capabilities resulting in a negative minimum power limit and state-of-charge, (SOC), issues. One of the most important components to the operation of an energy storage element in a Microgrid using the CERTS concept is the on-board management of state of charge. As the CERTS concept employs autonomous operation of individual distributed energy resources maintaining controlling the SOC is a task appointed to the on-board controller.

Assuming bi-directional power flow, the upper and lower SOC limits can be defined. Secondarily, by defining the amount of reserve energy required for backup purposes in the event of islanding, the nominal operating space is limited further by an amount proportional to the duration and power rating of the specified backup requirement, defined as the energy reserve limit. Another point above the energy reserve limit, named the lower marginal limit is specified marginally greater than the energy reserve limit. The marginal limit defines a hysteretic point where the control of the energy storage element will return to nominal operation, as opposed to the at-limit control strategy. Key 
control of the SOC is through control of the power limits. For example if SOC is below the energy reserve limit the maximum output power limit is set to zero. The same concept applies for the minimum power level or charge rate as the storage reached its maximum SOC.

This work focuses on the SOC-limit operation of the energy storage element through load transients and SOC paths across specified limits. This is achieved through simulation and hardware studies on the UW microgrid. The basic systems studied are storage only, storage and inverter based source and storage and a CERTS diesel genset.

\section{Islanding in a low SOC condition}

\begin{tabular}{|c|c|c|}
\hline Time & Event & Lower SOC Controller Action \\
\hline $3 \mathrm{sec}$ & $\begin{array}{l}\text { Lower reserve limit } \\
\text { reached, Figure } 8 .\end{array}$ & $\begin{array}{l}\text { Regulates output power to }-2 \mathrm{~kW} \text { by decreasing the frequency } \\
\text { until the remaining sources on the microgrid increase their } \\
\text { output power to match the desired decrease in output from the } \\
\text { energy storage element }\end{array}$ \\
\hline $9 \mathrm{sec}$ & $\begin{array}{l}\text { Island event occurs } \\
\text { increasing power required } \\
\text { from local sources to } \\
\text { support load }\end{array}$ & $\begin{array}{l}\text { Decreases output frequency to maintain } 2 \mathrm{~kW} \text { charging, } \\
\text { causing extra power to come from microsource alone }\end{array}$ \\
\hline $15 \mathrm{sec}$ & Step-increase in local load & decreases output frequency to maintain $2 \mathrm{~kW}$ charging \\
\hline $22 \mathrm{sec}$ & $\begin{array}{l}\text { Step-decrease in local } \\
\text { load }\end{array}$ & Increases output frequency to maintain $2 \mathrm{~kW}$ charging \\
\hline $22.5 \mathrm{sec}$ & $\begin{array}{l}\text { SOC reaches above lower } \\
+ \text { marginal limit }\end{array}$ & $\begin{array}{l}\text { Disengages reducing net effect to zero at a rate of } \\
0.1 \mathrm{~Hz} / \text { second }\end{array}$ \\
\hline
\end{tabular}

One of the greatest concerns about implementing a controller that overrides the output power command is whether it will interfere with the ability of the system to remain stable during islanding and other load-transients while in an island condition. The most concerning of the at-limit situations is at the lower limit which is a condition that will persist at least momentarily when islanded. A hardware test was conducted with a microsource, the energy storage element, and a grid connection to illustrate a typical sequence of events following an islanding event when the SOC of the battery had previously reached the lower reserve limit and was currently in a controlled stated. 
Figures 6-9 and table describe the sequence of events that result in a return to nominal SOC operation while remaining in island. In this case, the on-site load combined with the charging power to the energy storage element was within the maximum power capabilities of the microsource, which allowed the battery to be recharged to a nominal level. In this experiment, the margin was quite small and only took approximately 20 seconds to cross. This was done to shorten the length of the experiment and practically the margin would be set to a larger value.

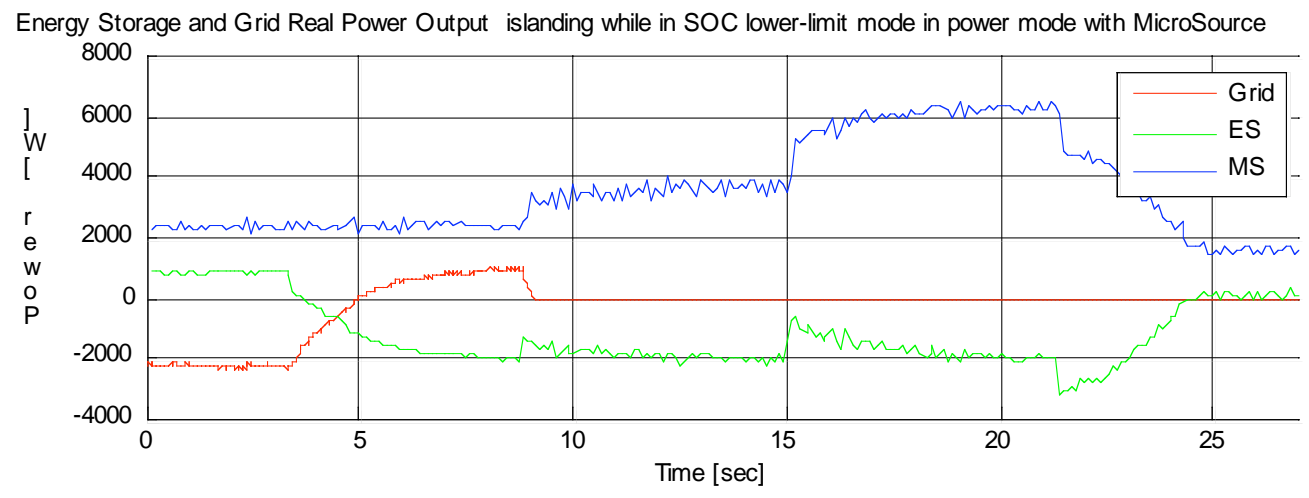

Figure 6. Instantaneous power traces through the at-lower-limit island event

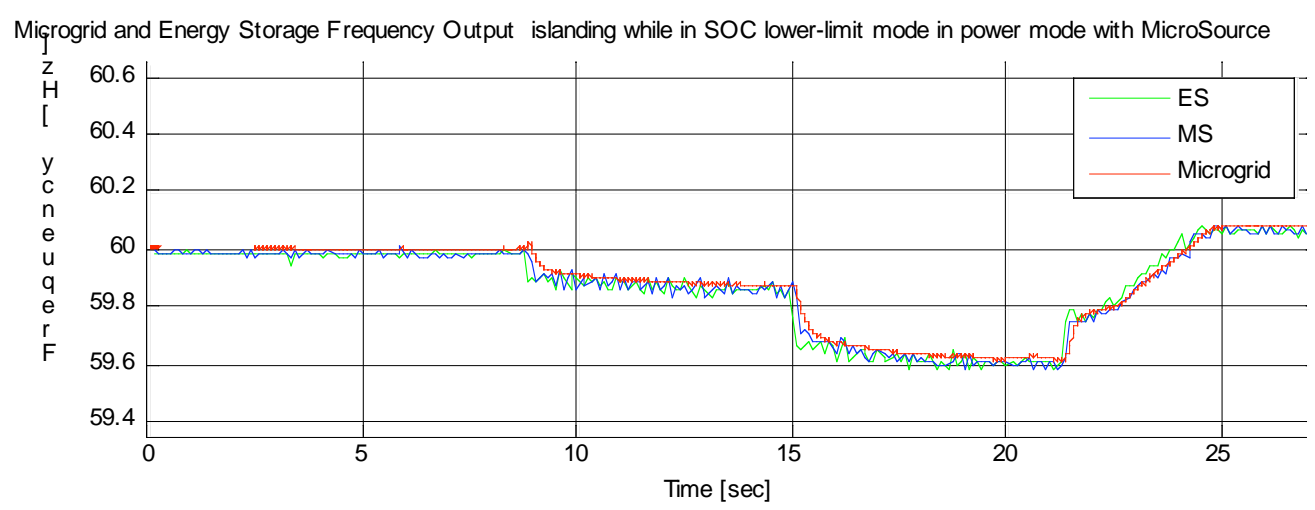

Figure 7 System frequency through island event w/ Microsource 


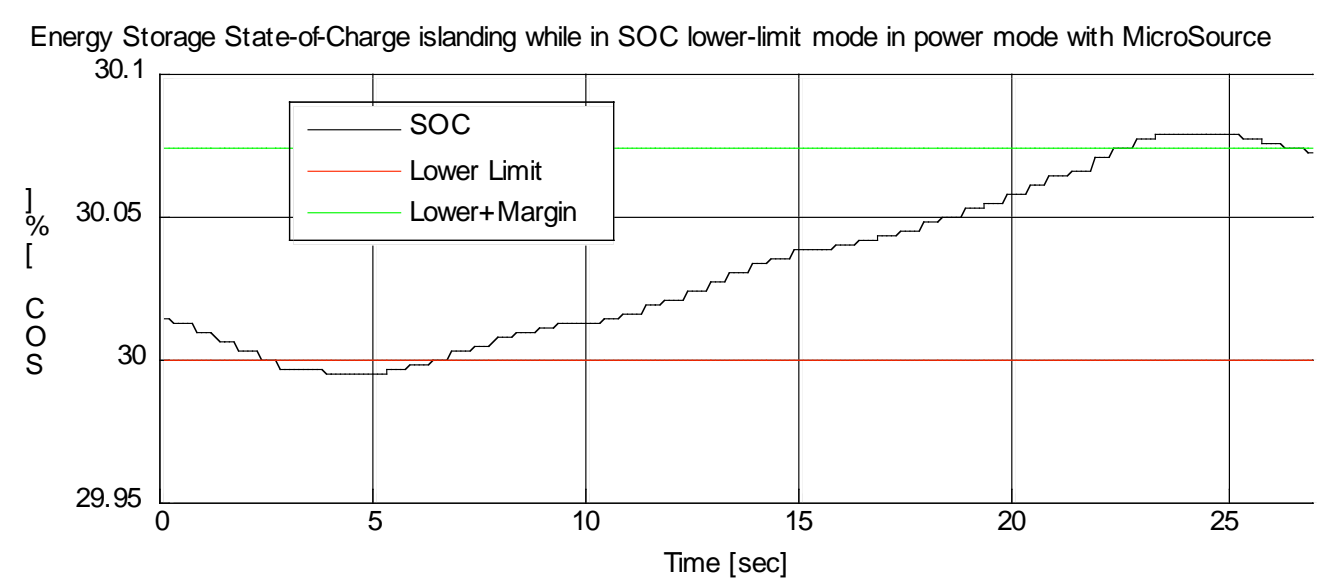

Figure 8 Energy Storage SOC through island event w/ Microsource

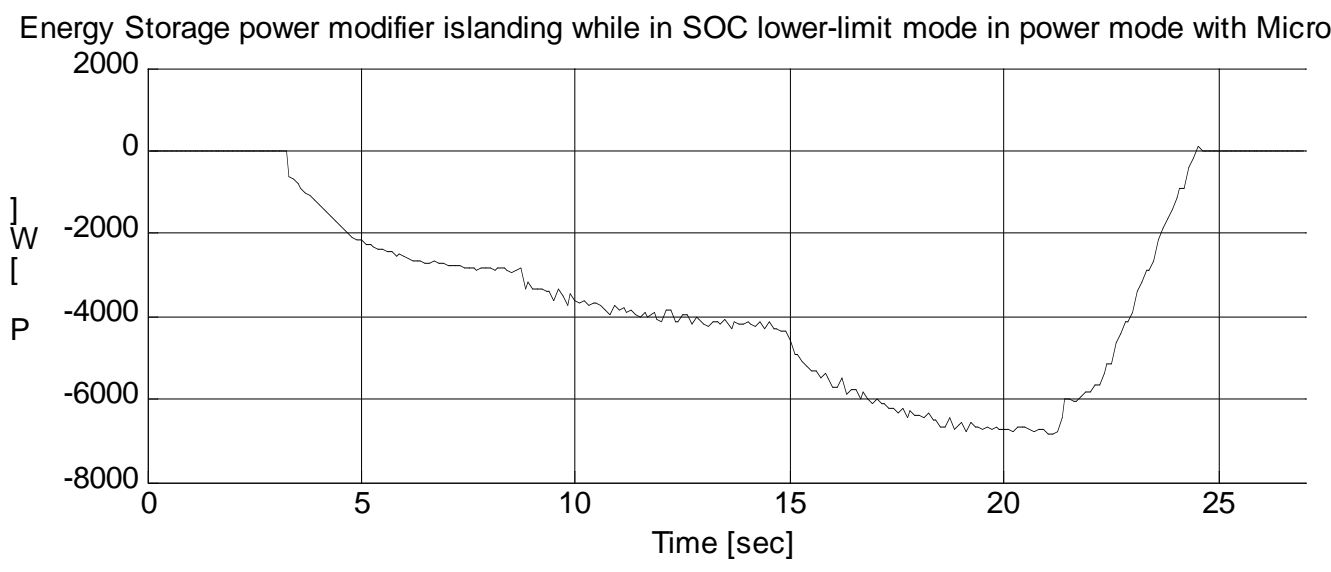

Figure 9. Power Modifier command through island event w/Microsource

Other tests include the step-changes of load, islanding and events that occur when SOC limits are encountered. Their response is dictated by the natural response of the system, in whatever mode it happens to be in, limited or nominal operation. The events that occur when SOC limits are encountered are intentionally slower in response than the loadchanging transients to avoid imparting resonant dynamics on the system. The time constant of each system is between two and four seconds, which is intentionally gauged against the time constant of a slow-reacting source such as a diesel genset. This ensures that even though the SOC limit controller will dictate the power output of the energy storage element in steady state, the transient power-sharing characteristic will still exist for conditions when slow-reacting sources suffer an output capability deficit during load transients. The accumulated SOC error during these transients is not significant in this case as it is assumed that the capacity of the energy storage element is much greater than 
that of the temporary accumulated error. Secondarily, although the exact time-based characteristic of the charge current limitations is not known, the average recommended charge current may be exceeded in transient conditions but should not pose any significant battery damage. This conclusion comes from the relatively small response time to system transients on the order of seconds compared to the battery handling recommendations from the battery manufacturers that were reported to be on the order of fractional minutes.

\section{Summary}

This work shows that ac energy storage add an extra degree of flexibility to a microgrid by allowing the temporal separation between generation and consumption of power. Regardless of what other purposes the energy storage unit is used, it was investigated here primarily for its backup power capabilities, ensuring that when an islanding event occurs that there will be a sink or source for power depending on the disparity between fixed-power sources such as wind, solar, and geothermal plants and the microgrid's power demand. This investigation utilized batteries as the energy storage medium for both its power capabilities as well as the energy reserve capacity

Extensive testing of hardware revealed that the system is inherently stable under a variety of operating conditions, including upper and lower controlled states. The algorithm was demonstrated to operate autonomously, providing an added feature to the plug-and-play topology of the CERTS microgrid. Various additions to the control laws included a saturation that limited the role of the limit controllers beyond $0.6 \mathrm{~Hz}$ in either direction, slew rate limitations on the power modifier command, and limit-triggered controller engagement. The $0.6 \mathrm{~Hz}$ limitation provides a nominal operating point just beyond the specified operating frequency range of the microgrid, which is $0.5 \mathrm{~Hz}$. This allows for operation at a region beyond the $0.5 \mathrm{~Hz}$ limit, but within the $1 \mathrm{~Hz}$ limit, to signal a nonpreferential situation such as a critically low battery state of charge

Overall, the limit controller has well behaved characteristics. It provides autonomous management of the state of charge of the battery, retains some of the transient suppression abilities even in a controlled state, and operates seamlessly regardless of 
system frequency. Regardless of the power set-point specified by the supervisory controller, this control methodology will ensure plug-and-play functionality of the energy storage unit.

\section{References}

1. Erickson, Micah, Robert Lasseter. Integration of Battery-Based Energy Storage Element in the CERTS Microgrid, University-of Wisconsin report on Value and Technology Assessment to Enhance the Business Case for the CERTS Microgrid October 27, 2009 


\subsection{Task-5 Microgrid Operation with Non-Inverter-based DG.}

The objective of this work is to develop the modeling and control framework to enable an internal combustion engine driven, wound-field synchronous generator to operation in a CERTS microgrid contains multiple DG's including inverter-based sources. The key elements are to demonstrate that the genset can seamlessly balance the power on the islanded microgrid using real power vs. frequency droop and maintain voltage using the reactive power vs. voltage droop. The work presents simulations and experimental results for the interaction of gensets with inverter-based sources in a CERTS microgrid test system at the University-of-Wisconsin [1-2].

\section{Field wound synchronous generators}

Sources such as natural gas-based microturbines, fuel cells, PV panels, wind turbines use a power electronics interface on the front end to provide the necessary $\mathrm{AC}$ voltage at the utility frequency. The CERTS inverter is typically a voltage-source converter that provides the necessary control of the bus voltage phase and magnitude. Electrical energy storage can be added to the DC bus to decouple the dynamics of the prime mover from the output. Sources such as fuel cells and PV panels produce DC directly and only an inverter is needed to produce AC output at the desired voltage and frequency. A traditional genset consists of an internal combustion (IC) engine and a synchronous generator coupled on the same shaft. Such systems are widely used as backup or emergency power in commercial as well as industrial installations. Diesel gensets are also heavily used in remote locations where it is impractical or prohibitively expensive to connect to utility power. Diesel gensets used in prime and continuous power applications are typically designed to operate at higher efficiencies since, in the long run, the fuel costs will dominate the initial capital costs.

The generator in the genset is typically either a permanent magnet or a wound-field synchronous machine. In the case of a permanent magnet generator, the front end consists of a rectifier and a voltage-source converter to provide the necessary AC voltage at the desired frequency. The presence of a power electronics front end increases the overall cost of the system and decreases its fault tolerance. However, the presence of the 
inverter enables non-synchronous operation of the engine which makes it possible to achieve increased power density and higher efficiency.

Machines with wound-field generators require an exciter and a voltage regulator to control the AC voltage produced by the machine. No inverter is needed since the machine provides the AC voltage at the desired frequency provided that the speed of the shaft is held close to the required fixed value. The reduced cost of the system due to the absence of the power electronics front end is one of its major advantages. However, a significant drawback of this system is that without the inverter front end, the dynamics of the prime mover cannot be decoupled from the output of the generator an the natural power vs. frequency droop is much greater.
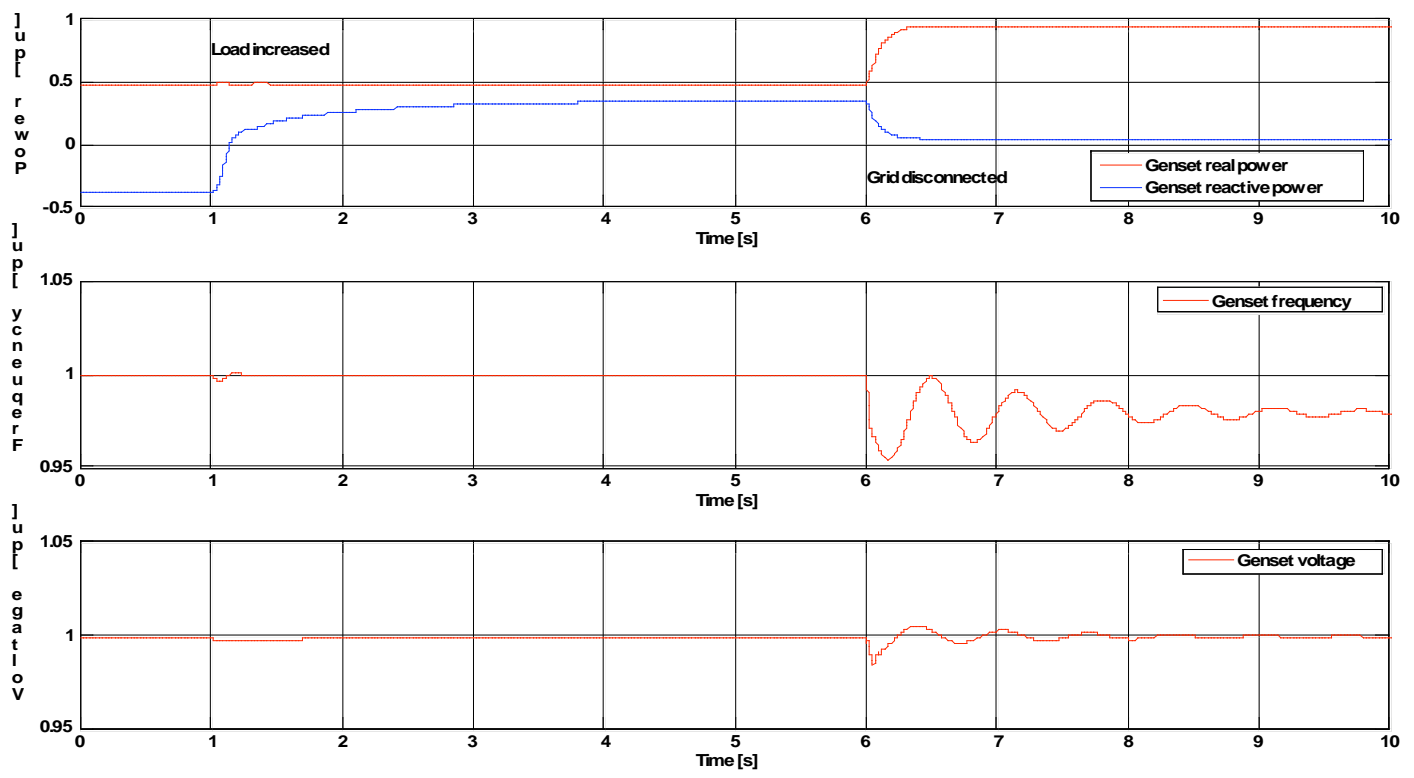

Figure 1. Real power, reactive power, frequency and terminal voltage for load increase $(t=3 s)$ and islanding $(10.2 s)$

When the grid disconnects the genset has to pick up the additional load and the second order dynamics of the mechancial governor are reflected in frequency waveforms shown in figure1. The drop in frequency depends on the initial setpoint of the genset, the final load on genset and the frequency droop characteristics. After islanding the governor takes upto $5 \mathrm{~s}$ to stabilize the speed of the machine. Furthermore depending on the load change 
the $5 \%$ droop of the governor can lead to a change in frequency beyond the limits of microgrid operation.

In Fig. 1 the dynamics of the diesel genset in the microgrid network system are stable during both grid connected and islanded mode. The steady state frequency of the system during islanded mode is governed by the genset frequency droop of 5\%. This droop can cause the system to operate at frequencies which may be undesirable from the power quality standpoint. The droop must be decreased to meet the desired norms. Furthermore the mechanical governor introduces frequency dynamics which are undesirable and hence an electronic governor is required. It is clear that without QV droop there will be significant circulating VAR's in the system. Hence a modified voltage regulator which implements the QV droop is also required.

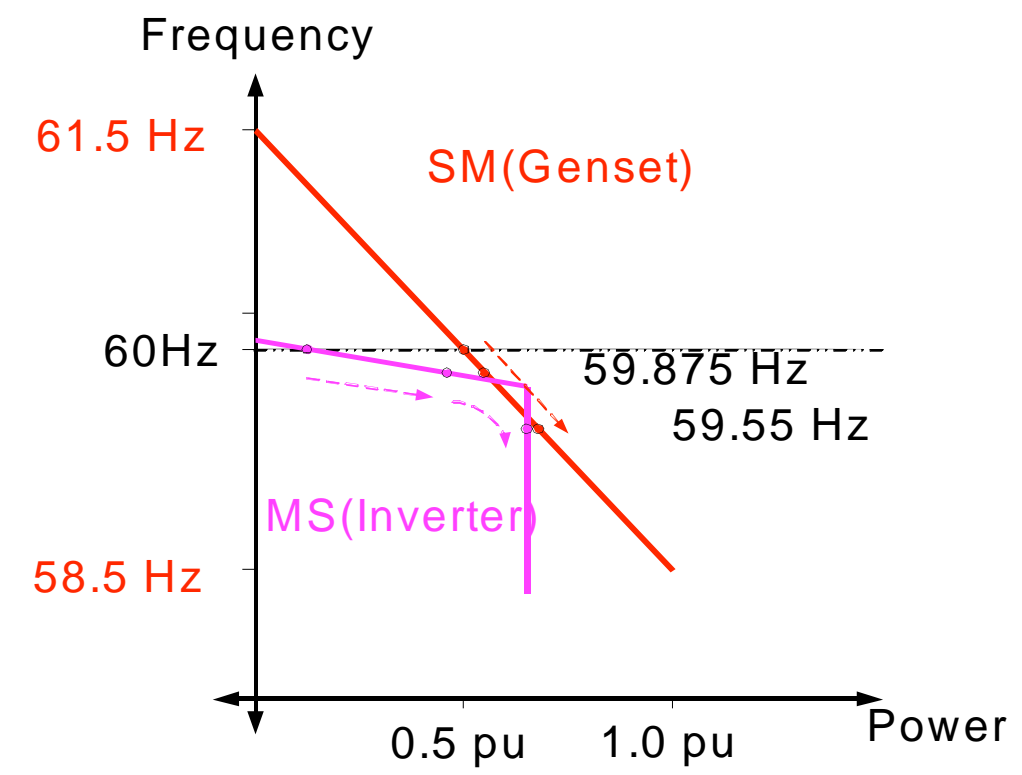

Figure 2. Power frequency droop curves for the genset and inverter based source.

The power frequency droop curves of both types of microgrid sources are shown in Figure 2. We can see that the inverter based microsource has a smaller power frequency droop in comparison to the diesel genset. Hence in island mode the inverter based source will dictate the frequency in the system. The diesel genset will follow the frequency set by the inverter and produce the desired output and the sum of the power produced by the two sources will be equal to the load power plus losses. 
The CERTS inverter-based source has a droop of $0.5 \mathrm{~Hz}$ over its entire range of operation from no load to full load. In constrast, the genset with the conventional controller has a droop of $3 \mathrm{~Hz}$ (i.e., 5\%) from no load to full load. For any change in load, the output power of the genset will vary by a very small amount and the inverter-based source will track the load. Once the inverter based source reaches its output limit (minimum or maximum), the genset output will change to track the load. With the genset fully loaded the frequency change would be much larger (i.e., $5 \mathrm{~Hz}$ ) that $0.5 \mathrm{~Hz}$ seen by the CERTS inverter.

A major challenge is to modify the generator's governor to exhibit the same droop seen by the CERTS inverter. In a like manner it is necessary to modify the exciter controls to maintain the same reactive power vs. voltage droop as a CERTS inverter based sources.

\section{Genset Modifications}

The mismatched performance characteristics described in the previous section can be substantially improved by designing new control algorithms for the engine governor and voltage regulator in the diesel genset. The modified genset controller has been designed using state feedback techniques. As a first step, an observer has been developed to estimate the state of the system. An operating model for the genset has been developed from the system state equations.

The machine model developed for the synchronous machine depends on knowledge of the rotor position for achieving the rotor reference frame transformation. In order to address this need, a rotor angle observer has been developed using the measured rotor position as input to accurately estimate the rotor speed. In addition, the observer output provides accurate angular information that is used to convert the stator terminal quantities into the synchronous reference frame aligned with the machine rotor.

In the wound-field machine, the $d$-axis field voltage is the only control variable that is available to change the terminal voltage. More specifically, this field voltage controls the mutual $d$-axis flux linkage that governs the output $q$-axis terminal voltage. As a result, the $d$-axis flux linkage should be accurately estimated in order to control the output 
voltage. A closed-loop observer based on the machine state equations has been developed for this purpose.

The reference commands for the genset speed and terminal voltage are derived from the curves for the real power vs. frequency droop and the reactive power vs. terminal voltage droop curves. The desired terminal voltage and speed is then passed on as commands to the speed controller and voltage regulator.

The mechanical governor is replaced by an electronic actuator that utilizes a PWM command to vary the fuel input to the engine. The speed controller output is a PWM signal with a variable duty ratio. The voltage regulator controls the output of the brushless exciter by varying the input current of the exciter machine. Controlling the exciter input current has the beneficial effect of decoupling it from the speed of the machine.

\section{Hardware test of modified genset}

A testbed for the diesel genset has been established at UW-Madison. The test setup consists of a Kohler commercial 10kW diesel genset connected to the UW Microgrid test bed with inverter based sources including storage. A transformer is placed in series with the machine to step down the output of the machine to $208 \mathrm{~V}$ which is the nominal voltage of the microgrid. Resistor banks are connected at the secondary of the transformer to load the machine.

The parameters of the main generator, exciter, and the voltage regulator in the genset were obtained from the manufacturer. The genset diesel engine is a four-stroke threecylinder engine operating at rated speed of $1800 \mathrm{rpm}$. The time delay for a power stroke of this engine is calculated to be $22 \mathrm{~ms}$. The relationship between the fuel input and torque output of the engine was obtained from the torque-fuel map at rated speed provided by the engine manufacturer. Initial test on the mechanical governor confirm that there is a change in the steady-state frequency with loading. The change in frequency is consistent with the manufacturer-specified droop value of 5\%. The secondorder dynamics of the mechanical governor are visible in the speed waveform. 
This large droop required a new governor and exciter to be compatible with the CERTS microgrid criteria. An enhanced luenberger topology is chosen for the observer that accurately estimates the rotor speed and genset ' $d$ ' axis mutual flux voltage. The observer guarantees zero steady state error within its bandwidth even in the presence of parameter errors. Using the output of the observer an electronic governor and a voltage regulator was designed and implemented. The electronic governor incorporates command feed forward, state variable controller and a disturbance input decoupler. Due to the presence of the engine delay the governor cannot instantaneously correct for sudden load changes. This time delay ensures that the shaft mechanical torque does not change instantaneously after a fuel command change. Hence during this time interval the speed will vary and the difference in power would need to be supplied from the other sources in the system and the mechanical inertia in the genset. However the incorporation of the electronic governor significantly decreases the time during which the other sources have to contribute the excess power. Simulation and experimental results confirm that the incorporation of the reactive power droop characteristic decreases the amount of circulating VAR's in the system. The decoupling of the electrical torque in the electronic governor is one of the critical elements of the speed controller. The presence of this disturbance input decoupling helps the control to respond quickly to load changes and enhances the performance of the genset in a CERTS microgrid.

Test of the controller demonstrates the ability of the IC engine based source to work in conjunction with inverter based sources in a microgrid environment and share load evenly, maintain system voltage and improve the genset dynamics during various events. Tests also demonstrate the performance of multiple gensets operating in a microgrid environment in the absence of any inverter based sources. Due to the time delay inherent to the operation of IC engines there is a drop in frequency during load changes occurring in an islanded operation. This drop in frequency is absent if an inverter based source is present due to the much faster response of such sources, however the absence of an inverter based source does not cause any system instability. 


\section{Summary}

With growing consumer demand the current electric power grid infrastructure is becoming increasingly strained. This has resulted in congestion of the transmission system and operation of the power grid near its stability limit. To relieve the congestion and to reduce the stress on the power grid system planners have been favoring the use of distributed generators located near the loads. Among the various existing DG technologies conventional IC engine gensets have the lowest capital cost since they do not require a power electronic interface. This report has discussed the modeling and control issues related to the operation of an IC engine based wound field synchronous genset in a microgrid environment.

The report discusses the salient features of IC engine gensets and presents models for each of the individual components. Conventional IC engine gensets utilize a voltage regulator that controls the terminal voltage to a fixed value. In a distribution system like the microgrid that has multiple sources, the absence of reactive power droop curves results in large circulating VAR's in the system. These circulating VAR's decrease efficiency of the system and increase the ratings of key system components. Gensets with low ratings (less than $100 \mathrm{~kW}$ ) utilize a mechanical governor to control the speed. The mechanical governor of small gensets can cause islanded systems to experience frequency transients that include significant damped oscillations that can take up to 3-5 seconds to dissipate. The simulation studies and experimental tests have been presented that illustrate the circulating VAR's and frequency oscillations.

Gensets also typically utilize a 5\% power frequency droop instead of a $1 \%$ droop used by other DG's in a microgrid. This causes other distributed resources in the system to pick up load changes and operate close to their limits while under-utilizing the genset.

To improve the performance of the genset for operation in a microgrid environment a state variable controller based on a system observer has been developed. The state variable controller incorporates more suitable droop curves for both the real and reactive power components that enable the IC engine genset to rapidly respond to load changes and interact positively with other sources in the absence of any form of external communication system. The observer for the system includes two components that 
measure the mechanical parameters of the system such as rotor position and speed and the electrical parameters of the system such as flux voltages. The observer designed in the continuous time domain accurately estimates the various quantities (within a certain bandwidth) even in the presence of parameter errors.

The proposed controller has been implemented on a test genset and various experiments have been carried out to verify its operation. The operation of the observer and controller has been demonstrated using EMTP based simulations and further validated using the test setup. The results show that the IC engine based genset is well-behaved during load changes and islanding maintaining system frequency and voltage within prescribed limits.

\section{References}

1. Krishnamurthy, Shashank, Robert Lasseter. Control of Wound Field Synchronous Machine Gensets for Operation in a CERTS Microgrid. University-of Wisconsin report on Value and Technology Assessment to Enhance the Business Case for the CERTS Microgrid March 6, 2009

2. Krishnamurthy, Shashank, T.M. Jahns, Robert Lasseter. The Operation of Diesel Gensets in a CERTS Microgrid, Proc. of IEEE Power \& Energy Society Gen. Meeting, Pittsburgh, July 2008, certs.lbl.gov/pdf/diesel-gensets.pdf 


\subsection{Task-6. Continuous Run of the CERTS Microgrid}

The continuous run test phase was performed to collect information on a number of long term operational characteristics of the CERTS Microgrid, such as Power Quality and response to grid disturbances. The testing was performed in two sections, 3/27/09 4/27/09 and 10/02/09 - 10/10/09, totaling approximately 1026 hours. The testing consisted of operating the genset and load bank equipment based on simulated load profiles. The Static Switch was also automated to allow for unattended operation. The meter data collection system was also setup in such a way as to capture system disturbances such as voltage swells and sags. The extent of data collected included disturbance captures and genset and load operational logs. This data was later scrutinized for events of interest.

\section{Distribution Disturbances}

One distribution disturbance event was captured on 8/28/2009 at 14:17,(see below). The event appears to be an A phase to B phase to Ground fault. The depth of the voltage sag is mild and the duration short term. The cause was either an intermittent fault like a tree contact or a distant fault which was cleared by a downstream recloser. To our knowledge no upstream distribution protection equipment operated to clear this fault. This fault resulted in an $83 \%$ Voltage sag to phases A and B of the distribution supply. The unprotected load in Load Bank 6 of 18kW experiences the full $83 \%$ voltage sag event lasting over a 1.5 second window. The time from fault, thru detection, to clearing appears to be $\sim 25 \mathrm{msec}$. At this point the voltage within the islanded microgrid recovers having only experienced 1.5 cycles of sag.

The load closest to the SS, Load Bank 2 of $8 \mathrm{~kW}$ and $6 \mathrm{kVar}$, experiences a voltage sag for approximately 1.5 cycles to $94 \%$. The difference in sag percent from the utility entry point to the protected section of the microgrid bus is attributed primarily to the impedance of connection cabling and the Static Switch. 

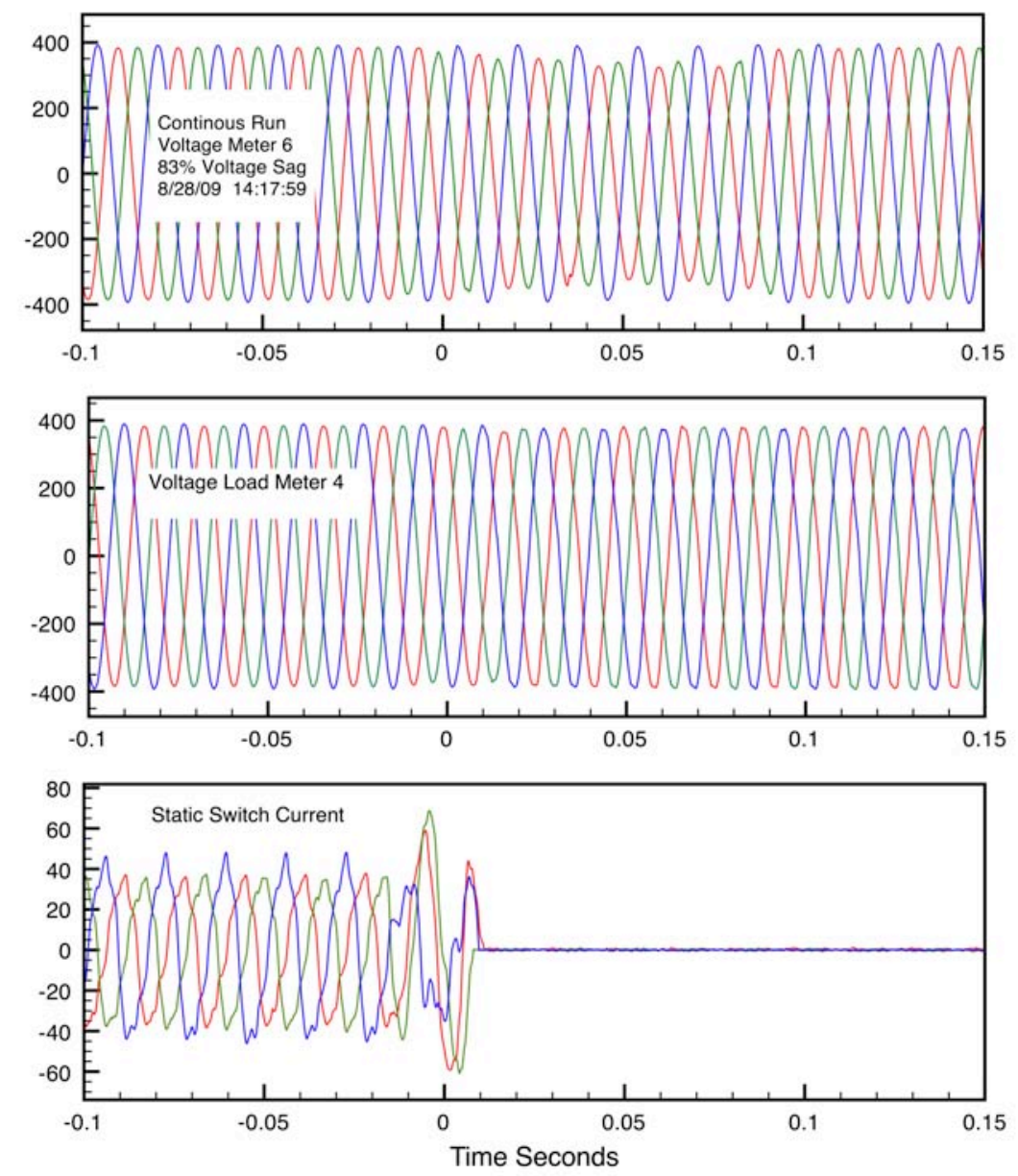

Power Quality Event 8/28/09

Load Bank 3 of $18 \mathrm{~kW}$, experiences a $95 \%$ voltage sag for 1.5 cycles. The load furthest from the SS, Load Bank 4 of 18kW, experiences a similar voltage sag for approximately 1.5 cycles to $95 \%$. This $1 \%$ improvement over that of the protected section entry point can be attributed to cabling impedance and the microgrid source immediately adjacent. Genset A2 was the only genset online at the time and it supported the microgrid bus once the SS opened.

\section{Reliability}

One important characteristic examined during the continuous run testing dealt with quantifying the reliability of the various sections of a microgrid. Assessments of reliability for the generating equipment as well as each individual zone have been made. 
The definition of reliability used below is; Reliability = Run Hours / (Run Hours + Forced Outage Hours).

\section{Genset Reliability}

The genset equipment is considered prototypical and the reliability of the individual machines was not considered a top priority. Because of this the information collected is considered not representative of the commercialized version of this equipment, the Tecogen INV-100 Co-gen unit.

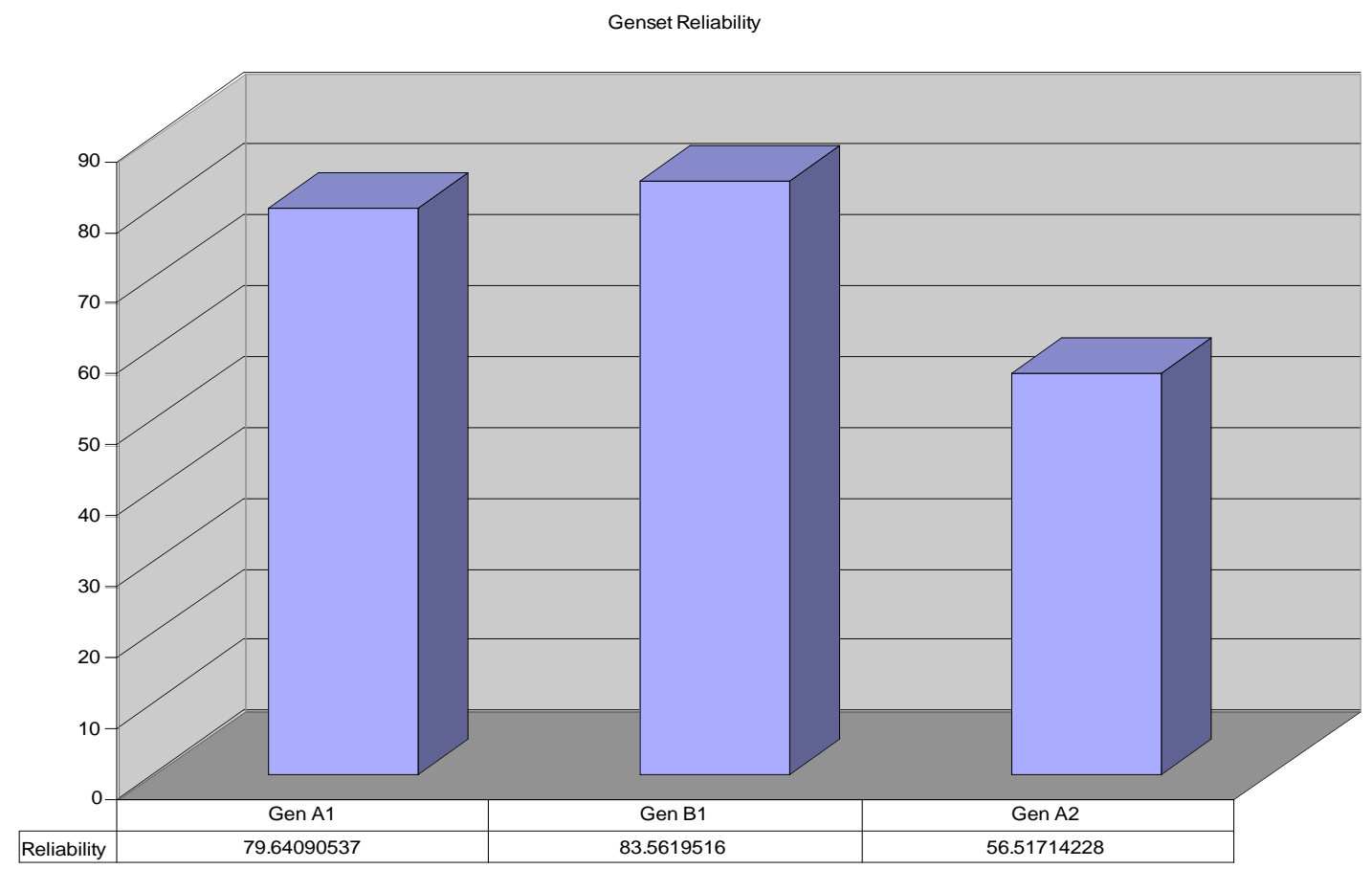

The generating equipment is considered identical in construction and programming, we have no explanation as to why Genset A2 is an outlier. The alarms from each forced outage were captured and tabulated below.

\section{Genset Alarms}

\begin{tabular}{|r|c|c|c|}
\hline \multicolumn{1}{|c|}{ Shutdown Alarm } & Genset A1 & Genset B1 & Genset A2 \\
\hline CAN Bus Comms Failure & 5 & 5 & 8 \\
\hline Fow Water Pressure Fault & 1 & & 7 \\
\hline
\end{tabular}




\begin{tabular}{|r|c|c|c|}
\hline Boost Fault & 6 & & 1 \\
\hline DC Overvoltage Fault & 3 & 1 & \\
\hline Power Supply Fault & 1 & & \\
\hline Overload Fault & & 1 & 1 \\
\hline Logic Voltage Fault & & 1 & \\
\hline No Field Signal Fault & & 1 & \\
\hline
\end{tabular}

The reliability of each zone is a combination of the reliability of the utility and generating sources as well as the protection and load equipment within that zone. Because of this the zone furthest into the system is likely to be the least reliable.

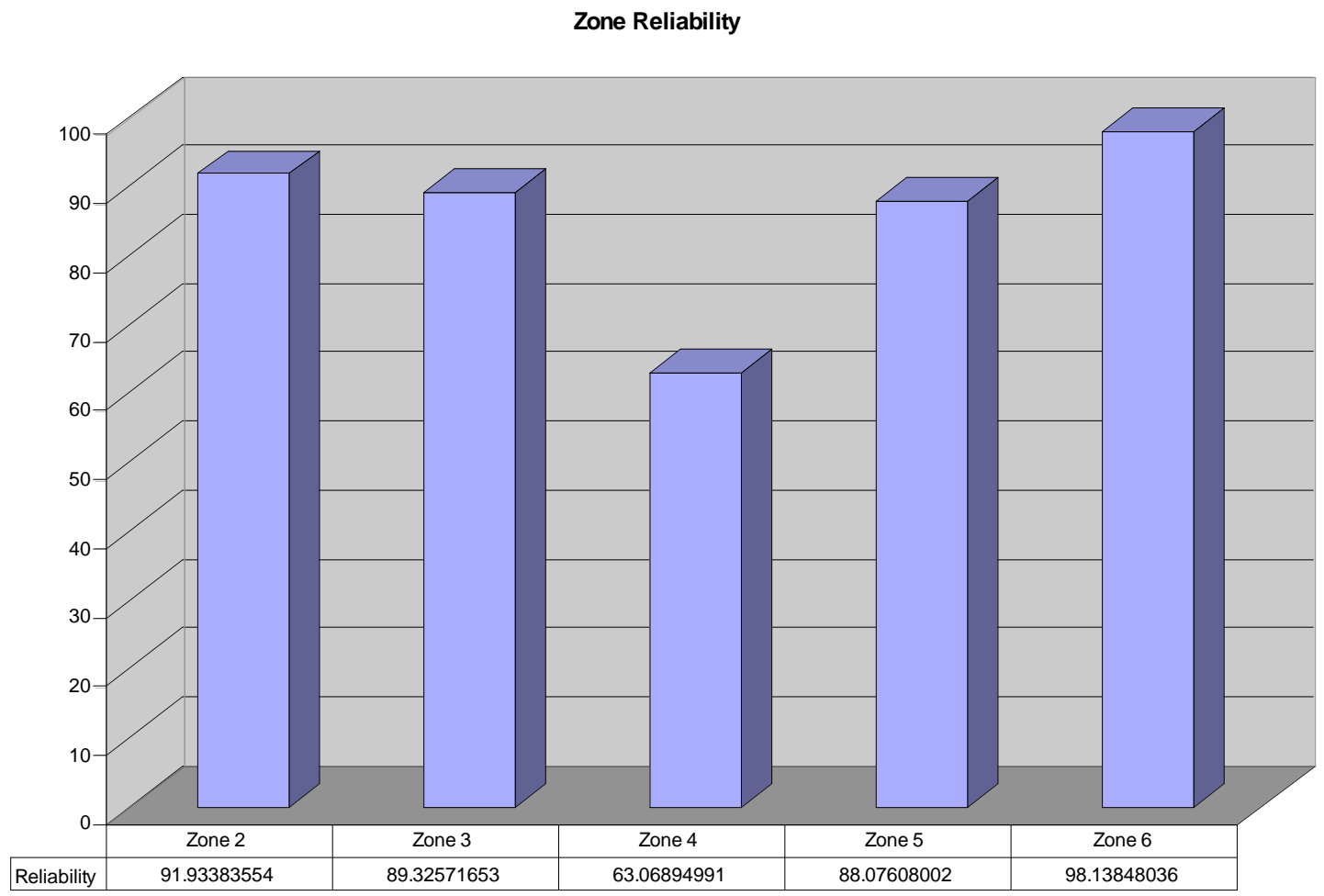

Zone 6 is outside of the protected area of the microgrid and relies solely on the utility supply. This zone employs traditional phase over-current protection which is coordinated to remove faults with the least amount of interruption. Zone 2 has the best reliability of the protected areas. However due to the sensitive nature of the protection employed and the lack of a generating asset in this zone the reliability is less than that of the utility system. Zones 3 and 5 are both a level deeper into the protected area of the microgrid and 
display similar reduced reliabilities. Finally Zone 4 is the deepest zone electrically from the utility grid. This zone is the least reliable due to the protection scheme and the fact that it contains genset A2, which itself is dramatically less reliably. This is further compounded by an operational philosophy which requires downstream zones to be tripped off line to an upstream but separable fault. This is a requirement as the feeder breakers are presently not considered a point of resynchronization to the greater microgrid.

The sensitive protection scheme coupled with shunt trip feeder breakers is the primary contributor to the overall reduced reliability. This type of protection is effective at clearing both major and minor faults quickly but is not properly coordinated with downstream minor protecting devices. The sensitive, fast feeder protection operates not only clearing the fault but also needlessly de-energizing large sections of the electrical bus.

Typical downstream protection is of a phase over-current design, generally due to its inexpense and insensitivity to inrush and unbalance. This type of protection is less sensitive to low grade faults and requires more fault time to operate. Because the majority of faults occur in connected equipment, these lesser breakers are the expected clearing devices of choice. Feeder breaker protection is typically reserved for major faults, such as bus faults, which occur less frequently. The sensitive, fast feeder protection operates not only clearing the fault but also needlessly de-energizing large sections of the electrical bus. Because of this an alternative method for protection is recommended.

Before beginning this testing, the initial hypothesis was that the protected areas of the microgrid would have superior reliability, above that of the utility system. This turned out to be incorrect and therefore a predictive calculator of the various reliabilities was constructed. This tool incorporates a very basic reliability calculation which can be further refine to contain greater detail of the CERTS microgrid. It does, however, provide an approximate result to reflect how adjustments in individual variables can affect the entire system. 
Reliability Calculations

Electrical reliability of an islanded bus employing multiple, equally reliable generators.

$$
\left(\begin{array}{l}
n \\
k
\end{array}\right) r^{k}(t)(1-r(t))^{n-k} \text { Where, }\left(\begin{array}{l}
n \\
k
\end{array}\right)=\frac{n !}{k !(n-k) !} \text {, and } n \geq k
$$

Electrical reliability of the paralleled utility and microgrid buses.

$$
R_{M B}(t)=R_{U S}(t)+R_{D G}(t)-R_{U S}(t) * R_{D G}(t) \text { Where, } R_{M B}(t)=\text { Reliability of the }
$$

Microgrid Bus, $R_{U S}(t)=$ Reliability of the Utility Supply, and $R_{D G}(t)=$ Reliability of the Distributed Generation.

Electrical reliability of the Zones

$$
R_{Z}(t)=R_{S B}(t) * R_{L}(t) \text { Where, } \quad R_{Z}(t)=\text { Reliability of the Zone, } R_{S B}(t)=
$$

\begin{tabular}{|c|c|c|}
\hline & Variables & \\
\hline Generator Reliability & $\operatorname{rdg}(t)=$ & 0.7 \\
\hline Number of Distributed Generators & $\mathrm{n}=$ & 3 \\
\hline Minimum Number of DG Required to meet Load Demand & $\mathrm{k}=$ & 3 \\
\hline Utility Grid Reliability & $r u(t)=$ & 0.9933 \\
\hline Reliability of the Load & $\mathrm{rl}(\mathrm{t})=$ & 0.988 \\
\hline \multicolumn{2}{|c|}{ Islanded Microgrid Reliability due to DG alone } & 0.343 \\
\hline \multicolumn{2}{|c|}{ Reliability of Microgrid due to DG and Utility } & 0.9955981 \\
\hline \multicolumn{3}{|c|}{ Reliability of bus in each Microgrid Zone (=Reliability of Load ${ }^{*}$ Reliability of Sourcing Bus) } \\
\hline & Zone 1 & 0.9933 \\
\hline & Zone 2 & 0.983650923 \\
\hline & Zone 3 & 0.971847112 \\
\hline & Zone 4 & 0.960184946 \\
\hline & Zone 5 & 0.971847112 \\
\hline & Zone 6 & 0.9813804 \\
\hline
\end{tabular}

Reliability of the Sourcing Bus, $R_{L}(t)=$ Reliability of the Load

\section{Power Factor Correction at the Point of Common Coupling}

Another important characteristic examined dealt with the customer power factor at the point of common coupling. From the first phase of testing it was observed that the customer power factor was rather low and depended highly on what the dispatched voltage setpoint of the microgrid equipment was. Also even with the voltage dispatched to match the utility voltage the operational $\mathrm{kVars}$ would flow from the utility when grid connected. Generally this is not a problem however because much of the $\mathrm{kW}$ load was 
being provided for by the distributed generation only a small amount of $\mathrm{kW}$ load was being placed on the utility. The larger $\mathrm{kVar}$ vs $\mathrm{kW}$ load made the power factor at the customer meter very poor. Customers with a persistently poor power factor will usually incur penalties and can potentially be refused electrical service. Because of this it was desirable to use the existing Energy Management System to control the reactive power being drawing from the utility. This motivation is two fold, one to avoid problems with the utility and two to potentially sell an ancillary service to the utility.

Because $\mathrm{kVar}$ usage is measured on 15 minute intervals this is a good fit for the global intelligence of the Energy Management System and it timing also does not require high speed correction. The EMS system can make the decisions of how many kVars are required and from where they should be generated. The below graph compares two periods of time; one with power factor correction enabled and a second without. The average power factor improved to 0.928 from 0.795 , approximately $16.7 \%$. It is also worth noting that a common trigger point for the requirement of customer power factor correction is 0.9 .

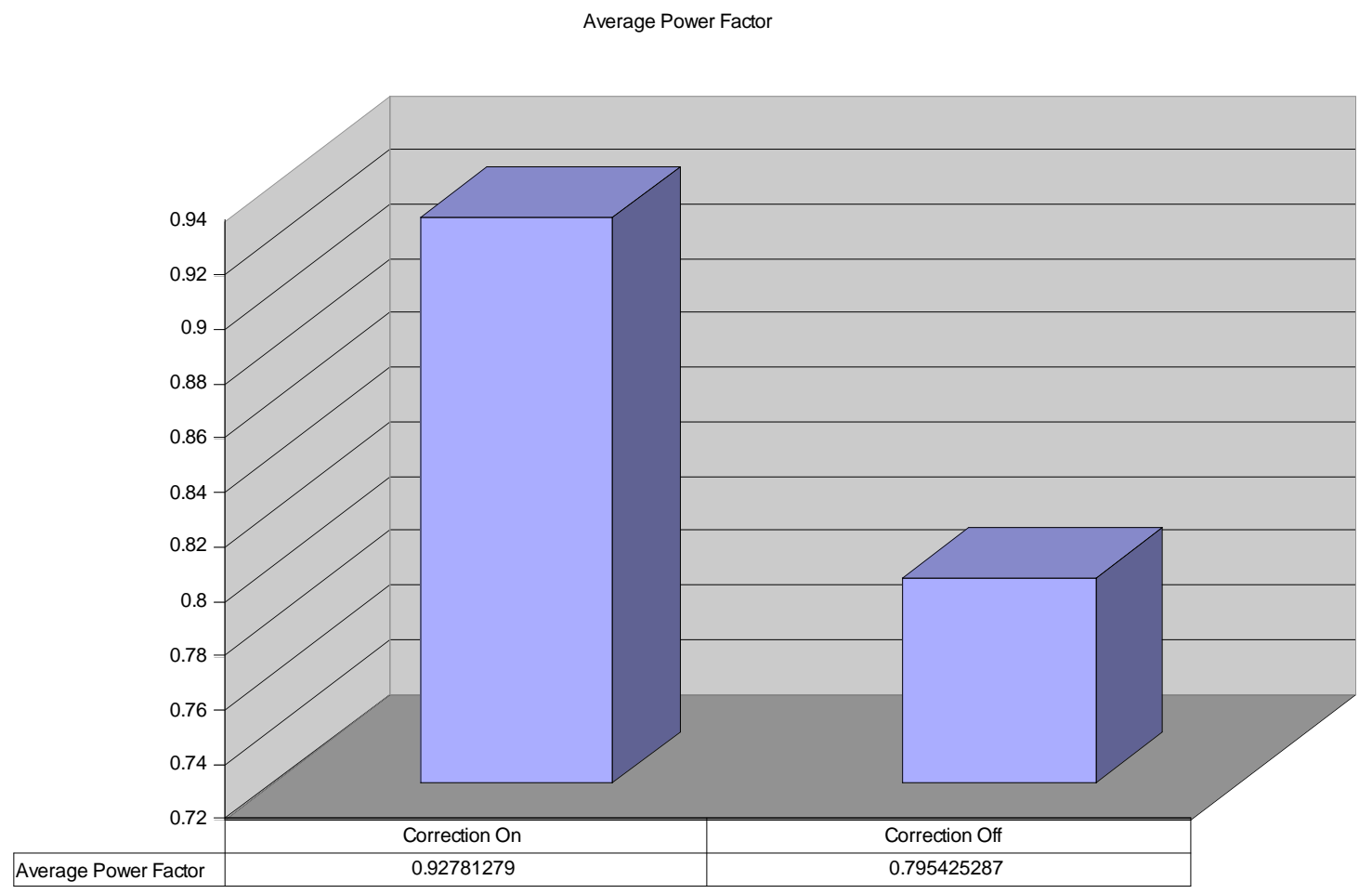




\section{Automation of Load and Generation}

The final area of interest deals with the automation of the load and genset equipment. During this continuous run period these systems were automatically operated by individual agents. These agents were given a base load profile for electrical $\mathrm{kW}, \mathrm{kVar}$ and thermal demand. They were also given the freedom to deviate from this base profile by a certain amount. This allowed for the bounded, random generation of a large number of load flows within the microgrid. In total the system operated through approximately 27, 300 load changes and approximately 5,800 generation dispatches.

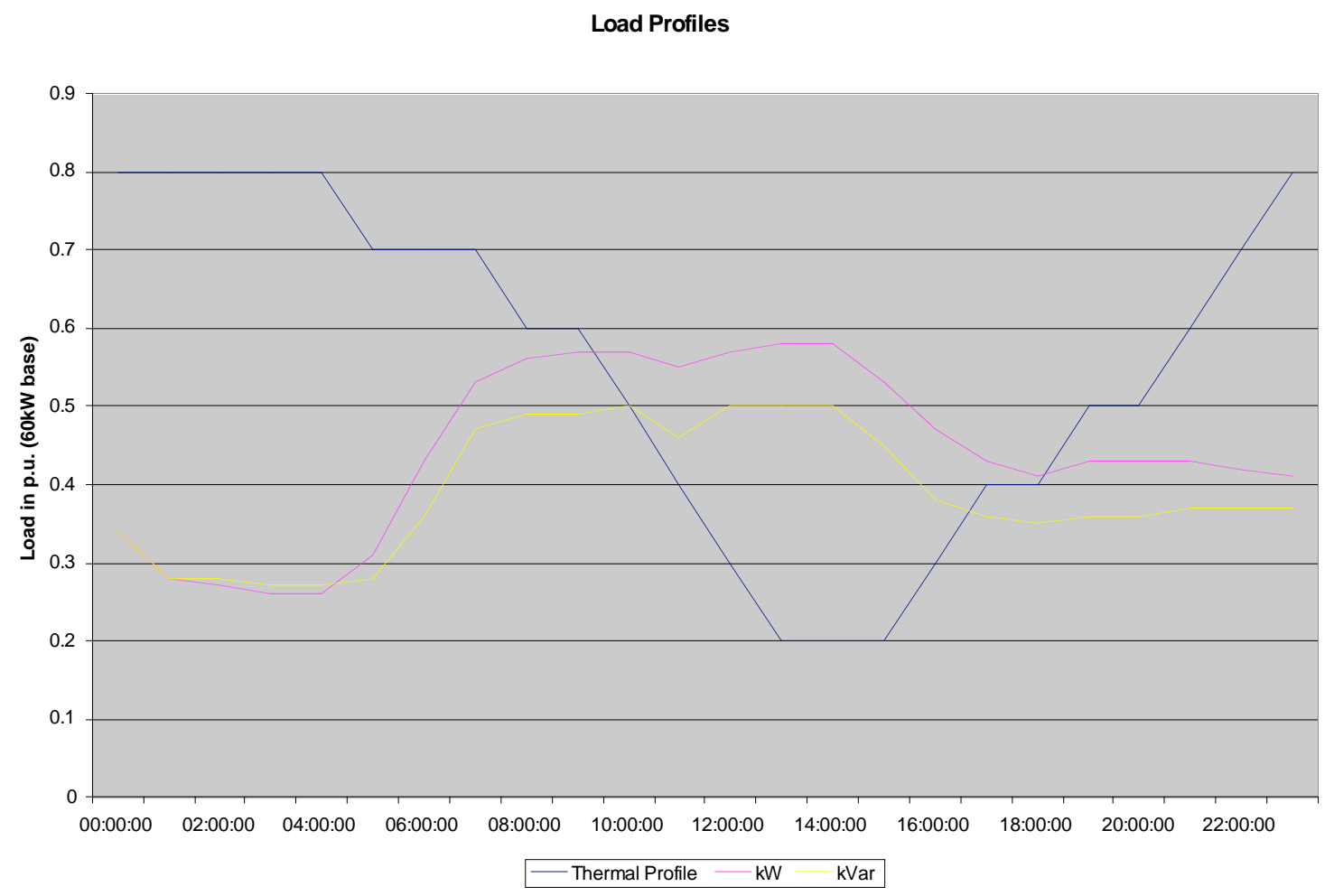

The base load profiles for thermal, $\mathrm{kW}$, and $\mathrm{kVar}$ demand. 
Genset Thermal Load Profile

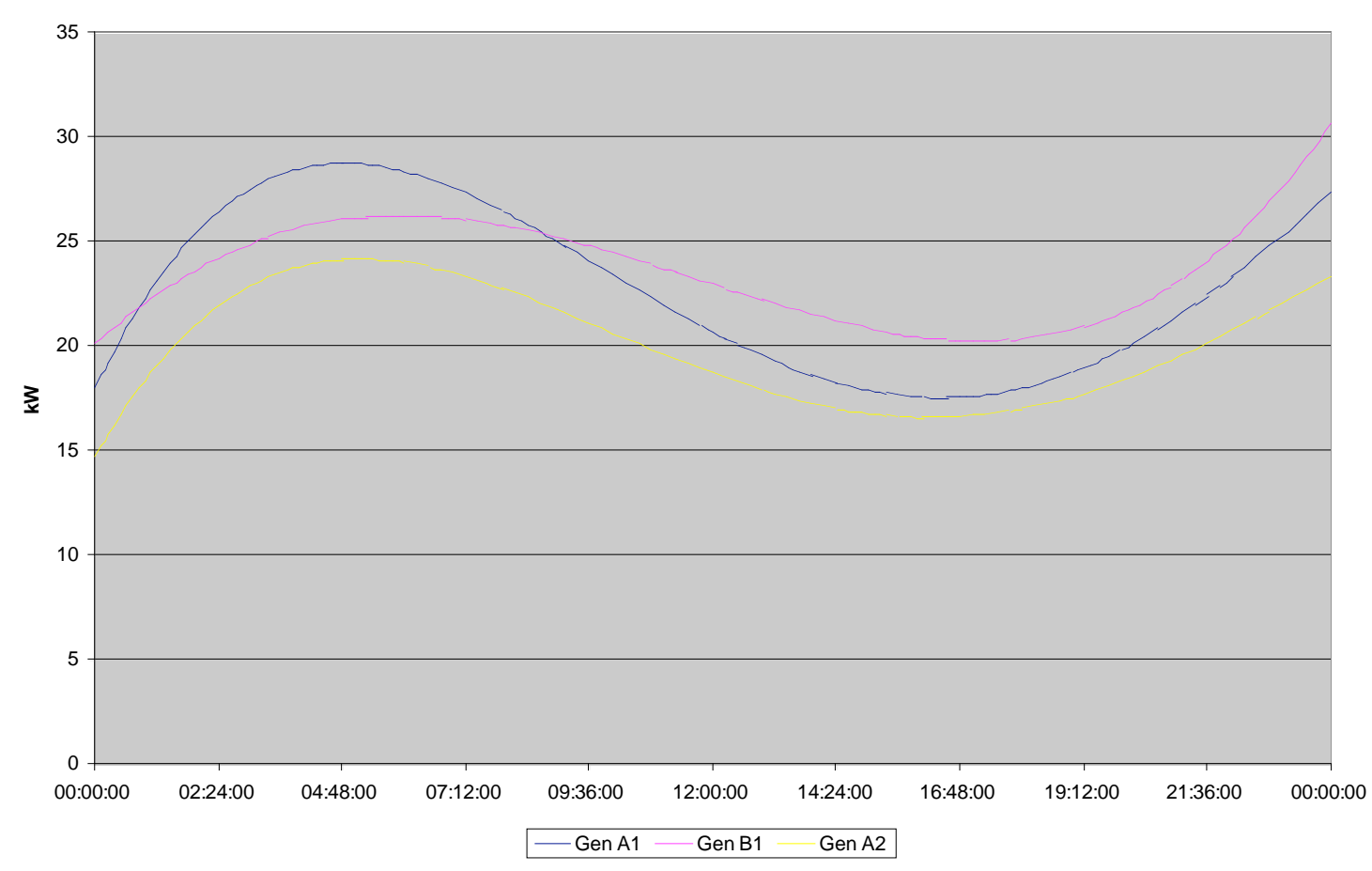

The averaged measured thermal load profile for each genset

A general deviation from the base profile can be seen in the early morning hours of operation by all three gensets. This was characteristic was inadvertently caused to maintain compliance with the IEEE 1547 standard at the point of common coupling. The base thermal demand profile was constructed around a customer with higher thermal demand in the late evening and early morning hours, similar to a customer space heating requirement in the winter season. The thermal generation and therefore electrical generation was high enough to frequently offset the entire electrical demand at the point of common coupling. Because the chosen technique for anti-islanding detection within the CERTS microgrid is a minimum real power import the static switch would open each 
time power was exported to the utility for more than two seconds. Finally the static switch was automated to re-dispatch the generators to a lower set point and resynchronize to the utility system. This effectively lowered the generation dispatch to match that of the electrical load in the late evening and early morning hours of interest. As a consequence, a customer with this particular thermal and electrical demand would need to make adjustments to their system operation to ensure there energy demands were met continuously.

\section{LB kW Load Profile}

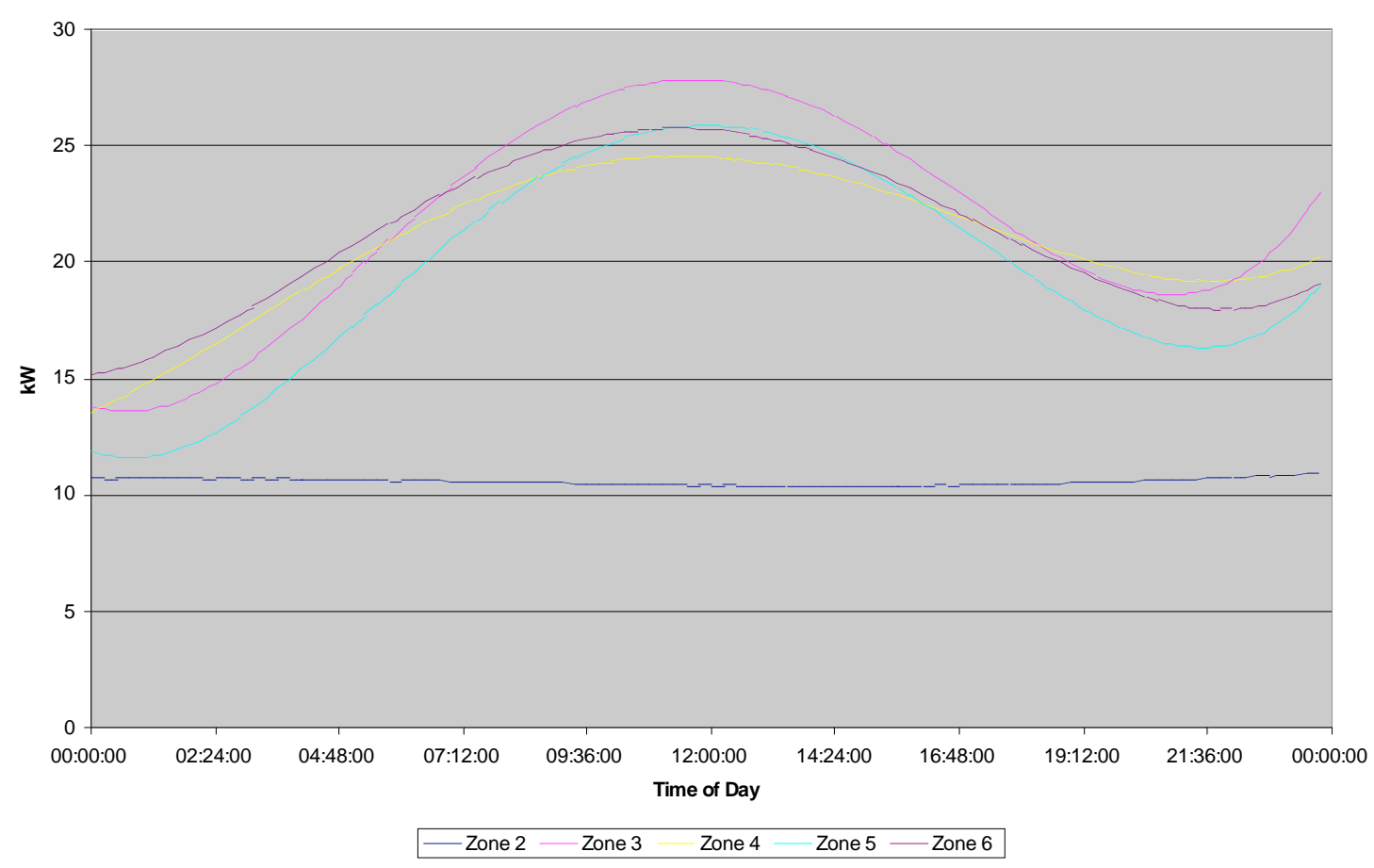

The averaged measured $\mathrm{kW}$ profiles for each Load Bank 
LB kVar Load Profile

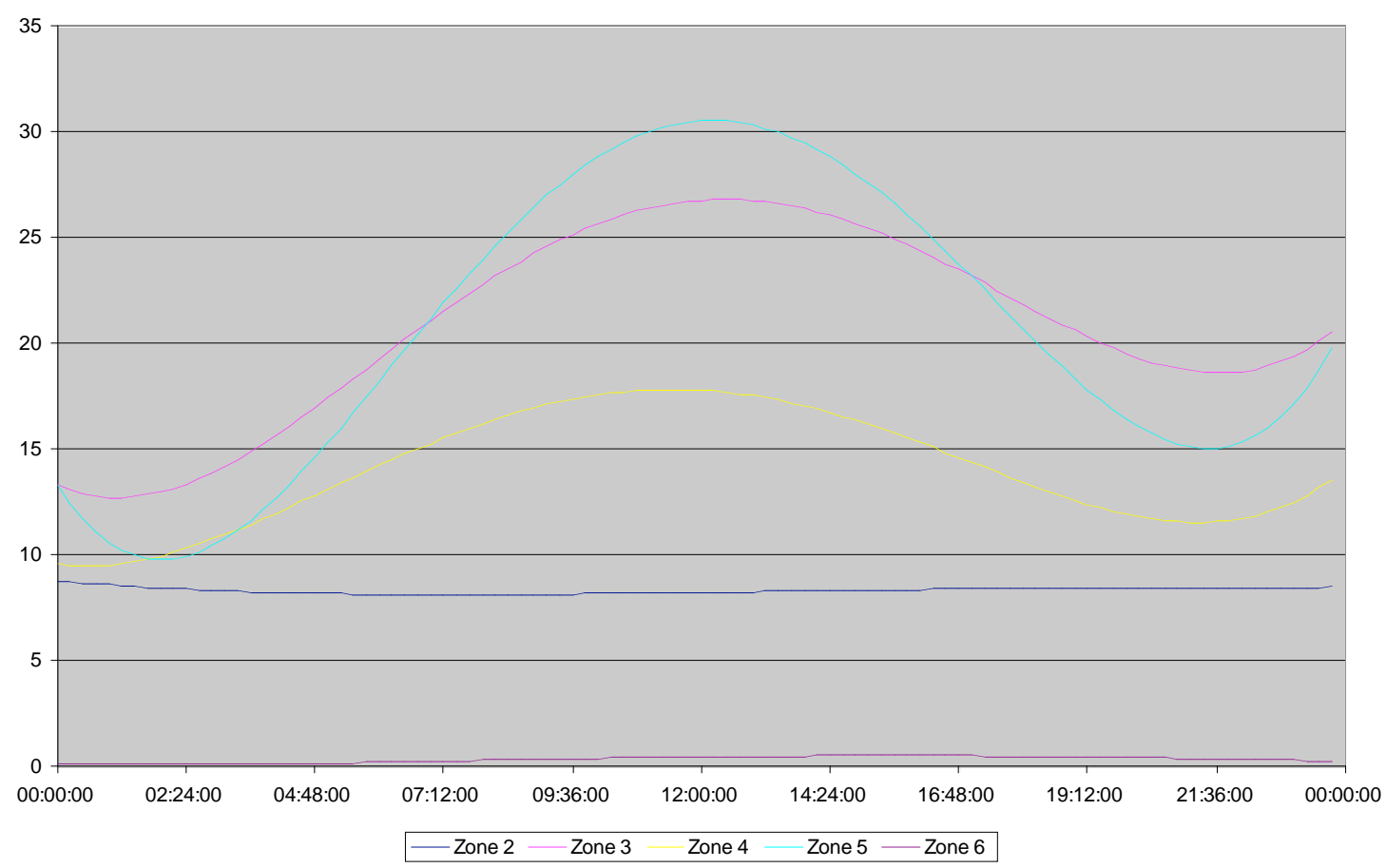

The averaged measured $\mathrm{kVar}$ profiles for each Load Bank

As point of interest, the averaged measured $\mathrm{kVar}$ profile shows the $\mathrm{kVar}$ demand of Load Bank 6 is flat at near zero for the entirety of the continuous run testing. This problem was tracked to an open breaker on the reactive load bank which went unnoticed during the testing.

\section{Summary}

The long term testing totaling approximately 1026 hours. This long term testing had three critical objective:

1). Collect data to substantiate the ability of a CERTS microgrid to provide UPS grade power. For this data collectiontask there where few events but for the capture events the contribution to load power quality was oustanding. The principle learning relates to the speed of the interface switch. At AEP site the interface swich can open in one cycle. If slower switching technologies are used the critical loads would be subject to power quality events for a longer time period. 
2) Demonstrate that energy manager system has control of the power factor seen by the utility. Over this 1026 hours period it was shown that the energy manager could control the interface power factor to a value greater than 0.91 . This task indicates that the interface power factor is continuously changing based on the utility feeder loading but can be effectively regulated. This also implies that the export of reactive power can also be actively controlled using the energy manager.

3) Demonstrate the flexibility of the microgrid to function seamlessly over a wide range of loads and power dispatches. In total the system operated through approximately 27,300 load changes and 5,800 generation dispatches without any degrading of the performance of the microgrid. 


\subsection{Task-7 Inverter Fault Current Contribution}

\section{Inverter Fault Current Contribution}

In the phase one testing of the CERTS microgrid, test 6.1.2 was performed which the main objective was to insure that the static switch would open during a three phase reverse power condition. Such a condition can develop when a section of a distribution circuit is islanded after an upstream utility protection device opens. The test involved placing a large electrical load connected outside of the microgrid system. An upstream utility protection device was opened islanding this electrical load with the microgrid. This leads to an outflow of electrical power from the microgrid sources feeding the distribution load until the microgrid protection opens, separating the microgrid from the utility system. During this event the expected result was that the genset would increase its current output to approximately two times its rated current, approximately 240 amps peak, based on a $90 \mathrm{KVa}$ rating.

Interestingly the results showed that the genset output current peaked closer to $600 \mathrm{amps}$ or a little over four times the rated current. At the time this result was unexpected although it has since been explained. In any case this also led to the question as to whether or not the fault current contribution of the microgrid genset equipment could be controlled to a known adjustable level. Generally with voltage source devices similar to the microgrid equipment this can be difficult and usually results in tripping the source device offline. Because one goal of the CERTS microgrid is to improve the reliability of energy delivery it is desirable that the microgrid source equipment successfully ride through an event of this nature. With this in mind it is also important to understand and be able to predict the fault current that will be delivered into a utility fault.

This testing repeats the test procedure 6.1.2 previously preformed to demonstrate control over the microgrid source fault current. With the same $500 \mathrm{~kW}$ load applied to the utility connection an upstream protection device is opened. In each case the microgrid SS detects the event and opens in approximately 2 cycles or less. The control software of the microgrid source is adjusted each time to demonstrate varying levels of fault current. The software adjustments were controlled by two variables, SA Loop and Percent Surge. SA 
Loop is the stand alone current control loop enable which turns the current control on or off. \%Surge is related to the level at which the current is limited.

Below are the tabulated results of the tests. Genset A1 without current control had a maximum recorded current of 669 Amps. Genset A1 was able to successfully reduce its current contribution when the current control was enabled, as seen in Table 1.

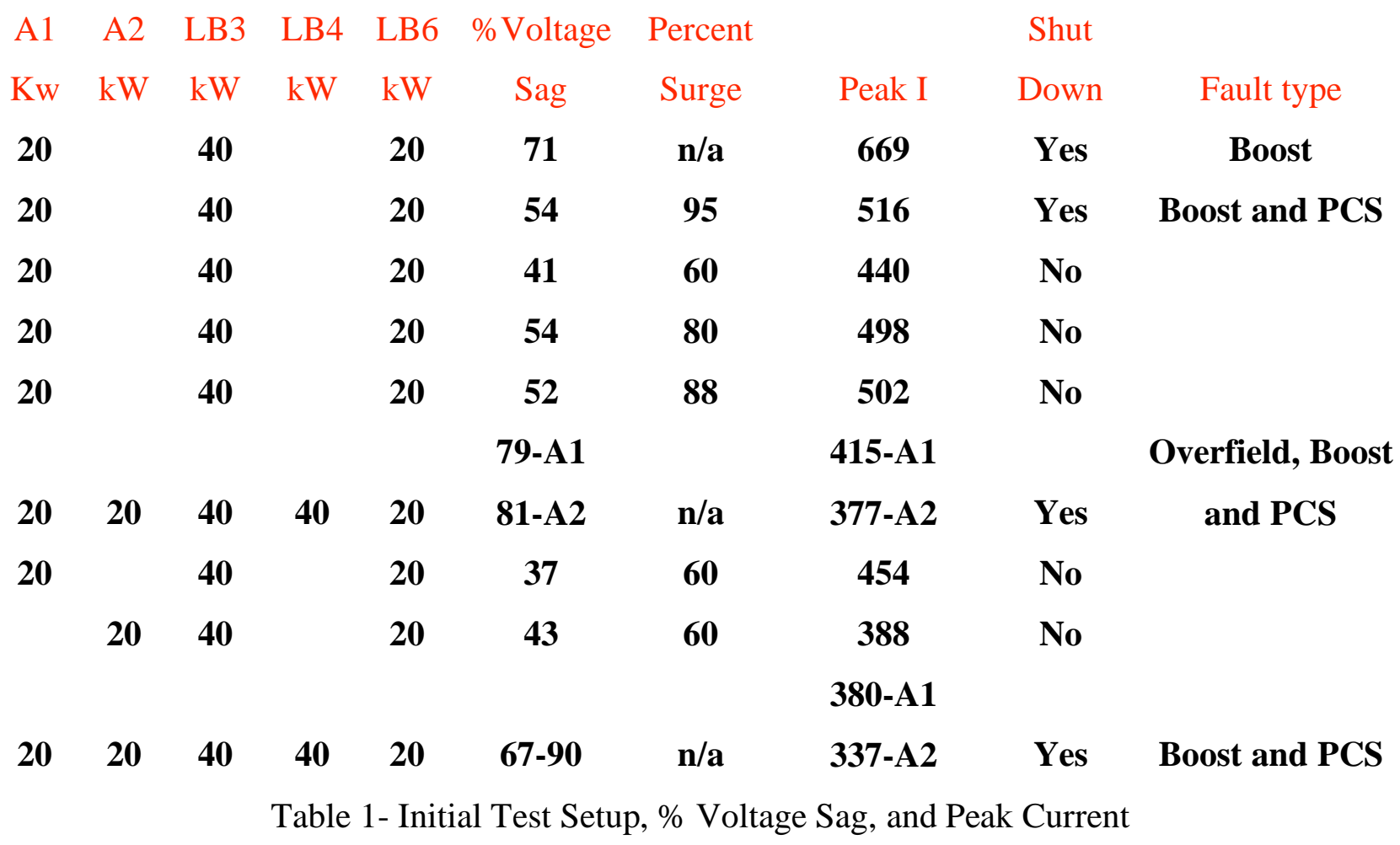

The largest change in peak current resulted from enabling the current control with a 95 Percent Surge value. At this setting a 23\% reduction in peak current was observed. The lowest set point tested was a 60 Percent Surge resulting in a 38\% total reduction in peak current. A comparison was also made between Genset A1 and Genset A2 at the 60 Percent Surge level. The fault current levels were similar but not equal. A portion of the difference in current contribution between the two gensets can be attributed to the difference in connecting cable impedance.

For all tests conducted at 60,80 and 88 Percent Surge levels the genset was able to remain online through the duration of the event and continue to carry the islanded 
microgrid loads after the SS opened. Tests with SA Loop enabled and greater than an 88 Percent Surge or with SA Loop disabled resulted in the microgrid source shut down. Interestingly this is a different result than that of the first phase of testing in April of 2007. Then a similar test was performed on Genset A1 using the same load bank, distribution load and genset settings. The results of that test can be seen in Table 3. As indicated, the peak current then was $622 \mathrm{amps}$ as compared to $669 \mathrm{amps}$ on the recent test. Then voltage then sagged to 51 percent of pre-trigger values where as to 71 percent in the recent test.

\begin{tabular}{|c|c|c|c|c|c|c|c|c|c|}
\hline $\begin{array}{c}\text { Percent } \\
\text { Surge }\end{array}$ & Genset & $\begin{array}{l}\text { VArms } \\
\text { pre-test }\end{array}$ & $\begin{array}{l}\text { VBrms } \\
\text { pre-test }\end{array}$ & $\begin{array}{l}\text { VCrms } \\
\text { pre-test }\end{array}$ & $\begin{array}{c}\text { VArms } \\
\text { during sag }\end{array}$ & $\begin{array}{c}\text { VBrms } \\
\text { during sag }\end{array}$ & $\begin{array}{c}\text { VCrms } \\
\text { during sag }\end{array}$ & Peak I & \%Vsag \\
\hline $\begin{array}{l}\text { SA Loop } \\
\text { Disabled }\end{array}$ & A1 & 267 & 268 & 272 & 189 & 212 & 188 & 669 & 71 \\
\hline 95 & A1 & 266 & 267 & 270 & 182 & 144 & 170 & 516 & 54 \\
\hline 88 & A1 & 266 & 267 & 270 & 139 & 139 & 156 & 502 & 52 \\
\hline 80 & A1 & 267 & 267 & 271 & 143 & 160 & 162 & 498 & 54 \\
\hline 60 & A1 & 266 & 266 & 269 & 110 & 143 & 137 & 440 & 41 \\
\hline 60 & $\begin{array}{c}\text { A1 } \\
\text { Retest }\end{array}$ & 267 & 268 & 271 & 136 & 151 & 100 & 454 & 37 \\
\hline \multirow[t]{2}{*}{$\begin{array}{l}\text { SA Loop } \\
\text { Disabled }\end{array}$} & A1 & 270 & 271 & 273 & 229 & 215 & 231 & 415 & 79 \\
\hline & A 2 & 270 & 270 & 273 & 241 & 219 & 239 & 377 & 81 \\
\hline \multirow[t]{2}{*}{$\begin{array}{l}\text { SA Loop } \\
\text { Disabled }\end{array}$} & $\begin{array}{c}\text { A1 } \\
\text { Retest }\end{array}$ & 271 & 272 & 274 & 229 & 197 & 209 & 380 & 72 \\
\hline & $\begin{array}{c}\text { A2 } \\
\text { Retest }\end{array}$ & 271 & 271 & 273 & 231 & 200 & 211 & 337 & 73 \\
\hline 60 & $\mathrm{~A} 2$ & 271 & 272 & 275 & 118 & 156 & 133 & 388 & 43 \\
\hline
\end{tabular}

Table 2: RMS Voltages before and during the test

Table 2 shows the voltage RMS on each phase prior to each test, followed by the minimum voltage recorded on each phase during the test. This table also shows that the peak current did decrease with a decrease in Percent Surge set point. 


$\begin{array}{cccccccccc}\begin{array}{c}\text { Percent } \\ \text { Surge }\end{array} & \text { Genset } & \begin{array}{c}\text { VArms } \\ \text { pre-test }\end{array} & \begin{array}{c}\text { VBrms } \\ \text { pre-test }\end{array} & \begin{array}{c}\text { VCrms } \\ \text { pre-test }\end{array} & \begin{array}{c}\text { VArms } \\ \text { during sag }\end{array} & \begin{array}{c}\text { VBrms } \\ \text { during sag }\end{array} & \begin{array}{c}\text { VCrms } \\ \text { during sag }\end{array} & \text { Peak I } & \text { \%Vsag } \\ \begin{array}{l}\text { SA Loop } \\ \text { Disabled }\end{array} & \text { A1 } & 280 & 277 & 278 & 151 & 165 & 141 & \mathbf{6 2 2} & 51\end{array}$

Table 3: RMS Voltages before and during the test of April 2007

\section{Summary}

The results of these tests indicate that the inverter equipment can control the fault current contribution. They also demonstrate an approximately linear relationship between the

Peak Amperage vs Percent Surge

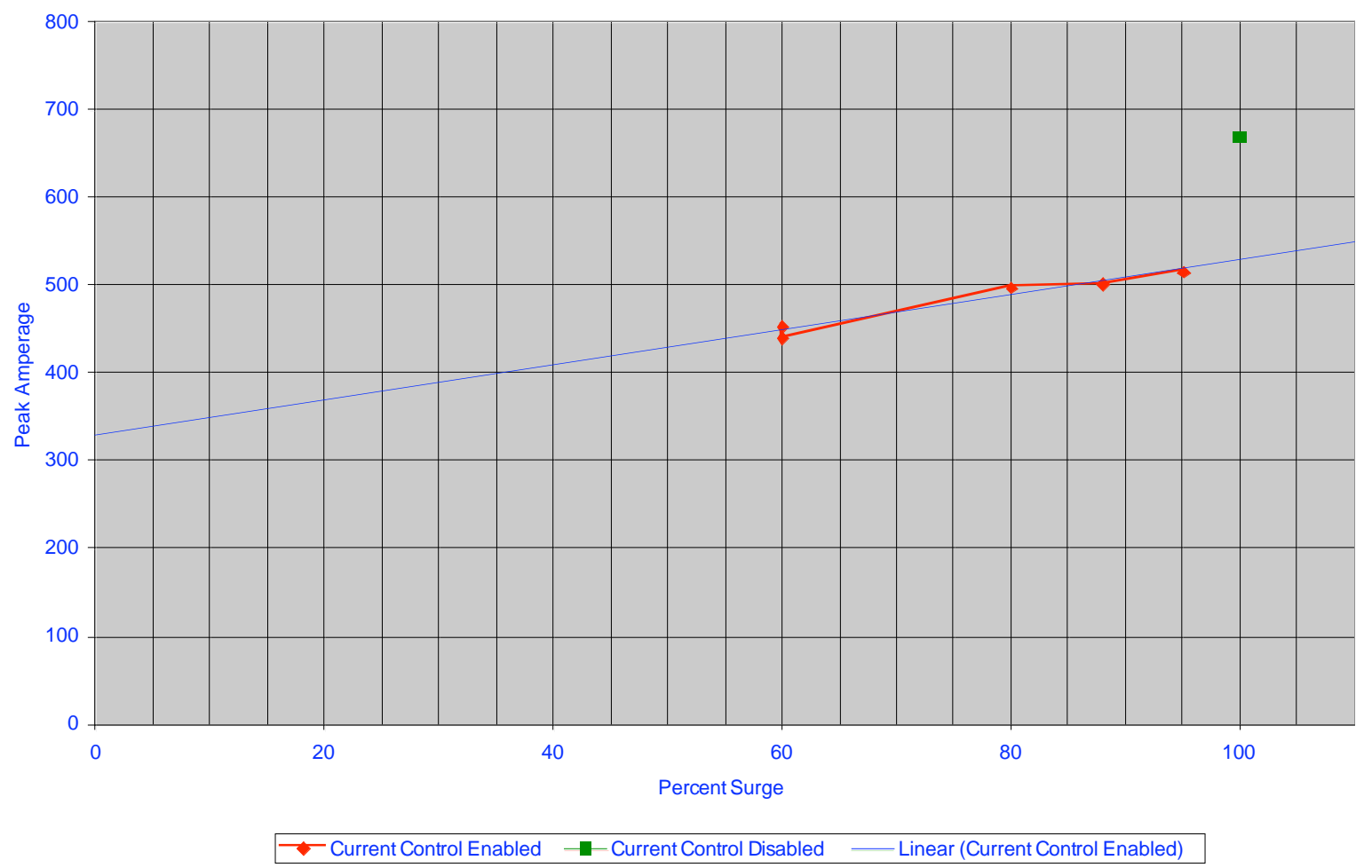

Percent Surge and the fault current contributed. However if the value for Percent Surge is projected to 0 , the fault current contribution is projected to be approximately 325 amps, not 0 amps as intuition would suggest. A similar relationship may exist past a Percent Surge value of 100. In this case the term Percent Surge is misleading and should be better connected to a deliverable value of fault current contribution. It is important to realize that the level of surge current is also critical in protection design. 


\section{CHAPTER 4. Conclusions and Recommendations}

\subsection{Conclusions}

The work conducted in this phase of RD\&D on the CERTS Microgrid Concept built upon the original base of technical accomplishments to prioritize, develop, and then demonstrate technology enhancements to further enhance the business case for microgrids. That is, having demonstrated the technical feasibility of microgrid functions, RD\&D optimization efforts were now needed to accelerate commercial deployment. The current phase has been a contribution to these efforts.

The current phase involved seven distinct analysis, bench-, and full-scale testing tasks. The first five tasks were described in the original proposal submitted and awarded through DOE's solicitation. Two additional tasks were added to address issues that had been identified in the earlier, first phase of testing.

The work completed in this phase has made several notable contributions to the advancement and commercialization of the CERTS Microgrid Concept:

1. We have enhanced a design tool, called the DER-Customer Adoption Model, to include electrical and thermal storage, as well as reliability considerations, into its optimization of microgrid equipment selection and operation. We also applied the tool to explore commercial opportunities for microgrid adoption in promising market segments.

2. We examined a lower-cost method for implementing specialized protection schemes that we had assumed were required in order to accommodate the low fault current capabilities of inverters. However, we later found that these schemes may not be required because, in fact, fault current can be increased and convention protection, alone, may be adequate (further lowering the cost of a microgrid).

3. We reviewed information collected on DC storage in the first phase of the testing to suggest improvements to the future design and sizing of DC storage to greatly 
improve the reliability of these components, which will lead to cost savings in commercial-grade microgrids.

4. We demonstrated that CERTS algorithms could be successfully use to control AC storage as a back-up to conventional generation sources within a microgrid to control voltage and frequency. We also designed and implemented a state-ofcharge management system that also embodies the same plug-and-play philosophy that is central to the CERTS Microgrid Concept. Adding AC storage to a microgrid offers the potential to greatly enhance the flexibility of a microgrid, especially one containing variable renewable sources of generation, such as PV.

5. We demonstrated that conventional synchronous generators could be operated successfully within a CERTS Microgrid along-side inverter-based sources through modifications to governor controls. The potential for a hybrid CERTS Microgrid composed of both inverter-based and conventional synchronous generators will further improve the economics of microgrids.

6. We confirmed the power quality-enhancing capabilities of the CERTS Microgrid. We showed how a conventional energy manage system could be used to control power factor. We also thoroughly confirmed the flexibility of the microgrid operate under an enormous variety of dispatch configurations that far exceeded the number examined in the original phase of research. Each of these demonstrations documented a key value-added by the CERTS Microgrid Concept.

7. Finally, we demonstrated that fault current can be controlled and increased for inverter-based microsources, which opens up the potential for reliance on traditional forms of protection within a microgrid, rather than require specialized protection schemes. This will further reduce the cost of a CERTS Microgrid.

\subsection{Next Steps}

The next steps in the advancement and commercialization of CERTS Microgrid Concepts are two-fold. First, field demonstrations are needed to take the advances already demonstrated at the AEP Test Bed and work-through the site-specific, real-world challenges involved in deploying production-grade installations that embody CERTS Microgrid Concepts. Industrial partners must be sought and licensed to implement CERTS Microgrid Concepts in commercial products. 
Second, the integrated program of theory, simulation, bench-scale demonstration, and then full-scale demonstration at the AEP Test Bed needs to continue. Several advances demonstrated at bench-scale in this phase of research, including integration of AC storage and synchronous generation in a microgrid are now ready for demonstration at full-scale at the AEP Test Bed. In addition and in view of these enhancements, the benefits of the CERTS Microgrid for supporting integration of variable renewable generation in the form of PVs should be examined, ultimately, at full-scale at the AEP Test Bed. Finally, on-going work to examine alternatives to the static switch should be pursued to target market segments with less demanding requirements for power quality. 